Portland State University

PDXScholar

Fall 12-11-2015

\title{
Coyotes on the Web: Understanding Human-Coyote Interaction and Online Education Using Citizen Science
}

Zuriel Anne Rasmussen

Portland State University

Follow this and additional works at: https://pdxscholar.library.pdx.edu/open_access_etds

Part of the Human Geography Commons, and the Psychology Commons Let us know how access to this document benefits you.

\section{Recommended Citation}

Rasmussen, Zuriel Anne, "Coyotes on the Web: Understanding Human-Coyote Interaction and Online Education Using Citizen Science" (2015). Dissertations and Theses. Paper 2643.

https://doi.org/10.15760/etd.2639

This Thesis is brought to you for free and open access. It has been accepted for inclusion in Dissertations and Theses by an authorized administrator of PDXScholar. Please contact us if we can make this document more accessible: pdxscholar@pdx.edu. 
Coyotes on the Web:

Understanding Human-coyote Interaction and Online Education Using Citizen Science

by

Zuriel Anne Rasmussen

A thesis submitted in partial fulfillment of the requirements for the degree of

\author{
Master of Science \\ in \\ Geography
}

Thesis Committee:

Barbara Brower, Chair

David Banis

Martin Lafrenz

Bob Sallinger

Portland State University

2015 
(C) 2015 Zuriel Anne Rasmussen 


\begin{abstract}
Coyote (Canis latrans) numbers are increasing in urban areas, leading to more frequent human-coyote interactions. Rarely, and particularly when coyotes have become habituated to humans, conflicts occur. Effective education about urban coyotes and how to prevent habituation reduces conflict. Citizen science, in the form of online education, can be used to engage and educate city dwellers about urban coyotes.

In this research, I explore Portland Metropolitan Area (PMA) residents' baseline experiences with, and attitudes toward, urban coyotes. Next, I investigate citizen science as a tool for education. Using the Portland Urban Coyote Project (PUCP), a citizen science project, as a case study, I investigate people's experiences with citizen science and evaluate whether attitudes and knowledge about coyotes changes after an interactive online educational tool.

Most participants had seen a coyote at least once, were generally positive about coyotes, and were well-informed about basic facts. Participants who completed a tutorial that provided basic information about coyotes and dispelled common myths, showed higher knowledge scores and more positive, research-based attitudes. These results suggest that educational tools in citizen science projects can be effective for providing information and shaping attitudes about urban coyotes. Increased public access to education about how to live safely with coyotes is an important tool for proactive management. Online educational tools associated with citizen science projects are a viable option for efficient, inexpensive management of urban coyote populations.
\end{abstract}




\section{Dedication}

For my ever-supportive and endlessly patient partner, Jonathan van Belle. 


\section{Acknowledgements}

I am very grateful for the support of many people through this process. I would like to thank my advisor, Barbara Brower, for her flexibility and enthusiastic support of my many ideas around this project. I would like to thank my committee, David Banis, Martin Lafrenz, and Bob Sallinger, for their guidance, advice, and support. Also, I would like to thank Jenny Grant for her important role of initiating the Portland Urban Coyote Project. Thanks to the project volunteers, Emily Wise, Kira Smith, and Emily Pulliam, for their hours of effort. Furthermore, I would like to thank my cohort, Gwyneth Manser, Dirk Kinsey, Kevin Donohue, Zack Herzfeld, Ryan Pemberton, and Debbie Blackmore, for their collaboration, companionship, and counsel. Lastly, I would like to thank all of the people who participated in the Portland Urban Coyote Project, without whom this project would be impossible. 


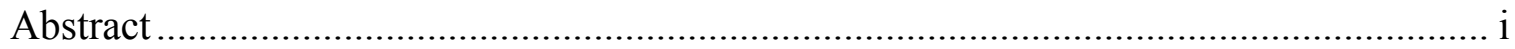

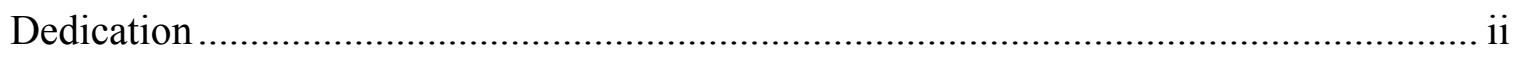

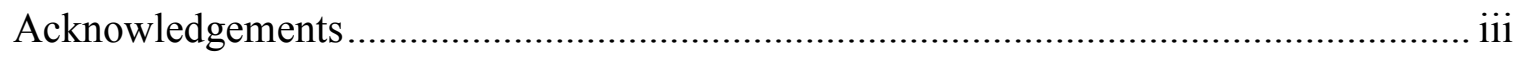

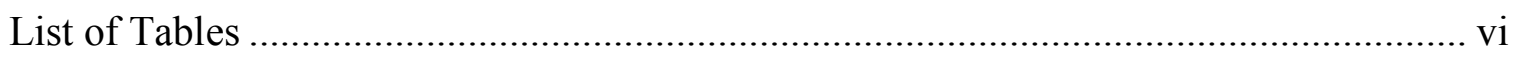

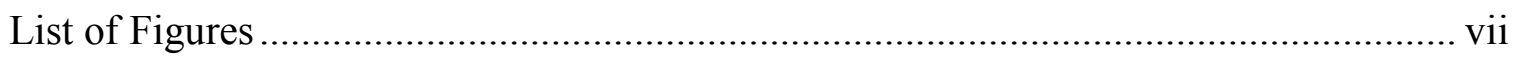

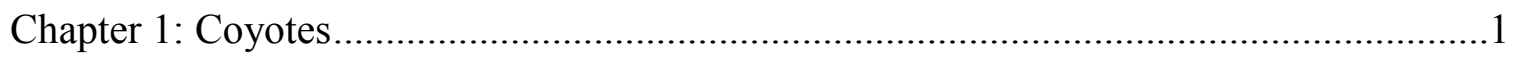

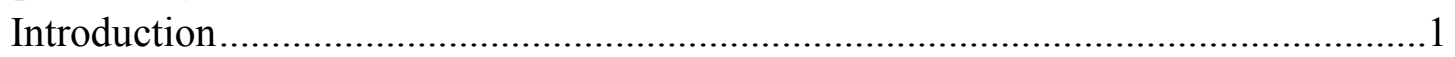

Human-animal Research in Geography ........................................................ 4

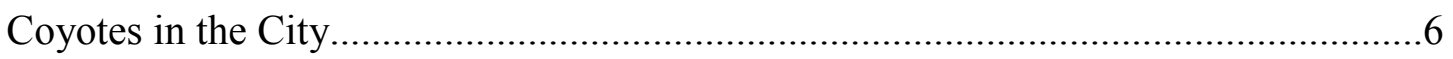

Urban Coyote Ecology .................................................................................... 7

Human-coyote Interaction ................................................................... 10

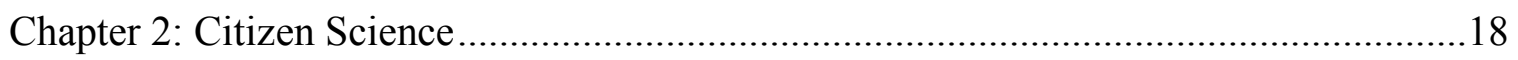

Citizen Science as a Tool for Education ........................................................21

Citizen Science and Coyotes: The Portland Urban Coyote Project .......................23

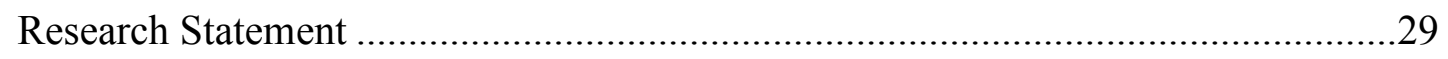

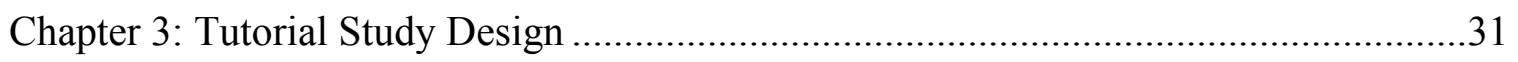

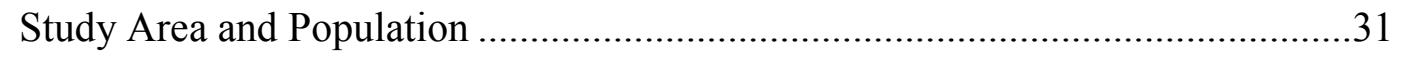

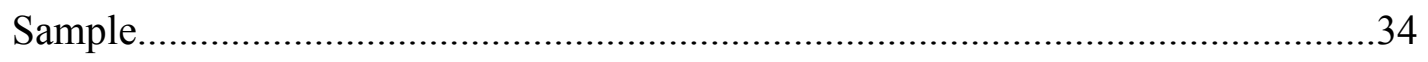

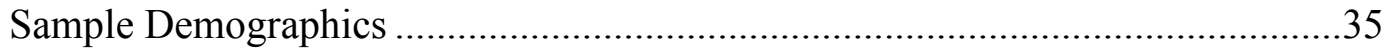

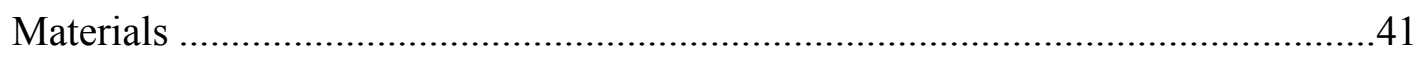

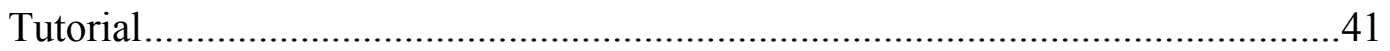

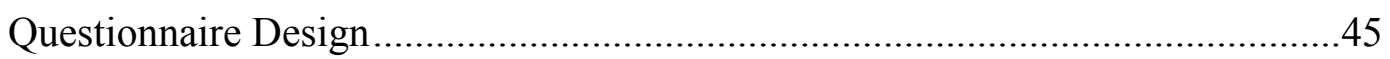

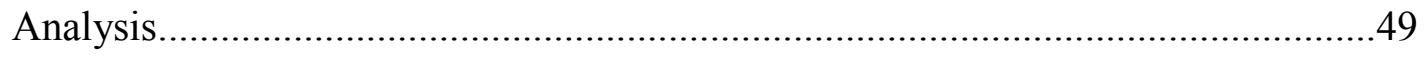

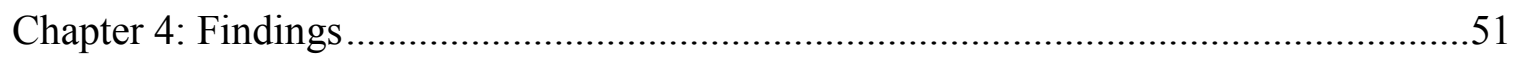

Baseline Familiarity and Experience ….....................................................51

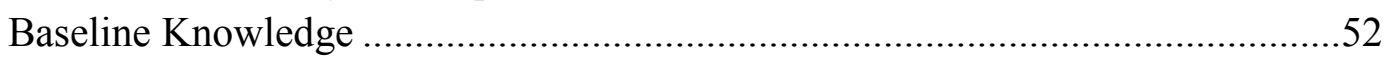

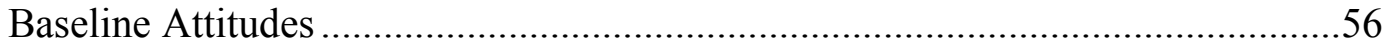

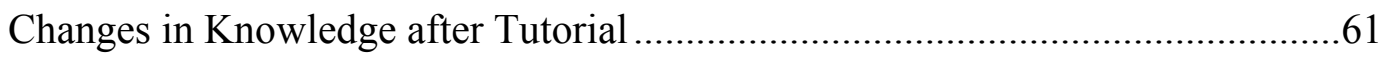

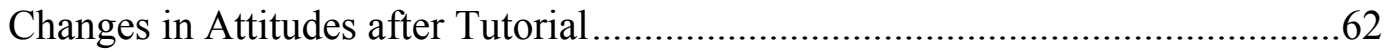

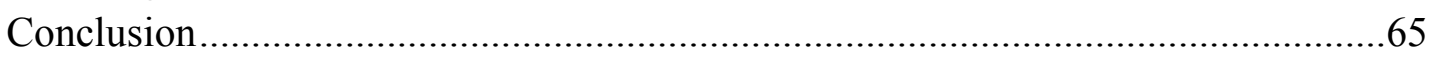




\section{Appendices}

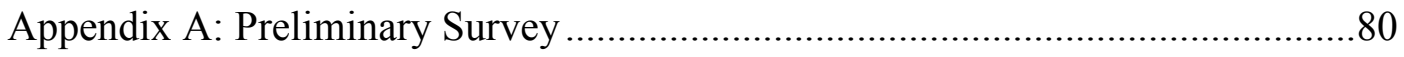

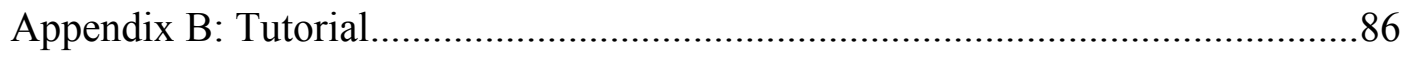

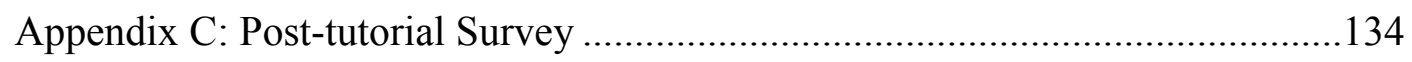

Appendix D: Human Subjects Review Approval.............................................140 


\section{List of Tables}

Table 3.1 Race/Ethnicity and Age distribution of Portland Metropolitan Area residents .33

Table 3.2 Education and income distribution of Portland Metropolitan Area residents ...34

Table 3.3 Gender, Ethnicity, Age, and Income distribution of sample

Table 3.4 Education, Student Status, and Length of Residence distribution of sample ....39

Table 4.1 Responses to questionnaire items about the Portland Urban Coyote Project....51

Table 4.2 Responses to questionnaire item: "Have you reported a sighting to the Portland

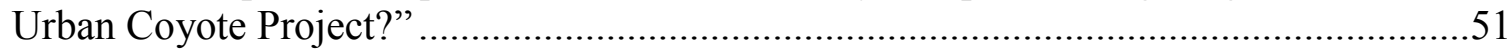

Table 4.3 Responses to questionnaire item: "Have you participated in citizen science besides the Portland Urban Coyote Project?" ............................................................52

Table 4.4 Responses to questionnaire items about coyote sightings .............................52

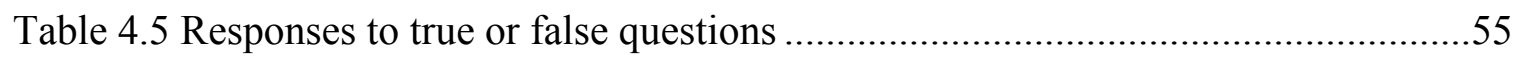

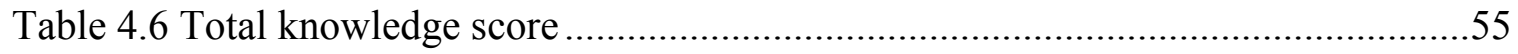

Table 4.7 Responses to questionnaire items about concern.......................................60

Table 4.8 Independent $t$ test results comparing mean pet owner and non pet owners for the question, "How concerned are you about coyotes attacking small pets?"..................61

Table 4.9 Paired $t$ test results for total knowledge score before and after tutorial ...........62

Table 4.10 Summary table of paired $t$ test results for attitudes questions before and after

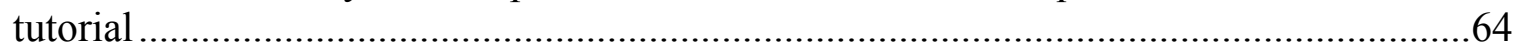




\section{List of Figures}

Figure 1.1 Current and historical range of coyotes.....................................................

Figure 2.1 Coyote on Portland Metropolitan Area Express (MAX) Light Rail ...............25

Figure 2.2 Screenshot of the home page of the Portland Urban Coyote Project ..............27

Figure 2.3 Coyote in a Portland cemetery …........................................................28

Figure 2.4 Screenshot of interactive coyote sightings map from the Portland Urban

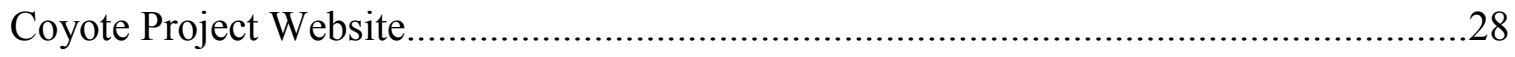

Figure 3.1 Map of study area: Portland Metropolitan Area.........................................32

Figure 3.2 Choropleth map of participant zip codes in Portland Metropolitan Area ........40

Figure 3.3 Example of introductory page in tutorial.................................................42

Figure 3.4 Example of section review page in tutorial ..........................................42

Figure 3.5 Example of interactive self-quizzes in tutorial, incorrect answer ..................43

Figure 3.6 Example of interactive self-quizzes in tutorial, correct answer ....................44

Figure 4.1 Responses to questionnaire item: "How much does an average coyote weigh?"

Figure 4.2 Responses to questionnaire item: “What do coyotes most commonly eat?"....54

Figure 4.3 Responses to questionnaire item: "How much do you like or dislike coyotes?"

Figure 4.4 Responses to questionnaire item: "How much do you support coyotes living in the Portland Metropolitan Area?"

Figure 4.5 Responses to questionnaire item: "How do you feel about lethally removing (killing) coyotes found in urban areas?" 


\section{CHAPTER 1: COYOTES}

\section{Introduction}

The coyote (Canis latrans) is an American animal with many histories. In folklore, the coyote is described in contradictions: "clever and foolish, creative and destructive, otherworldly and worldy, a community figure and a loner" (Leeming 2005, 83). There are hundreds of Native American myths that center around the coyote, who often appears as a trickster whose arrogance causes his downfall (Leeming 2005). Mark Twain wrote disparagingly about the coyote, reflecting a negative sentiment that persists today. Twain wrote, "The cayote [sic] is a living, breathing allegory of Want. He is always hungry. He is always poor, out of luck, and friendless...He is so spiritless and cowardly that even while his exposed teeth are pretending a threat, the rest of his face is apologizing for it" (Twain 1872, 24).

In popular culture, Wile E. Coyote is Road Runner's fool in the classic American cartoon. But the coyote is not always represented negatively. An old Mexican saying elevates the coyote, arguing that "The coyote is the smartest person next to God" (Leydet 1977, 39). Nature-writer Hope Ryden writes, “A part of me would die should coyotes ever cease to pour their throats in nightly celebration of life. Even the sublime grandeur of the West's towering mountain ranges would no longer evoke in me a sense of the divine mystery should those ancient faces ever cease to reverberate to the old wild song of the Trickster" (Ryden 1979, 292). The coyote, then, has been both respected and disdained, both intelligent and foolish. Now there is an emerging story of the urban coyote. 
About eighty percent of Americans live in urban areas and these areas are expanding into once-wild spaces (United States Census Bureau 2013). With this extensive urbanization of the United States, large carnivores such as bears, cougars, and wolves have experienced diminished ranges and extirpation. Coyotes, on the other hand, have found great success in urban environments (White and Gehrt 2009; Gehrt et al. 2009).

An adaptive and opportunistic species, coyotes have nearly doubled their historic range in the past 100 years (Figure 1.1). Coyotes have expanded from an original range encompassing the central United States and Mexico to a territory that spans the width of North America and reaches from Alaska to Central America (Gehrt 2007; Gehrt, Riley, and Cypher 2010). Coyotes, despite more than a century of intensive efforts at eradication, have flourished where wolves have failed (Connolly 1978; White and Gehrt 2009).

Coyotes are no longer animals of the desert, plains, forests, and mountains; populations have increased in cities across the United States and Canada (White and Gehrt 2009). The Portland Metropolitan Area (PMA) has had reports of coyotes since the 1980s (Sallinger 2011). With increased coyote presence in cities comes increased humancoyote interaction, and with more interaction, more risk of human-coyote conflict. One effective way to prevent human-coyote conflict is through community education (Gehrt 2007; White and Gehrt 2009). However, practical, effective, and inexpensive educational materials are not available in many cities. Communities would benefit from greater access to education about urban coyotes (Taylor 2004). 


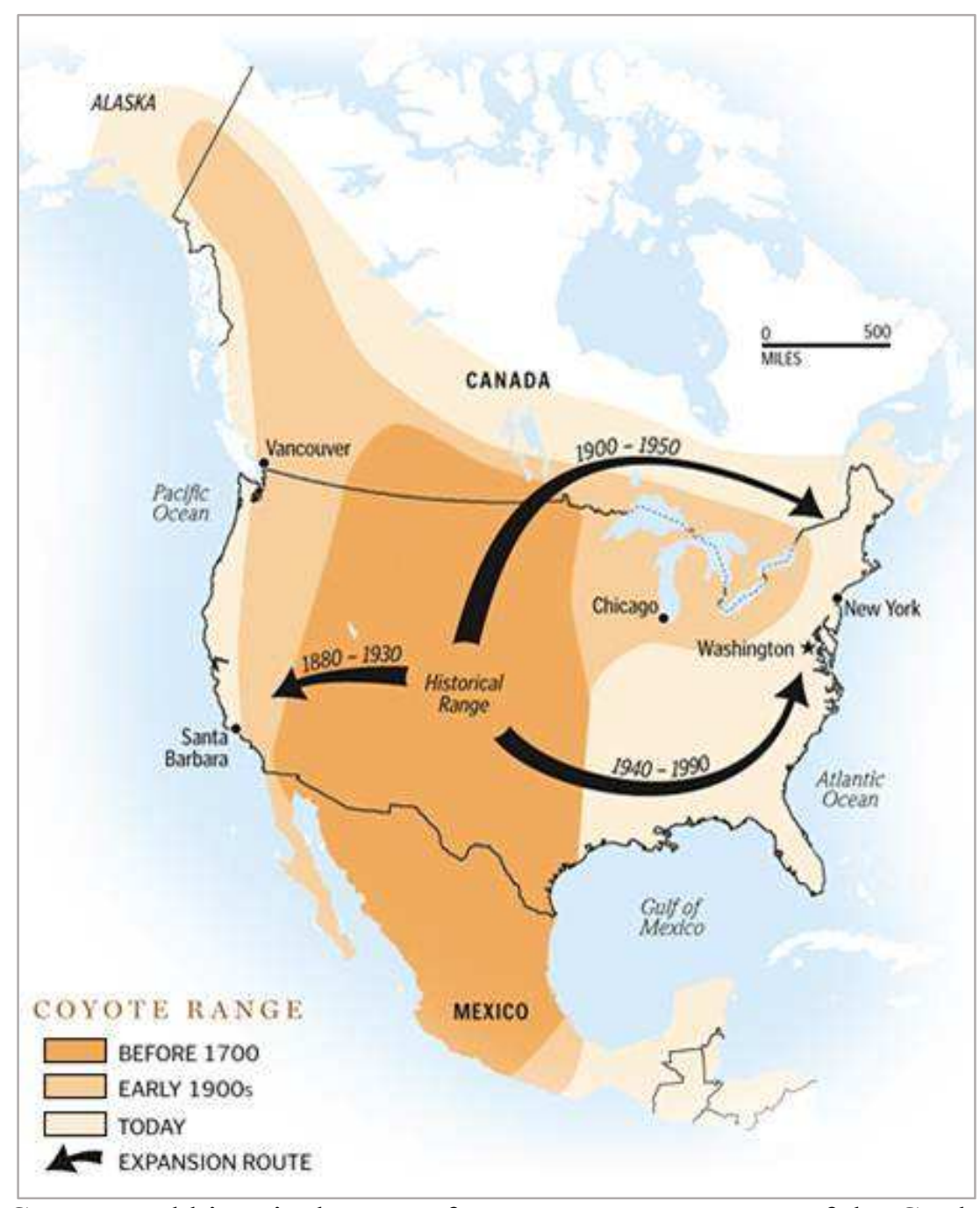

Figure 1.1 Current and historical range of coyotes. Map courtesy of the Cook County Coyote Project.

A promising option for community education is citizen science. Citizen science is a relatively new means for scientists to engage with the public. Citizen-science projects provide low-cost opportunities for the general public to become more educated while simultaneously making significant contributions to research (Evans et al. 2005). In this research, I explore how citizen science can educate residents in the PMA about urban coyotes using the Portland Urban Coyote Project (PUCP), a citizen science project, as a case-study. 
However, in the PMA, residents' opinions of and interactions with coyotes are not well understood. Understanding and shaping human attitudes toward coyotes is a crucial element of coexistence (Draheim 2007; Gehrt, Riley, and Cypher 2010; Jackman and Rutberg 2015). In this research, I investigate the relationship between humans and coyotes in the PMA. Using the PUCP and questionnaires, I explore human experiences and familiarity with coyotes, baseline attitudes and knowledge about them, and how online educational tools from citizen science can shape knowledge and attitudes about coyotes.

\section{Human-animal Research in Geography}

During the early 20th century, geographic study of animals, or zoogeography, primarily focused on descriptions and depictions of species distribution and behavior (Cowell and Parker 2004; Blumler et al. 2011). During the 1970s and 1980s, geographers began to examine the complexity of animal distributions with a different focusexamining how human and environmental factors might affect animals ${ }^{1}$ (Cowell and Parker 2004). By the 1990s, increased interest from geography and other disciplines (such as philosophy, anthropology, and sociology) led to an increase in animal studies of a new humanities-focused flavor. In geography, this approach was dubbed "new animal geographies" (Buller 2014).

\footnotetext{
${ }^{1}$ Geographers took a variety of approaches to the complex examination of human-animal interaction during this time. For example, Robin W. Doughty published excellent books that examined animals through their natural history, social history, distribution, and cultural impact (Doughty 1975; Smith and Doughty 1984; Doughty 1989a; Doughty 1989b).
} 
Many new animal geographers study urban animals—exploring the connections between animals, humans, places, and politics. Drawing from cultural geography, urban theory, critical theory, and Marxist and Foucauldian ideas, new animal geographers attempt to understand the many roles of animals in the city (Philo 1995; Wolch 1998; Emel, Wilbert, and Wolch 2002; Wolch 2002; Buller 2014). These geographers argue that an animal's position and experience in a city should be reexamined, often advocating for increased animal agency and liberty (Philo 1995; Wolch 1998; Wolch 2002; Wolch 1998). In this literature, a common argument is that humans view wild animals as transgressors of human-created, physical, psychological, and legal boundaries (Emel 1998; Philo 1995; Whatmore 1998). To understand human-animal relationships, new animal geographers use techniques such as conceptual analysis, political analysis, ethnographic research, and observational research (Buller 2015).

This human-animal research in geography takes a new animal geographies approach (firmly rooted in human geography), but some contemporary geographers also draw questions and methods from biogeography and human-environment interaction. Tools such as questionnaires, focus groups, interviews, tracking collars, scat analysis, and geographic information systems (GIS) ground this work on human-animal relationships (Butt, Shortridge, and WinklerPrins 2009; Goldman 2009; Lukasik 2009; Sakakibara 2010; Weckel et al. 2010; Lukasik and Alexander 2011; Olive 2014; Young et al. 2015). Often, human-animal research of this kind is the product of an interdisciplinary approach that incorporates geography, biology, environmental science, psychology, and other disciplines (Cowell and Parker 2004; Butt, Shortridge, and WinklerPrins 2009; Weckel et 
al. 2010; Jacobs 2012; Olive 2014; Young et al. 2015). In my research, I draw on this interdisciplinary approach to human-animal research.

\section{Coyotes in the City}

Coyotes have long been successful, extending their range despite more than a century of intensive coyote removal efforts and the killing of millions of coyotes (Connolly 1978). However, the success of coyotes in urban areas is a newer phenomenon. Over the past 30 years, coyotes have become more visible in cities, which is an example of their incredibly adaptive nature (White and Gehrt 2009).

Evidence of booming coyote numbers can be seen in the fact that only about 20 dead coyotes were removed from the Chicago Metropolitan Area in 1990, while 300 coyotes corpses were removed in 2000 (Gehrt, Anchor, and White 2009). Media stories about coyotes mirror this trend; between 1985 and 2006, media reports of human-coyote conflict in Chicago grew twenty-fold (White and Gehrt 2009). Although the uptick in the coyote population is well documented in Chicago, it is not the only city this urban mesopredator calls home. Studies in Denver, Calgary, Los Angeles, and Tucson have identified significant urban coyote activity (Gehrt and Prange 2007; Gehrt et al. 2009; Grubbs and Krausman 2009; White and Gehrt 2009; Poessel et al. 2013). With this increased presence in cities across the country, comes increased need for understanding. In the following sections, I review urban coyote ecology and human-coyote interaction research. 


\section{Urban Coyote Ecology}

Urban coyotes are not biologically different from their rural counterparts. Coyotes belong to the family Canidae with other canids, such as dogs, wolves, foxes, and jackals (Bekoff and Gese 2003; Bateman and Fleming 2011). There are 19 subspecies of coyote (Bekoff and Gese 2003; Wilson and Reeder 2005). They are medium-sized carnivores, weighing an average of 25-35 pounds, with females generally slightly smaller than males (Bekoff and Gese 2003). Coyotes can be divided regionally into western and eastern populations. In the West, coyotes are generally smaller, while eastern coyotes (thought to have significant wolf ancestry) tend to be larger (Gehrt, Riley, and Cypher 2010).

Coyotes in urban areas generally eat rodents, rabbits, fruit, birds, and sometimes young deer (Gehrt n.d.; Gehrt 2007). Contrary to popular opinion, anthropogenic food sources, such as garbage, account for a small to medium percentage (2-35\%) of an urban coyote's diet (Gehrt 2007; Morey et al. 2007). Coyotes are often maligned for eating domestic cats; however, research suggests that cats only make up about 1-2\% of an urban coyote's diet (Gehrt 2007). On the other hand, coyotes may kill more cats than they consume as a form of intraguild competition (Gehrt 2007; Gehrt et al. 2013).

Urban coyotes are usually seen alone, but most often live in family groups with five to six adult members (Bekoff and Gese 2003; Gehrt n.d.). Although coyotes are adapted for both crepuscular and diurnal activity, urban coyotes display increased nocturnal activity; coyotes in cities are thought to modify their waking hours to take advantage of the lack of humans and traffic at night. However, some urban coyotes are also spotted during the day (Kitchen, Gese, and Schauster 2000; Gehrt 2007; Kenaga, 
Krebs, and Clapham 2013). Urban coyotes seen during the day are most likely

habituated - they are less concerned with human activity because it has become routine (Gehrt 2007). Habituated coyotes have the highest likelihood of being involved in human-coyote conflict (discussed in detail below; Gehrt n.d.; Lukasik 2009; Gehrt, Riley, and Cypher 2010; Alexander and Quinn 2011).

Coyotes survive in cities by adapting to the new challenges of an urban habitat. They find creative shelter in such places as culverts, golf courses, and forgotten land by highways (Andelt and Mahan 1980; Gehrt, Anchor, and White 2009; Grubbs and Krausman 2009; Bateman, Fleming 2011). Urban coyote home ranges are, on average, significantly smaller than rural home ranges. Urban home ranges are estimated at $7.3 \mathrm{~km}^{2}$, while rural home ranges average out to a much larger $17.5 \mathrm{~km}^{2}$ (Gehrt 2007). Although the mean home range for a coyote is $7.3 \mathrm{~km}^{2}$ in an urban area, coyotes use only a portion of that space for hunting and living. Even in dense urban areas, coyotes are most commonly found in fragments of natural or undeveloped habitat. Overall, coyotes tend to avoid areas that are associated with humans (Gehrt, Anchor, and White 2009). Unsurprisingly, research shows that areas of higher development tend to have lower coyote densities. Although difficult to determine, urban coyote population density is estimated at 0.8 to 2.1 coyotes per $\mathrm{km}^{2}$ (Gehrt, Brown, and Anchor 2011).

Research specific to urban coyote ecology is a relatively new area of inquiry, despite the fact that coyotes are one of the most studied mammals in North America (Bekoff and Gese 2003; Gehrt, Riley, and Cypher 2010). Most urban coyote research 
focuses on ecological questions, e.g., examining coyote characteristics, life history, behavior, habitat selection, and disease transmission (Gehrt, Riley, and Cypher 2010).

One of the earliest studies of urban coyotes follows a particular coyote in Lincoln, Nebraska on its adventures through the city. Through observation and tracking by radio telemetry, researchers found that the coyote spent much of his time playing with domestic dogs, even mounting an especially intriguing golden retriever. This particular coyote's life was ended, one year after the case study began, by a hunter's bullet (Andelt and Mahan 1980). This case study is an early glimpse into the life of the urban coyote-a life rich with scavenging, hunting, hiding, howling, and playing.

With increased numbers and attention to urban coyotes, research technologies have widened. Now, researchers examine coyote behavior in great detail, using a variety of modern research tools. Methods such as radio telemetry, GPS tracking, and camera traps help researchers understand coyote habitat use, population density, and movement in the city (Gehrt 2007). Advances in genetic analysis led researchers to discover that urban coyotes are both socially and genetically monogamous, even with ample resources (lack of resources generally increases monogamous behavior; Hennessy, Dubach, and Gehrt 2012). One of the largest research groups to study urban coyotes is Ohio State University's Cook County Coyote Project, headed by environmental science professor and wildlife expert Stanley D. Gehrt. With the continuous adaptation and improvement of research techniques, urban coyote ecology research will further inform our understanding of how coyotes get by in cities. 


\section{Human-coyote Interaction}

Research into human-coyote interactions is even newer than urban coyote ecology research. As urban coyote populations increase, human-coyote interactions and conflicts increase. Studies have only recently started to focus on these human-coyote conflicts (Gehrt, Riley, and Cypher 2010). Researchers investigate the frequency and severity of conflicts as well as people's attitudes and knowledge of coyotes (Gehrt, Riley, and Cypher 2010; Draheim et al. 2011).

In a 2001 wildlife survey, coyotes were ranked by Chicago homeowners as "the most severe threat to human health and safety" out of twelve common wildlife species (Miller et al.). Gehrt et al. call coyotes "arguably the most controversial carnivore species in North American Metropolitan areas" $(2010,79)$. Coyotes are often the subject of passionate debate, seemingly with as many voices for them as against them.

The controversial status of coyotes has a long history. Early conflicts involved sheep and cattle ranchers worried for their livestock. Today, conflicts between ranchers and coyotes persist, along with new challenges associated with growing urban landscapes. In a 1985 study that polled Americans on their opinions of thirty-three animals, coyotes were the second least-liked animal, following wolves. In the same study, a sharp contrast between general public opinion and rancher opinion is evident. Ranchers were strongly in support of reducing coyote populations via shooting and trapping, while the general public was in favor of more conservative control methods, such as targeting specific problem animals and relocating coyotes (Kellert 1985). 
Researchers often evaluate attitudes by gauging support of lethal control (Vaske and Needham 2007; Jackman and Rutberg 2015; Sponarski, Vaske, and Bath 2015a; Sponarski, Vaske, and Bath 2015b). Research demonstrates that individuals who perceive coyotes as a direct threat tend to have more negative attitudes toward coyotes and are more likely to support extreme removal methods such as lethal control (Arthur 1981; Kellert 1985; Martínez-Espiñeira 2006). One framework that explains this phenomenon is impact dependency. Researchers find that people make decisions about wildlife based on the perceived impact of that wildlife. Decisions are most impact-dependent when a person thinks an animal might affect their basic needs (safety, shelter, etc.). In cases where animals threaten basic needs, people are more likely to support drastic control methods (Decker, Jacobson, and Brown 2006). Ranchers perceive different and often more severe impacts than the general public, such as a threat to their livelihood, which, according to the impact dependency framework, accounts for their support of more drastic control methods (Kellert 1985).

Fear of negative impacts can play a major role in attitudes about coyotes. A study in Canada's Cape Breton National Park surveyed residents after a fatal coyote attack (the second fatal attack ever reported). The study showed that residents felt more fear, less control, and had more negative attitudes toward coyotes than staff or visitors (Sponarski et al. 2015a). In another study, researchers found that people who reported more fear of coyotes were also less likely to have positive attitudes toward coyotes. These more fearful participants, in addition to not wanting coyotes to remain in cities, tended to hold pet owners less responsible for protecting their pets from coyotes (Draheim et al. 2013). 
Attitudes, like fear, can significantly affect the way people respond to urban coyote issues (Lawrence and Krausman 2011; Sponarski et al. 2015a).

Public attitudes about coyotes may be significantly influenced by media. Media coverage of human-coyote conflict often overemphasizes the severity of conflicts. Conservation director at the Audubon Society of Portland, Bob Sallinger, describes this kind of media coverage as "jaws and claws" stories, where the actual risk of coyote attacks are overestimated. Even when articles or newscasts conclude that coyote attacks are not a major threat, many people see only the "fear-mongering" headlines and "the damage is already done" (personal communication, November 18, 2015). News coverage reflects, influences, and often reinforces increasing public concern about coyotes (White and Gehrt 2009; Alexander and Quinn 2011).

Coyote attacks are relatively rare (White and Gehrt 2009). Estimating total coyote attacks per year is difficult because reporting is not standardized across agencies and municipalities (White and Gehrt 2009). What is known is that coyote attacks are uncommon, especially when compared to other human-animal conflicts. For example, there were 209 reported dog attacks in Aurora, Colorado in 2009. In the same year, only 2 coyote conflicts were reported (one attack and one "incident"; Poessel et al. 2013).

When conflicts between humans and coyotes do occur, they are usually minor ${ }^{2}$ (Lukasik and Alexander 2011; Poessel et al. 2013). Most reported human-coyote conflicts are classified as predatory or investigative (as opposed to rabid, defensive, or

\footnotetext{
${ }^{2}$ There have been two documented fatal attacks on humans by coyotes. In 1981, a small child was attacked and killed in a front yard in Glendale, California (Howell 1982). The second attack occurred in 2009 in Cape Breton National Park of Canada, when a group of coyotes attacked and killed a 19-year-old woman while she was hiking alone (CBC News 2009).
} 
pet-related). Children and adults are involved in conflicts at comparable rates, but predatory conflicts are more common with children (White and Gehrt 2009). Humancoyote conflict is more likely to be reported in suburban areas than rural or exurban areas. Contrary to their expectations, researchers found that conflicts are more often reported in open spaces and developed land rather than natural and agricultural areas (Poessel et al. 2013).

Human-coyote conflicts usually occur when a coyote has grown comfortable around humans (Gehrt n.d.; Lukasik 2009; Gehrt, Riley, and Cypher 2010; Alexander and Quinn 2011). Wildlife feeding, habituation to food sources, and pup-rearing season (spring and summer) are the most common factors in human-coyote conflict (Gehrt n.d.; White and Gehrt 2009; Gehrt, Riley, and Cypher 2010; Alexander and Quinn 2011; Lukasik and Alexander 2011). But deliberate or accidental feeding is by far the most problematic contributor to conflict (Gehrt n.d.; Lukasik 2009; White and Gehrt 2009; Alexander and Quinn 2011). In fact, one study found evidence of feeding in almost onehundred percent of coyote conflicts investigated (Alexander and Quinn 2011).

Researchers recommend increased educational efforts to reduce conflict (Siemer, Hudenko, and Decker 2007; White and Gehrt 2009; Alexander and Quinn 2011; Poessel et al. 2013). Many people do not know that they can help prevent negative interactions with coyotes by: using hazing techniques (scaring coyotes that are too comfortable); removing brush or food sources from their yards; and supervising pets (White and Gehrt 2009). Without access to this information, many people still encourage, intentionally or unintentionally, habituation and do not know the best way to react when they see a coyote 
(Siemer, Hudenko, and Decker 2007; White and Gehrt 2009; Gehrt, Riley, and Cypher 2010). However, high-quality and accessible education about urban coyotes is lacking in many places (Draheim 2007). Since habituation is such a major contributor to conflict, researchers argue that programs that equip residents with the knowledge they need to prevent habituation (and to react appropriately when they see a coyote) will result in less human-coyote conflict. As such, proactive educational materials can be the first line of defense in successful coyote management programs (Gehrt 2007; Draheim 2007; Siemer, Hudenko, and Decker 2007; Vaske and Needham 2007; White and Gehrt 2009; Weckel et al. 2010; Alexander and Quinn 2011; Draheim et al. 2011; Poessel et al. 2013; Sponarski et al. 2015).

In addition to better educational tools, experts recommend increased study of human attitudes toward coyotes. More information about public opinion of coyotes can help city officials, policy makers, and wildlife managers create more effective management strategies (Siemer, Hudenko, and Decker 2007). When managers understand people's knowledge of coyotes, attitudes toward coyotes, and experiences with coyotes, they are better equipped to develop management plans that are relevant and acceptable to residents (Siemer, Hudenko, and Decker 2007).

To understand knowledge of and attitudes toward coyotes, Megan Draheim, an urban coyote researcher at the College of Natural Resources and Environment at Virginia Polytechnic Institute and State University, uses widespread surveys. In her studies, Draheim found that people in the Washington D.C. area generally had a low level of awareness of coyotes and a slightly positive evaluation of their presence (Draheim 2007). 
Public knowledge about coyotes is generally moderate. Some studies have found that most people have major misconceptions, such as the idea that coyotes are an endangered species and that they weigh an average of 100 pounds (Kellert 1988; Draheim 2007). However, research also demonstrates that many people know basic facts about human-coyote interactions. For example, most people know that human attacks on coyotes are not common and that you should not run from a coyote (Draheim 2007).

Although coyotes have been loathed in rural and ranching areas and sensationalized in media coverage of attacks, there is increasing support for coyotes in urban areas. Between 2005 and 2012, a study in Cape Cod found that residents' opposition to lethal control increased and that their general attitudes toward coyotes became more favorable over the seven-year study period (Jackman and Rutberg 2015). Overall, urbanite attitudes about coyotes in urban areas are neutral to positive, with general support of coyotes' presence in cities (Draheim 2007; Draheim, Patterson, and Rockwood 2013; Jackman and Rutberg 2015).

Studies repeatedly find that attitudes change with time and education (Draheim 2007; Draheim et al. 2011; Jackman and Rutberg 2015). In a 2011 study, Draheim et al. found that college students' attitudes about coyotes were more positive after being shown images or information about coyotes. While extensive education is likely to make a larger impact on attitudes, even a short brochure or flyer about coyotes might improve attitudes and clear up misconceptions (Draheim et al. 2011).

Unfortunately, a practical approach to widely accessible and inexpensive education is lacking in many cities (Taylor 2004). Researchers and city officials are 
always looking for ways to better manage human-coyote conflict through education (Gehrt 2007; Draheim 2007; Siemer, Hudenko, and Decker 2007; Vaske and Needham 2007; White and Gehrt 2009; Weckel et al. 2010; Alexander and Quinn 2011; Draheim et al. 2011; Poessel et al. 2013; Sponarski et al. 2015). In many cases, human-coyote interactions are limited to brief visual encounters, yet some interactions are more problematic. Residents report coyotes behaving boldly, killing pets, and even behaving aggressively toward humans (Gehrt and White 2009). Although these interactions are rare, word-of-mouth, misinformation, and skewed media coverage can create fear of coyotes in the wider community. On the opposite end, some residents find coyotes fascinating and encourage their presence by feeding them, thereby increasing risk of conflict (Alexander and Quinn 2011). It is evident that there is both too little information and too much misinformation about urban coyotes. Education, as a tool for proactive management, can help dispel misunderstandings and provide the public with the information they need to reduce conflicts with coyotes.

Equipped with tools like education to reduce conflict, citizens will be more prepared for the ever-urbanizing future of the United States and the unstoppably adaptive coyote. A contemporary tool in the management of conflict, and a tool made more efficient by the internet and social media, is citizen science. Citizen science is scientific study that actively involves, through data collection or analysis, volunteers from the general public (Conrad and Hilchey 2011). Citizen science projects can be harnessed to engage the public, create knowledge, and provide education. In the next section, I review 
the research on citizen science for education and introduce the Portland Urban Coyote Project (PUCP), the citizen science project that is the focus of this research. 


\section{CHAPTER 2: CITIZEN SCIENCE}

In the last few decades, research methods have been developed, refined, and reinvented to incorporate new technologies. Access to the internet has made important research practices like collaboration and data analysis faster and more accessible. Citizen science, or research that is conducted (at least partially) by amateur scientists, has particularly grown in popularity. Citizen science projects have answered questions from across many disciplines, such as psychology, astronomy, climatology, geography, and environmental science (Conrad and Hilchey 2011). Citizen science, in some form, has been practiced since the 1880 s; however, citizen science as we currently understand itgenerally with an online component and an emphasis on public education and engagement - came to exist only in the past two decades (Bonney et al. 2009).

Many citizen science projects focus on collecting data related to the number, location, and attributes of plant and animal species; the purpose of many citizen science projects is to understand nature. A project might ask participants to count bird sightings, record when and where a particular flower blooms, or report endangered species sightings. These nature-related citizen science projects usually operate through a website, where participants can record and view collected data. The websites sometimes function as educational resources for the general public — with tutorials, videos, frequently asked questions pages, reading materials, and links to more resources to help participants (and anyone else who is interested) get more information about the study subject (Evans et al. 2005). 
Nature-related citizen science projects often have a strong geographic component, involving specific sighting locations and details about the environment in which the study subject was observed. Volunteers report addresses, place names, latitude and longitude, or even contribute geometries (lines and polygons). Geographer Michael F. Goodchild calls these geographic contributions volunteered geographic information (VGI; Goodchild 2007; Elwood, Goodchild, and Sui 2012). Like the PUCP coyote sightings map (described below in "Citizen Science \& Coyotes: The Portland Urban Coyote Project"), citizen science projects often use online maps to collect and display citizenreported data. These projects are often successful in engaging users and collecting valuable information. For example, when evaluating Oakmapper, a citizen science project that asks contributors to monitor sudden oak death, researchers found that the public mapping project resulted in multiple benefits, such as a high-quality dataset and a more engaged public (Connors, Lei, and Kelly 2012). Such projects have been met with an enthusiastic response from communities and scientists alike. Projects are often celebrated for their "win-win" status of educating the public and contributing to scientific understanding, but some researchers worry that there are still a host of unresolved issues in citizen science research (Riesch and Potter 2014, 108).

Online maps are relatively easy to produce and contribute to, which has led to an explosion in geographic data on the web (Elwood, Goodchild, and Sui 2012; Tang and Liu 2015). Projects that use VGI often collect data inexpensively and quickly compared to traditional methods (Haklay 2010; Newman et al. 2010). However, the accuracy of these data compared to traditional data has been called into question (Haklay 2010). On 
the other hand, in some studies, VGI data was found to be sufficiently accurate for research purposes (Haklay 2010; Elwood, Goodchild, and Sui 2012; Nagy et al. 2012; Cox et al. 2014). Accuracy can sometimes be enhanced by filtering data, such as recording and accounting for an individual user's expertise (Connors, Lei, and Kelly 2012; Tang and Liu 2015). Some researchers argue that the sheer volume of data often associated with VGI can help safeguard against major inaccuracies (Goodchild and Li 2012). However, the accuracy of VGI data across projects remains inconsistent; in part, this is because VGI is not, and sometimes cannot be, measured by traditional standards of accuracy (Haklay 2010; Elwood, Goodchild, and Sui 2010).

One issue with the accuracy of VGI is that it depends on accurate contributor knowledge. For example, in the Oakmapper project, researchers acknowledge that the ability or education level of contributors might affect data quality. In addition to recording the level of expertise of individual contributors (as mentioned above), projects like Oakmapper try to mitigate accuracy issues by providing resources on their website to educate contributors (Connors, Lei, and Kelly 2012). The Oakmapper website has a page of videos, photos, and links to in-depth resources about sudden oak death (2015). Such information might help less experienced contributors report cases of sudden oak death more accurately, but it is unclear to what extent these materials improve accuracy. The efficacy of citizen science as a tool for education remains variable. 


\section{Citizen Science as a Tool for Education}

Citizen science is often celebrated for its ability to engage, excite, and educate the public; however, the specifics of the educational value of citizen science materials are relatively understudied (Conrad and Hilchey 2011; Connors, Lei, and Kelly 2012). In their review of the past decade of research into citizen science, geographer Cathy C. Conrad and environmental scientist Krista G. Hilchey argue that one of the main benefits of citizen science projects is that they "increase scientific literacy" $(2011,280)$. Conrad and Hilchey's review mostly emphasizes the connection (or missing connection) between policy-makers and citizen science project findings (2011). When Conrad and Hilchey reference educational programs they discuss citizen science that takes place in schools; their findings do not center on the efficacy of the citizen science project as an educational tool outside the classroom (Au et al. 2000; Nali and Lorenzini 2007; Conrad and Hilchey 2011). Most studies have examined successful citizen science projects that educate through in-person educational programs (Au et al. 2000; Nali and Lorenzini 2007; Conrad and Hilchey 2011; Jordan et al. 2011). On the other hand, online educational tools for citizen science are not studied as frequently.

The Cornell Lab of Ornithology is a pioneer in citizen science for online nature education and has at least nine active citizen science projects. A main goal of these projects is to educate. Researchers have found that these projects are educational, but the scope and extent of learning is limited (Trumbull et al. 2000; Evans et al. 2005; Thompson and Bonney 2007; Brossard, Lewenstein, and Bonney 2005). For example, in 2005, researchers studied the educational value of the Cornell project, Nestwatch, a 
project that asks participants to learn about, find, and record nesting patterns in their area. The Nestwatch project has two main goals: to contribute scientific data and to engage and educate the public. Nestwatch particularly focuses on educating participants to improve scientific literacy and sense of place. Researchers found that the Nestwatch project is reasonably educational (by conducting a small sample of surveys and interviews); however, the researchers argue that the project has not reached its full educational potential and suggest that future studies explore education in citizen science further (Evans et al. 2005).

Growing research on the educational value of citizen science demonstrates that these projects can change participant behavior, encouraging them to engage with the study subject more deeply and more often. For example, individuals watched birds more often and took more detailed notes after participating in eBird, a Cornell Lab of Ornithology citizen science project (Thompson and Bonney 2007; Bonney et al. 2009). On the other hand, in a different Cornell Lab study, researchers found that participants learned new knowledge, but participants' attitudes toward the environment did not change (Brossard, Lewenstein, and Bonney 2005). In a 2015 study, researchers found that citizen scientists knew more about coral reef biology and human impacts on the environment after participating in a coral reef monitoring citizen science project (Branchini et al.).

Similar studies have evaluated other citizen science projects and recommend future study to better understand educational outcomes and efficacy (Haywood 2014; Sickler et al. 2014). A 2014 study that examined a citizen science project about ladybugs 
(The Lost Ladybug Project) recommends that more research be conducted to explain how to attract, engage, and retain participants (Sickler et al.).

Geographer Benjamin Kent Haywood takes a more conceptual approach. Haywood argues that citizen science projects are "inherently place-based" because they are necessarily an interaction between the participant and a place - the place where the citizen science occurs (Haywood 2014, vi). Haywood's research examines the more broad educational impacts of citizen science by studying how engagement with citizen science affects the way an individual experiences the world (2014).

Citizen science is gaining popularity as a way to contribute to science and engage and educate participants across subjects. Widely used for nature-related projects, citizen science has great potential for wildlife education. Research demonstrates that education through citizen science can be effective (Brossard, Lewenstein, and Bonney 2005; Thompson and Bonney 2007; Bonney et al. 2009; Branchini et al. 2015), but the possibilities for education remain in their infancy. With more research on how educational tools associated with citizen science projects can be used, and more research on how effective these tools are, citizen science can be used as a valuable instrument for nature education and wildlife management. Citizen science could play a key role in harnessing public interest for education-based proactive management.

\section{Citizen Science and Coyotes: The Portland Urban Coyote Project}

There have been just a few studies that investigate the impact and effectiveness of citizen science projects on urban coyotes. These studies primarily involve the analysis of citizen-reported coyote sightings. First, in 1995, researcher Timothy Quinn compiled 
sightings reported during telephone interviews to understand coyote habitat use. Quinn then compared these results to telemetry locations and found that coyotes stayed closer to forest habitat during daylight, and that public sightings were more common in populated areas, but were otherwise similar to telemetry locations (1995). Next, in 2010, researchers used citizen-reported coyote sightings to create a model that described the locations of coyote sightings across Westchester County, New York (Weckel et al.). Then, in 2012, researchers tested the validity of the citizen-reported sightings model, finding that it adequately predicted coyote presence (Nagy et al.). In 2015, researchers again examined citizen-reported coyote sightings. In this study, they found that socioeconomic factors (such as building density, occupation, and income) were associated with citizen-reported coyote sighting locations; coyote sightings occurred more often in wealthy neighborhoods and in areas with higher building density (Wine et al. 2015).

Finally, in 2014, researchers explored the connection between citizen science and coyote management through education. After being involved in Coyote Watch, a citizen science program in Denver, Colorado, participants were more knowledgeable about coyotes and more prone to take action in the community to prevent or manage humancoyote conflict (Adams 2014). This recent research demonstrates the promising future of using citizen science for coyote education and management. The PUCP will serve as a case-study in the Portland Metropolitan Area to build on this Denver research to further understand how citizen science can provide community education.

Public concern about urban coyotes in Portland, like many cities, has been an issue since their appearance 30 years ago (Sallinger 2011). The appearance of coyotes in 
Portland posed new challenges for residents, wildlife organizations, and city officials (Figure 2.1). With increased coyote encounters across the city, many people reached out to the Audubon Society of Portland to report their coyote sightings, express concern, to request more information about their new neighbors. Conservation director of the Audubon Society of Portland Bob Sallinger recounted that "coyotes have been, without question, the most consistent and high-pitched issue we've been contacted about." Sallinger went on to explain that during the 1990s people's concern about coyotes was "fueled by word of mouth and the occasional media story" but now with instant communication through the internet "misinformation spreads like wildfire." In many cases people's concern comes from lack of knowledge about coyotes, Sallinger says "basic information tends to alleviate the majority of concerns" (personal communication, November 18, 2015).

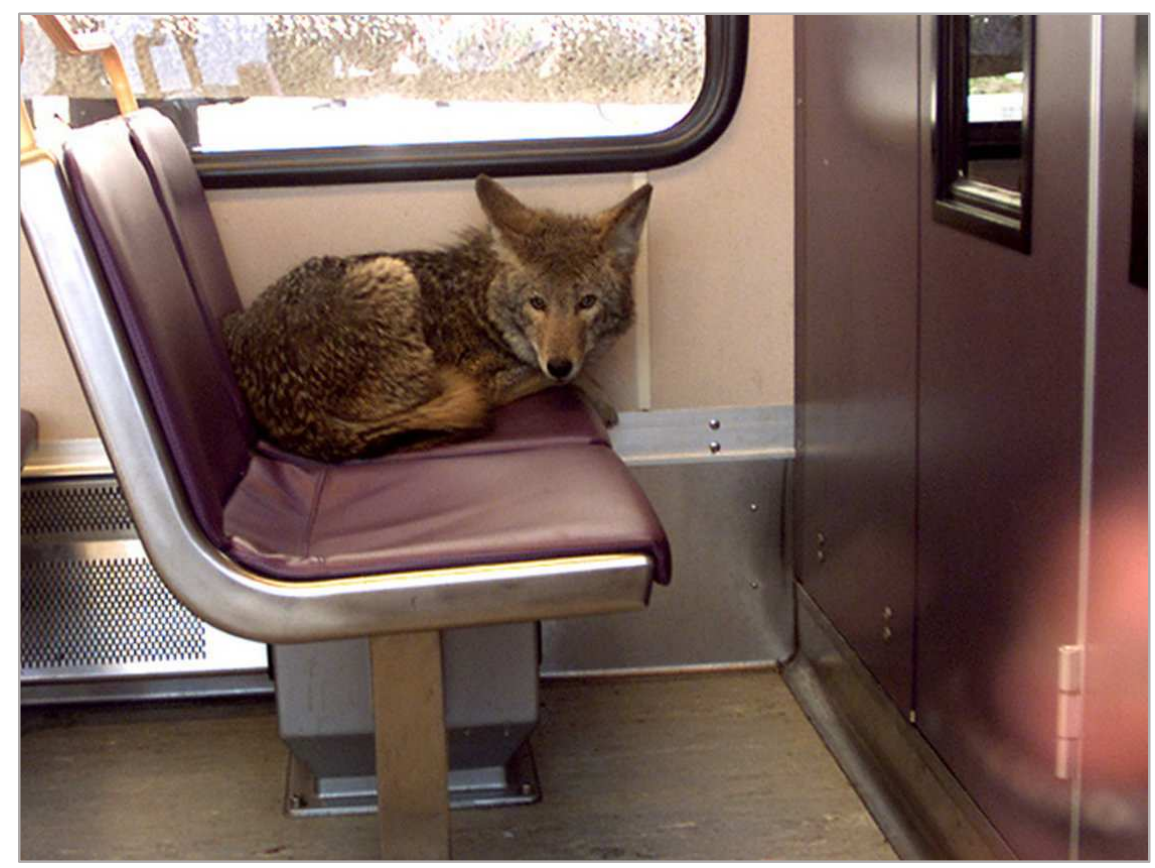

Figure 2.1 Coyote on Portland Metropolitan Area Express (MAX) Light Rail (Photo courtesy Trimet) 
Before the PUCP, citizen education about coyotes was primarily available from the Audubon Society of Portland in the form of online materials and in-person presentations by Bob Sallinger. These presentations last around sixty to ninety minutes and consist of general life history about urban coyotes and tips for mitigating humancoyote conflict. The establishment of the PUCP increased information about humancoyote interactions in Portland and provided increased access to educational resources about coyotes.

Initiated in 2010 by geography graduate student Jenny Grant with Professor Barbara Brower, and further developed since 2013 by Zuriel Rasmussen, the PUCP asks PMA residents to report coyote sightings by completing an online survey. The PUCP, a partnership of the Department of Geography at Portland State University and Audubon Society of Portland, has a website (Figure 2.2) with user-submitted photos (Figure 2.3), information about the project, an interactive sightings map (Figure 2.4), more than 1,500 citizen-reported sightings, and a click-through tutorial about urban coyotes (the subject of this research). The tutorial was developed to address the requests by residents for more information about urban coyotes and to explore whether online education associated with citizen science is an effective tool for proactive management. 


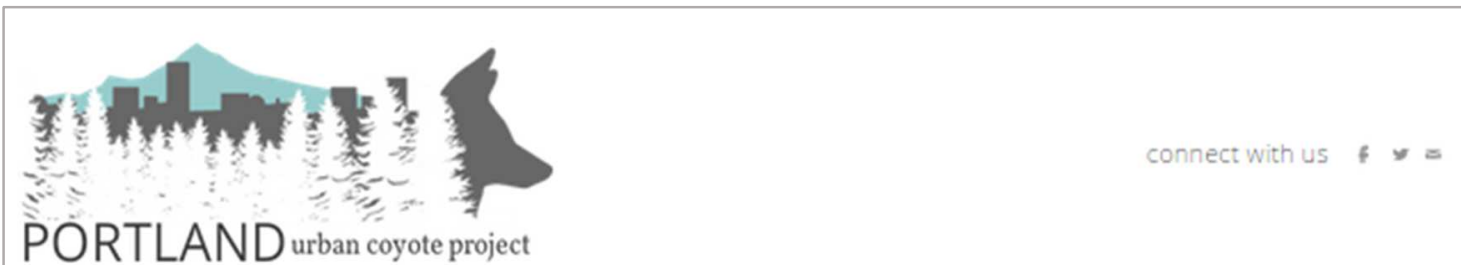

HOME 2015MAP URBAN COYOTE TUTORIAL STUDY ABOUT THE PROJECT PHOTOS VIDEOS RESEARCH

Have you seen a coyote? Help us learn about coyotes by reporting your sighting.

\section{CLICK HERE TO REPORT A SIGHTING}

\section{Explore our interactive sightings maps by clicking below}
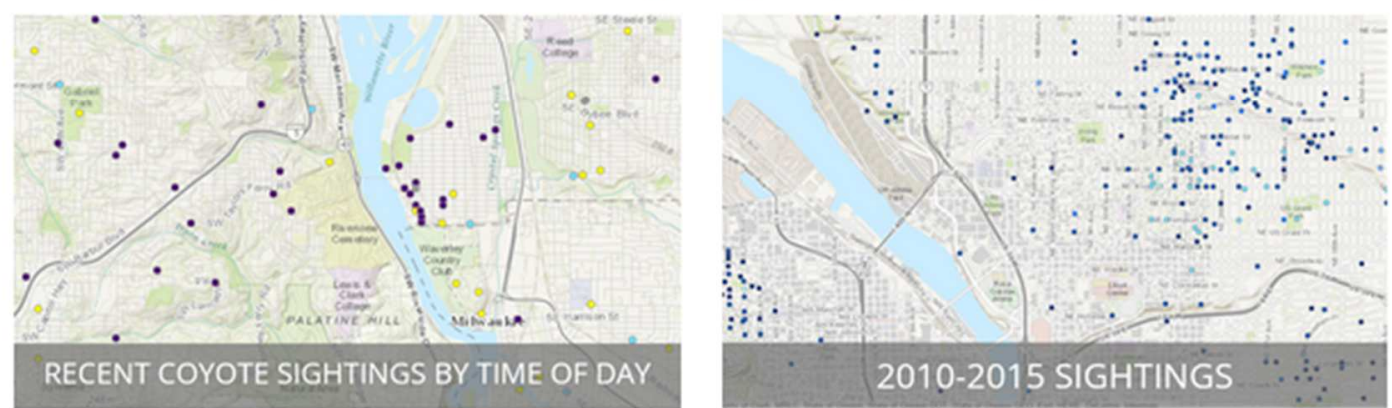

Want to learn more about coyotes? Participate in our Urban Coyote Tutorial Study and be entered to win a $\$ 50$ gift certificate from Fred Meyer by clicking the button below!

\section{TAKE THE SURVEY}

Become a citizen scientist by reporting urban coyote sightings in the Portland metropolitan area.

What is citizen science?

Citizen science is a method of data collection in which researchers and community members work together to collect and compile data.

For the Portland Urban Coyote Project, we are counting on community members to report coyote sightings from across the Portland metropolitan area. We will then compile the data and try to answer scientific questions like "Where do coyotes live in cities?" and "How many coyotes live in Portland?

Your observations are the most important part of this project! The involvement of the community is crucial to the development of our knowledge about coyotes in the city.

Report a sighting by clicking the button above and become a citizen scientist!

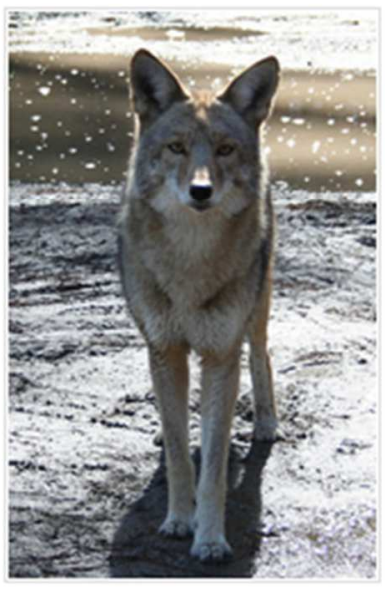

Figure 2.2 Screenshot of the home page of the Portland Urban Coyote Project. 


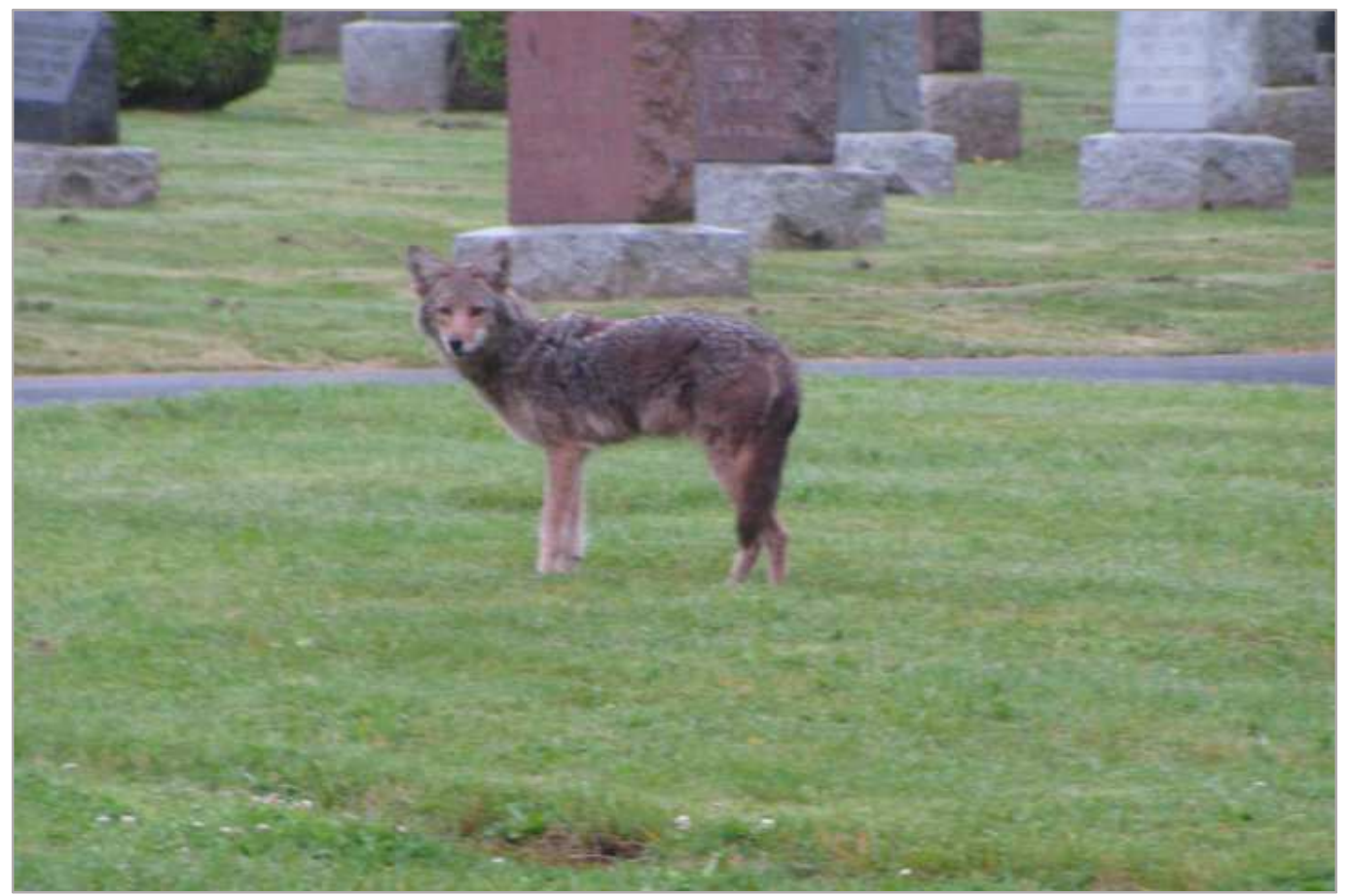

Figure 2.3 Coyote in a Portland cemetery. Photo submitted to the PUCP by citizen scientist Steve Owen (2010).

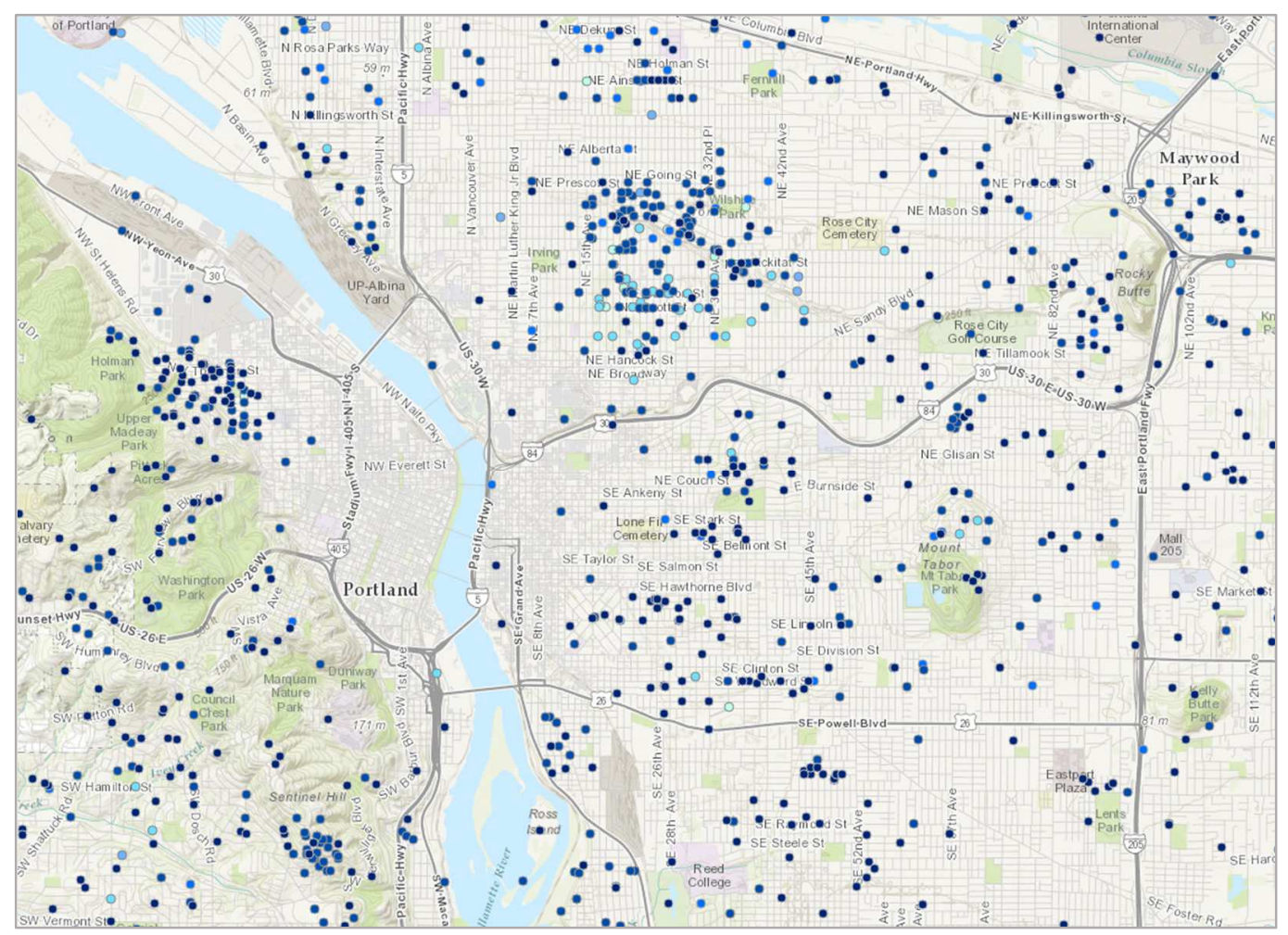

Figure 2.4 Screenshot of interactive coyote sightings map from the Portland Urban Coyote Project Website (sightings from 2010-2015). 


\section{Research Statement}

Urban coyotes are being investigated across North America. Researchers explore habitat use, behavior, mating strategies, and human-coyote interactions. In the PMA, documented human-coyote interactions occur almost every day (Rasmussen 2015). However, PMA residents' experiences with coyotes, knowledge of coyotes, and attitudes about coyotes are not well-understood.

The research I conducted and report below uses questionnaires and the PUCP online tutorial to understand: (1) experiences with, attitudes toward, and knowledge of coyotes in the Portland Metropolitan Area; and (2) how citizen science can be employed as a tool for community education.

The first goal of my study is to investigate experience, knowledge, and attitudes by surveying Portland Metropolitan Area residents. Research suggests that many people are moderately informed about coyotes and tend to have neutral to positive attitudes about coyotes (Draheim 2007). In this research, I explore whether residents in the PMA follow this trend.

The PUCP is part of a growing library of online, nature-related citizen science projects that offer educational materials. As described in previous sections, the educational efficacy of these types of projects warrants further exploration. Researchers find that even small amounts of knowledge can shape attitudes. Furthermore, access to education can improve participant knowledge of coyotes (Draheim 2007). Time and time again researchers suggest that education is key in successful coyote management, arguing that when people are more informed about coyotes, they can make decisions that reduce 
human-coyote conflict (Gehrt 2007; Draheim 2007; Siemer, Hudenko, and Decker 2007; Vaske and Needham 2007; White and Gehrt 2009; Weckel et al. 2010; Alexander and Quinn 2011; Draheim et al. 2011; Poessel et al. 2013; Sponarski et al. 2015). Efficient and inexpensive education is crucial in successful proactive management of urban coyotes; educational materials from citizen science projects offer solutions (Taylor 2004).

The second goal of my research is to investigate whether a short online tutorial hosted through the PUCP influences existing attitudes and knowledge about coyotes. I measure influence by comparing pre-tutorial and post-tutorial questionnaire scores. Based on previous research, I expected to find that:

Hypothesis 1: Participants will have higher knowledge scores after taking the tutorial.

Hypothesis 2: Participants will have more positive attitudes about coyotes after taking the tutorial.

In the following chapters, I describe: (1) the study area and population; (2) sample characteristics; (3) study materials; (4) results and conclusions; and (5) areas for future research. 


\section{CHAPTER 3: TUTORIAL STUDY DESIGN}

To study both the baseline attitudes and knowledge of participants and whether citizen science education changed attitudes and knowledge, I developed a preliminary questionnaire, an educational tutorial, and a post-tutorial questionnaire (together, the

“Tutorial Study"). The Tutorial Study was administered through the Portland Urban Coyote Project (PUCP) website to self-selected participants in the Portland Metropolitan Area (PMA). Responses to the post-tutorial questionnaire were evaluated to determine whether knowledge and attitudes could be influenced during a short web-based educational session. This chapter describes: the study area and population; sample demographics; creation of the click-through tutorial; questionnaire design; study procedures; and methods of analysis.

\section{Study Area and Population}

The Tutorial Study was aimed at the general population of the PMA. The city of Portland is about 145 square miles with a population of 583,776 (US Census 2010; RLIS 2014). For the purposes of this study, the PMA was defined as the boundary subject to Metro's (regional government) regulation and taxation, designated by the Oregon Legislature (RLIS 2014). PMA characteristics were analyzed using this boundary in ArcGIS. In this definition, the PMA includes the cities of Beaverton, Camas, Cornelius, Damascus, Durham, Fairview, Forest Grove, Gladstone, Gresham, Happy Valley, Hillsboro, Johnson City, King City, Lake Oswego, Maywood Park, Milwaukie, Oregon City, Portland, Rivergrove, Sherwood, Tigard, Troutdale, Tualatin, Vancouver, West 
Linn, Wilsonville, and Wood Village (Figure 3.1; RLIS 2014). The PMA is about 467 square miles with a population of 1,592,004 (US Census 2010; RLIS 2014).

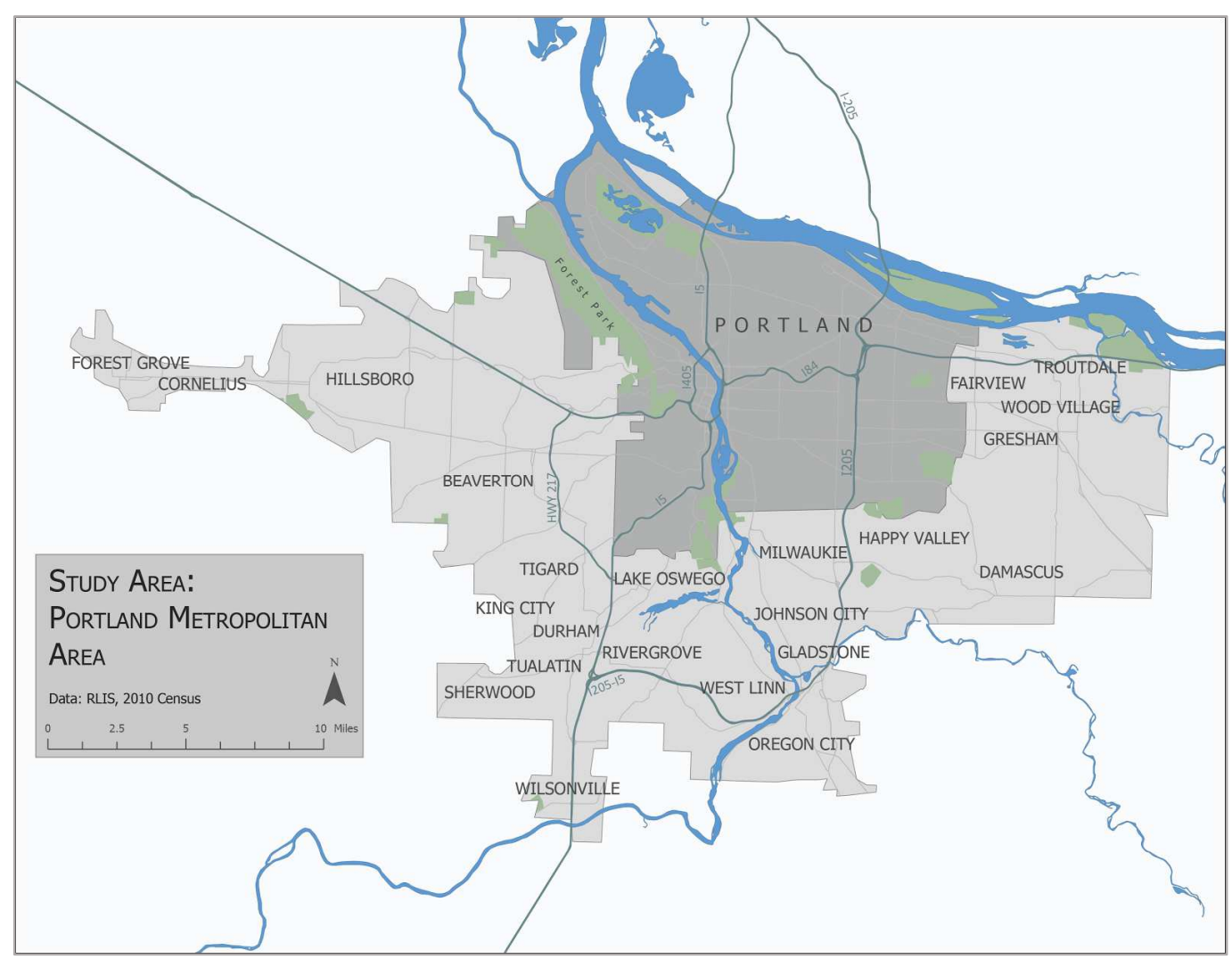

Figure 3.1 Map of study area: Portland Metropolitan Area.

The PMA is $51.32 \%$ female and $48.68 \%$ male (over age 18 ). The majority of PMA residents are white at $78.96 \% ; 11.76 \%$ of PMA residents identify as Hispanic/Latino. All other categories each make up less than $10 \%$ of the population (Table 3.1). PMA resident age is relatively evenly distributed across age ranges, with notably smaller percentages of the population in the 65-74 and over 74 categories (US Census 2010; Table 3.1). 
Table 3.1 Race/Ethnicity and age distribution of Portland Metropolitan Area residents (RLIS; US Census 2010).

\begin{tabular}{|l|l|}
\hline $\begin{array}{l}\text { Race/Ethnicity distribution of Portland Metropolitan Area } \\
\text { residents }\end{array}$ & Percent \\
\hline White & $78.96 \%$ \\
\hline Hispanic/Latino (of any race) & $11.76 \%$ \\
\hline Asian & $6.83 \%$ \\
\hline Some other race & $5.42 \%$ \\
\hline Two or more races & $4.25 \%$ \\
\hline Black/African American & $3.43 \%$ \\
\hline American Indian/Alaskan Native & $.9 \%$ \\
\hline Native Hawaiian/Other Pacific Islander & $.47 \%$ \\
\hline Age distribution of Portland Metropolitan Area residents & Percent \\
\hline $0-14$ & $19.03 \%$ \\
\hline $15-24$ & $12.57 \%$ \\
\hline $25-34$ & $16.19 \%$ \\
\hline $35-44$ & $14.90 \%$ \\
\hline $45-54$ & $14.14 \%$ \\
\hline $55-64$ & $12.08 \%$ \\
\hline $65-74$ & $5.92 \%$ \\
\hline Over 74 & $5.15 \%$ \\
\hline
\end{tabular}

PMA residents tend to be well-educated. A majority (67.2\%) of residents over age 25 have at least some college education. Median yearly family income in the PMA is $\$ 68,924$, with $33.5 \%$ of residents earning $\$ 50,000$ to $\$ 99,999$ and $24.9 \%$ earning less than $\$ 30,000$ per year (US Census 2010; Table 3.2). 
Table 3.2 Education and income distribution of Portland Metropolitan Area residents (US Census 2010).

\begin{tabular}{|l|l|}
\hline Education distribution of Portland Metropolitan Area residents & Percent \\
\hline Less Than High School & $10.0 \%$ \\
\hline High School Graduate (includes equivalency) & $22.9 \%$ \\
\hline Some college & $33.7 \%$ \\
\hline Bachelor's degree & $21.5 \%$ \\
\hline Master's degree & $8.2 \%$ \\
\hline Professional school degree & $2.4 \%$ \\
\hline Doctorate degree & $1.4 \%$ \\
\hline Income distribution of Portland Metropolitan Area residents & Percent \\
\hline Less than \$30,000 & $24.9 \%$ \\
\hline$\$ 30,000-\$ 49,999$ & $19.4 \%$ \\
\hline$\$ 50,000$ to \$99,999 & $33.5 \%$ \\
\hline$\$ 100,000$ to \$199,999 & $18.3 \%$ \\
\hline$\$ 200,000$ or More & $4.0 \%$ \\
\hline
\end{tabular}

\section{Sample}

Participants were selected based on their residency in the PMA and their willingness to take part in the study. There were 145 participants who participated in both questionnaires and 175 participants who participated in the preliminary questionnaire only. Because of limited funding, research was limited to self-selected participants; however, efforts were taken to reach a wide variety of participants. The study was promoted both online (Craigslist, Nextdoor, Facebook, etc.) and offline (community centers, public libraries, grocery stores, etc.). Promotional materials for the study included entry into a drawing for $\$ 50$ at Fred Meyer (a regional grocery store). The 
questionnaire was available only online. Participants who reported where they heard about the study $(\mathrm{N}=145)$ found the study through Facebook $(38.9 \%)$, the PUCP website (18.1\%), flyers (19\%), miscellaneous sources (12.5\%), such as word of mouth, Craigslist (10.4\%), and Nextdoor (6.9\%), a neighborhood community website.

\section{Sample Demographics}

Participants were asked demographic questions in the last section of the posttutorial survey (described below in "Materials"). Participants who did not complete the post-tutorial survey did not report demographic data; however, this was deemed necessary to avoid early abandonment of the survey and priming effects (altered responses because of prior questions; Bradburn, Sudman, and Wansink 2004; Parkin 2008).

Almost three-quarters of participants reported their gender as female: of the 138 participants who reported gender, $72.5 \%$ reported female and $27.5 \%$ reported male (Table 3.3). In the PMA there are more females than males (described above in "Study Area and Population"), but not by a large enough margin to explain such a large proportion of female participants. In related research, female participants have also been the majority (Draheim 2007; Draheim et al. 2013; Sponarski et al. 2015). Additionally, the Denver citizen science project Coyote Watch found that their volunteers were more likely to be female (Adams 2014). It is not clear why female participants are more likely to participate in these projects; however, the sample for this study follows this well established, but not well understood, pattern. 
The majority of the sample reported their ethnicity as White/Caucasian. Of the 144 participants who reported their ethnicity, 85.4\% reported White/Caucasian, 5.6\% reported more than one ethnicity, 3.5\% reported Hispanic/Latino, 3.5\% reported an ethnicity not otherwise listed, and 2.1\% reported Asian (Table 3.3). The sample had a slightly over-representative White/Caucasian rate, while Hispanic/Latino and Asian rates were underrepresented. American Indian/Alaskan Native and Native Hawaiian/Other Pacific Islander individuals were barely represented — participants only reported these ethnicities in conjunction with other ethnicities (collapsed into the more than one ethnicity category).

Participants from each age range were represented, with a disproportionately small amount of participants between 18 and 24 and over 74 compared to the PMA in general. Of the 143 participants that reported their age, $25.9 \%$ were ages $25-34,23.1 \%$ were ages $35-44,21.7 \%$ were ages $55-64,17.5 \%$ were ages $45-54,7.7 \%$ were ages $65-74$, $3.5 \%$ were ages $18-24$, and $.7 \%$ were over 74 (Table 3.3 ).

Participants from across income levels were represented in this sample. Of the 143 participants who reported their income, $27.3 \%$ made $\$ 100,000$ to $\$ 249,000,27.3 \%$ made $\$ 50,000$ to $\$ 99,000,22.4 \%$ made $\$ 30,000$ to $\$ 49,999,20.3 \%$ made less than $\$ 30,000$, and $2.8 \%$ made over $\$ 250,000$. Most income brackets mirrored PMA statistics; however, more participants made over $\$ 100,000$ than PMA residents in general (30.1\% versus $22.3 \%$ respectively; US Census 2010; Table 3.3). 
Table 3.3 Gender, Ethnicity, Age, and Income distribution of sample.

\begin{tabular}{|c|c|}
\hline Gender distribution of study sample, $N=138$ & Percent (n) \\
\hline Female & $72.5 \%(n=100)$ \\
\hline Male & $27.5 \%(\mathrm{n}=38)$ \\
\hline Ethnicity distribution of study sample, $N=144$ & Percent (n) \\
\hline Asian & $2.1 \%(n=2)$ \\
\hline Hispanic/Latino & $3.5 \%(n=5)$ \\
\hline White/Caucasian & $85.4 \%(n=123)$ \\
\hline More than one ethnicity & $5.6 \%(\mathrm{n}=8)$ \\
\hline Other & $3.5 \%(\mathrm{n}=5)$ \\
\hline Age distribution of study sample, $N=143$ & Percent (n) \\
\hline $18-24$ & $3.5 \%(n=5)$ \\
\hline $25-34$ & $25.9 \%(\mathrm{n}=37)$ \\
\hline $35-44$ & $23.1 \%(\mathrm{n}=33)$ \\
\hline $45-54$ & $17.5 \%(\mathrm{n}=25)$ \\
\hline $55-64$ & $21.7 \%(\mathrm{n}=31)$ \\
\hline $65-74$ & $7.7 \%(n=11)$ \\
\hline Over 74 & $.7 \%(n=1)$ \\
\hline Income distribution of study sample, $N=143$ & Percent (n) \\
\hline Less than $\$ 30,000$ & $20.3 \%(\mathrm{n}=29)$ \\
\hline$\$ 30,000-\$ 49,999$ & $22.4 \%(\mathrm{n}=32)$ \\
\hline$\$ 50,000-\$ 99,999$ & $27.3 \%(\mathrm{n}=39)$ \\
\hline$\$ 100,000-\$ 249,000$ & $27.3 \%(\mathrm{n}=39)$ \\
\hline$\$ 250,000$ or more & $2.8 \%(n=4)$ \\
\hline
\end{tabular}

The sample had a large majority (93.8\%) of participants with at least some college credit (much more than PMA residents in general at 67.2\%; US Census 2010). Of the 145 participants who reported their highest level of education, $34.9 \%$ held a Bachelor's 
degree, $29.5 \%$ held a Master's or Doctoral) degree, $21.9 \%$ had some college credit, but no degree, $7.5 \%$ held an associate's degree, $4.8 \%$ were high school graduates (or equivalent), and $1.4 \%$ did not complete high school (Table 3.4).

In addition to education level, participants were asked if they were students at the time of taking the survey. This question was important to understand if and how the PUCP's affiliation with Portland State University affected the sample. An overwhelming majority of participants were not college students when they took the survey. Of the 145 participants who reported their student status, $90.3 \%$ were not college students, $4.1 \%$ were graduate students, $2.8 \%$ were undergraduate students at a 4 -year university, and $2.8 \%$ were undergraduate students at a 2 -year university (Table 3.4 ). There did not appear to be overrepresentation of Portland State University students.

Many participants were long-time residents of the PMA. Of the 145 participants who reported their residency length, $46.9 \%$ reported living in the PMA for over 20 years, while $17.9 \%$ reported $6-10$ years, $16.6 \%$ reported $1-5$ years, $14.5 \%$ reported $11-20$ years, and $4.1 \%$ reported less than one year (Table 3.4). Participants who reported their zip codes were distributed across the PMA, with a large proportion of participants coming from the city of Portland (Figure 3.2). 
Table 3.4 Education, Student Status, and Length of Residence distribution of sample.

\begin{tabular}{|c|c|}
\hline Education distribution of study sample, $N=145$ & Percent (n) \\
\hline Did not complete high school & $1.4 \%(\mathrm{n}=2)$ \\
\hline High school graduate, diploma, or equivalent (for example: GED) & $4.8 \%(n=7)$ \\
\hline Some college credit, no degree & $21.9 \%(n=32)$ \\
\hline Associate's degree & $7.5 \%(\mathrm{n}=11)$ \\
\hline Bachelor's degree & $34.9 \%(\mathrm{n}=51)$ \\
\hline Master's or Doctoral degree & $29.5 \%(n=43)$ \\
\hline Student status distribution of study sample, $N=145$ & Percent (n) \\
\hline Yes, I attend a 2-year college or technical school. & $2.8 \%(n=4)$ \\
\hline Yes, I am an undergraduate at a 4-year college. & $2.8 \%(n=4)$ \\
\hline Yes, I am a graduate student & $4.1 \%(n=6)$ \\
\hline No, I am not currently a college student. & $90.3 \%(\mathrm{n}=131)$ \\
\hline $\begin{array}{l}\text { Length of residence in the Portland Metropolitan Area distribution } \\
\text { of study sample, } N=145\end{array}$ & Percent (n) \\
\hline Less than 1 year & $4.1 \%(n=6)$ \\
\hline $1-5$ years & $16.6 \%(\mathrm{n}=24)$ \\
\hline $6-10$ years & $17.9 \%(n=26)$ \\
\hline $11-20$ years & $14.5 \%(n=21)$ \\
\hline Over 20 years & $46.9 \%(n=68)$ \\
\hline
\end{tabular}




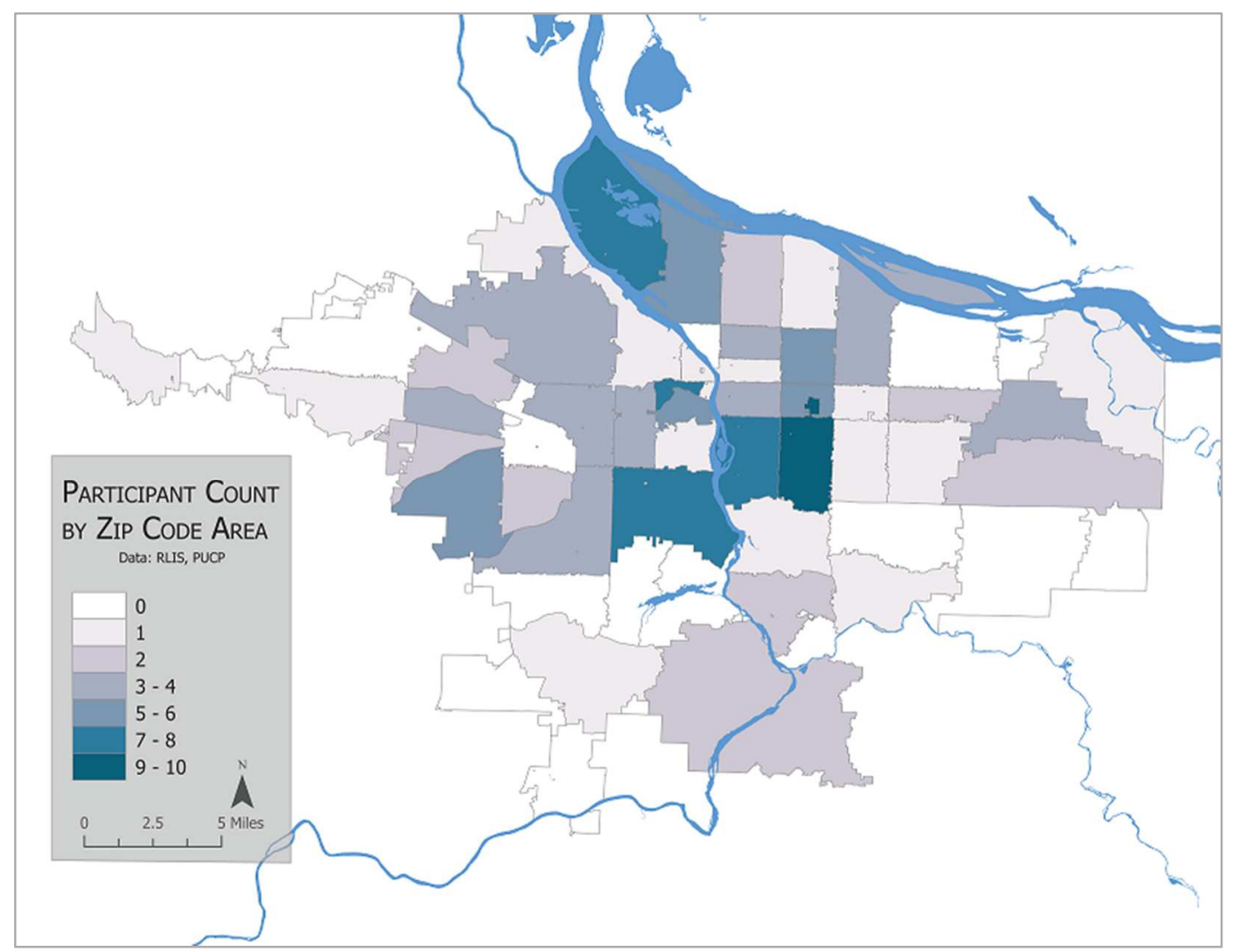

Figure 3.2 Choropleth map of participant zip codes in Portland Metropolitan Area.

As this was a convenience sample, the participants were not representative of Portland Metropolitan Area residents in general. Overall, the sample was more female, more educated, whiter, and wealthier than PMA residents in general. As such, generalization from the sample to the Portland Metropolitan Area cannot be made.

However, the sample provides a relevant snapshot of baseline attitudes and knowledge, as well as a measure of attitude and knowledge change, for people who volunteered to take part in the study (discussed further in Chapter 4). 


\section{Materials}

The study materials for the Tutorial Study were a click-through tutorial and two anonymous questionnaires (a preliminary questionnaire and a post-tutorial questionnaire). Participants completed all components of the study online in one unsupervised sitting, beginning with the preliminary questionnaire (10 minutes), moving to the click-through tutorial (20 minutes), and ending with the post-tutorial questionnaire (10 minutes). Participants were given the option to enter a gift card drawing after completing the posttutorial questionnaire. Of the 145 participants that completed the post-tutorial questionnaire, 131 opted to enter the gift card drawing.

\section{Tutorial}

The click-through tutorial was created and hosted on a website builder (Weebly). The tutorial was separated into four categories: (1) Coyote Life History; (2) Coyotes in Portland; (3) How to Identify Coyotes and Coyote Signs; and (4) Coexisting with Coyotes. Each section began with an introductory page outlining the general topics covered (Figure 3.3) and ended with a review of the key concepts from that section (Figure 3.4). For concepts that were more complex or controversial, such as coyotes killing cats, links to in-depth articles about the subject were provided at the bottom of the page. The tutorial covered topics that are the subject of frequent misinformation, such as coyote weight and diet (Gehrt 2007; Draheim 2007). Also, the tutorial included information about whether coyotes are dangerous to humans and pets and what people can do when they encounter a coyote. Content of the tutorial was developed to give 
participants general knowledge of coyotes and to address the knowledge and attitudes questions in the preliminary and post-tutorial questionnaires (discussed below in “Questionnaire Design”).

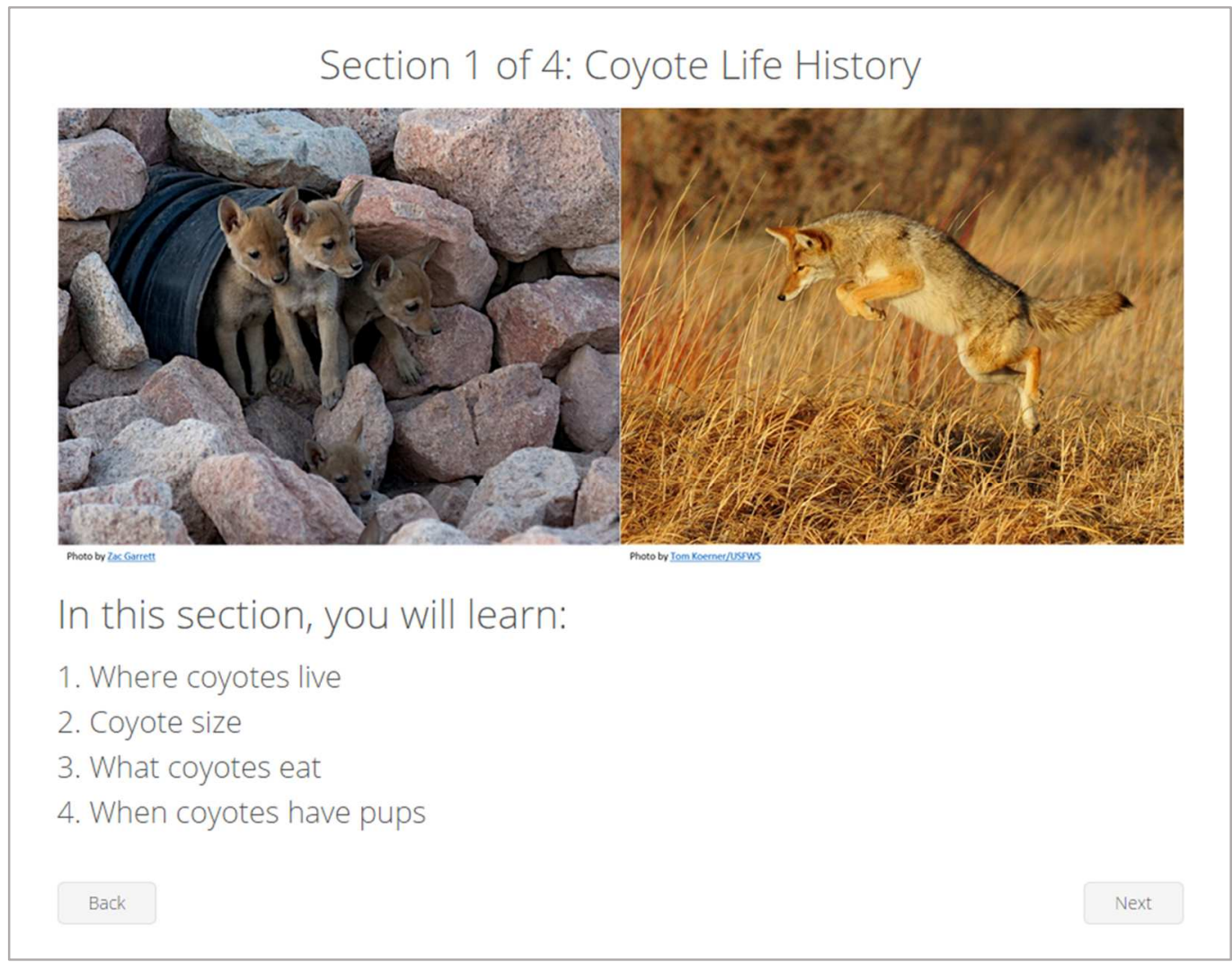

Figure 3.3 Example of introductory page in tutorial.

\section{Let's review! In this section, you learned:}

1. Coyotes originated from deserts and prairies in Mexico and central North America, but are now found from Mexico to Canada.

2. Western coyotes weigh about as much as a Whippet (around 15-40 pounds), but their dense fur can make them appear larger.

3. Coyotes primarily eat rodents, but will also eat birds, insects, fruits, and vegetables. They do kill cats, but studies show that cats make up a very small percentage of a coyote's diet.

4. Coyotes typically have young from March to May. Coyote pups stay with their parents throughout the summer months.

Figure 3.4 Example of section review page in tutorial. 
Each section of the tutorial had a combination of images, text, and self-quizzes.

Text was kept short to maintain participant attention. To encourage active participation, the tutorial included four self-quizzes where participants were asked to choose from a number of options until they selected the correct answer (Figure 3.5; Figure 3.6).

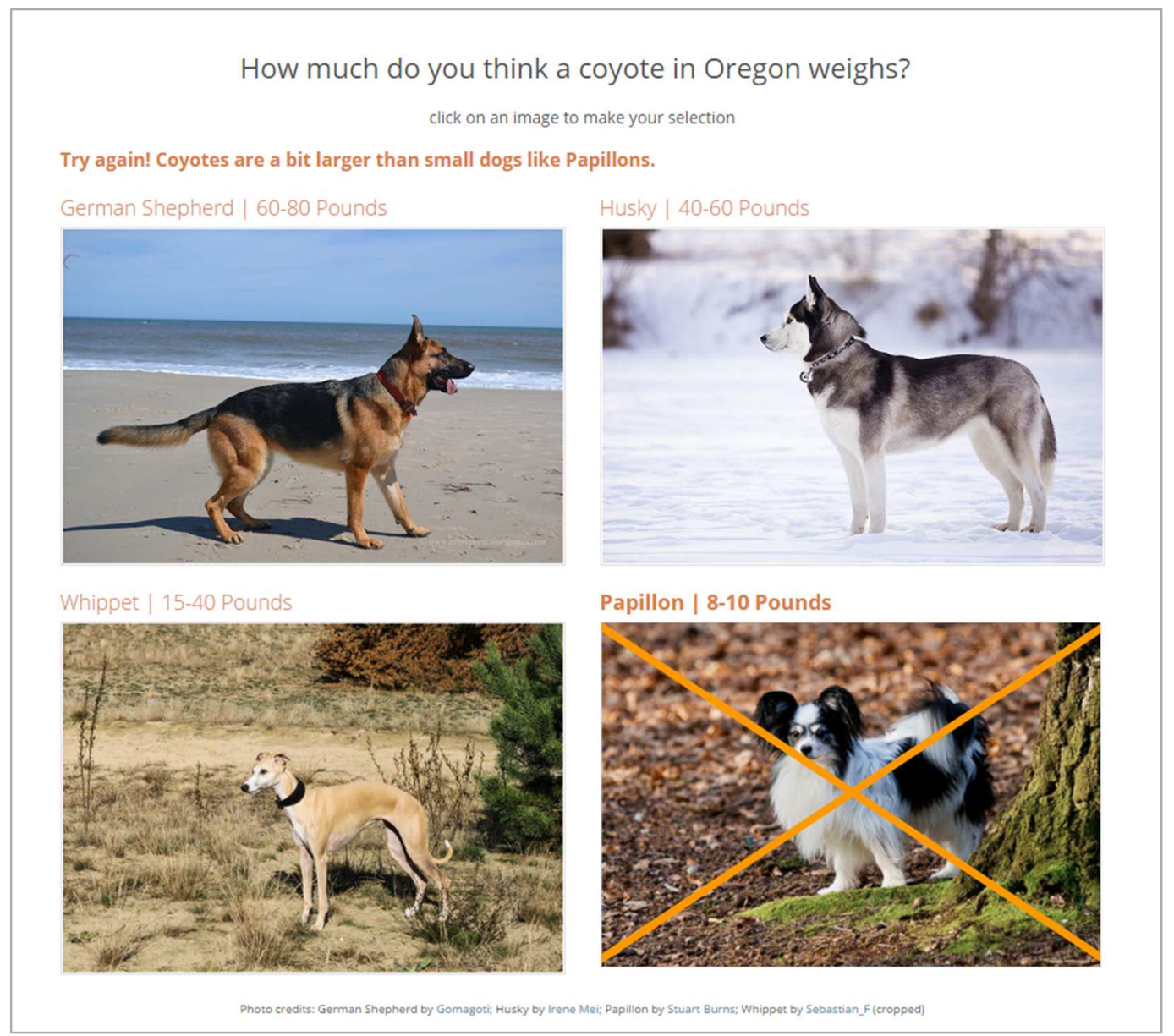

Figure 3.5 Example of interactive self-quizzes in tutorial, incorrect answer. 
How much do you think a coyote in Oregon weighs?

That's right! Thick dense fur can make coyotes appear larger than they really are. Coyotes found in Oregon (western coyotes) typically weigh between 22 and 30 pounds.

German Shepherd | 60-80 Pounds

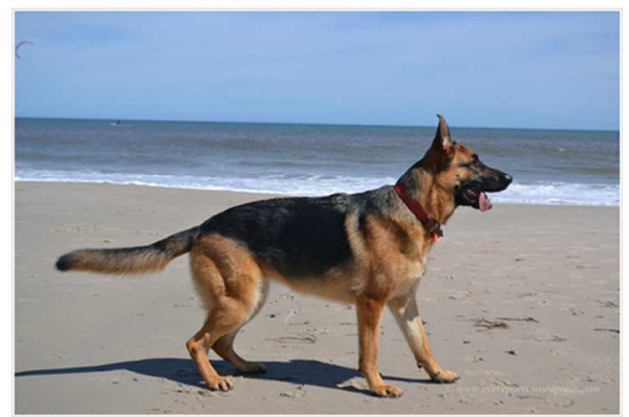

Whippet | 15-40 Pounds

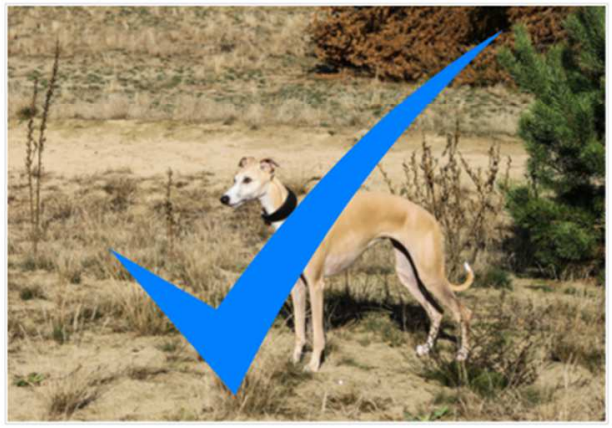

Husky | 40-60 Pounds

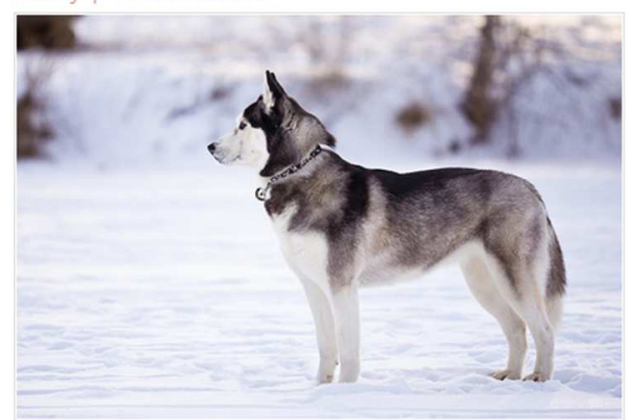

Papillon | 8-10 Pounds

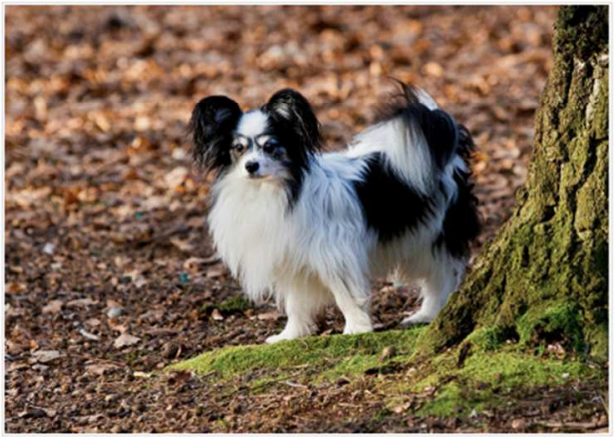

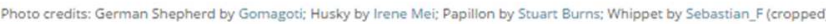

Figure 3.6 Example of interactive self-quizzes in tutorial, correct answer.

Additionally, there was an interactive sightings map in the "Coyotes in Portland" section. The interactive map displayed coyote sightings reported to the PUCP. Participants were asked to pan around the map and find their neighborhood to see if coyotes had been observed nearby. There were two videos: one user-submitted video of a coyote walking down a Portland street; and one video demonstrating how to make a hazing rattle out of a coffee can and coins. The tutorial ended with a review of each section and a link to move on to the post-tutorial questionnaire (see Appendix B for the full tutorial). 


\section{Questionnaire Design}

The preliminary questionnaire had twenty-one questions split into three sections of seven questions each. The three sections were: general knowledge about coyotes; attitudes about coyotes; and experience with urban coyotes and citizen science. The preliminary questionnaire served two main functions: (A) a standalone survey of experience, attitudes, and knowledge; and (B) the preliminary data in the pre/post portion of the study (to compare with post-tutorial results to see if knowledge and/or attitudes changed during the tutorial).

The first section, the general knowledge section, consisted of multiple choice and true or false questions that measured participants' basic knowledge of coyotes. This section had two questions that asked participants about the basic characteristics of coyotes (weight and diet). For example, participants were asked, "How much does a coyote weigh?" with six weight ranges from which to choose.

Next, participants were asked five true or false questions that measured whether participants believed common misconceptions about coyotes. The misconceptions measured were: that cats are a main food source for coyotes; that coyotes live alone; that coyotes are responsible for human deaths every year; and that coyote removal efforts have been effective. For example, participants were asked to answer questions like, "True or False: Studies show that cats are a main food source for coyotes." The purpose of the first section was to understand participants' baseline knowledge of urban coyotes.

The second section, the attitudes section, was made up of Likert scale questions aimed at understanding how participants felt about coyotes. Likert scales were chosen 
because they have been found to be less likely to cause statistical error than a yes/no or checklist survey. Also, Likert scales may allow for a finer measure of variability between participants (Jacobs et al. 2012). Item specific scales, scales that use a tailored scale for a particular question instead of using the generic agree/disagree scale, were preferred because they have been shown to produce higher quality responses (Saris et al. 2010). For example, to understand a participant's concern about coyotes near their home, the questionnaire asked, "How concerned are you about coyotes near your home?" with the response options: not at all concerned, slightly concerned, moderately concerned, and very concerned. This is in contrast to a common agree/disagree structure, e.g., "I am concerned about coyotes near my home," with the response options: strongly agree, agree, neutral, disagree, and strongly disagree.

The attitudinal questions were developed based, in part, on Draheim and colleagues' questionnaire items from multiple attitudinal studies (Draheim 2011; Draheim 2013). Draheim and colleagues developed their questions to understand attitudes about coyotes in Northern Virginia, building upon previous urban coyote attitudinal research by urban coyote researcher Jennifer Jackman (Draheim et al. 2013).

Of seven attitudinal questions, three measured participants' general feelings toward coyotes. Participants were asked: how much they like or dislike coyotes; how much they support or do not support coyotes' presence in the PMA; and how they feel about lethally removing coyotes. These questions are standard in many urban coyote studies because they identify participants' general sentiments toward coyotes. For example, measuring support of lethal control is often widely used to understand 
participant fear of coyotes. This question is used because support for lethal control has been associated with higher fear of coyotes (Vaske and Needham 2007; Jackman and Rutberg 2015; Sponarski, Vaske, and Bath 2015a; Sponarski, Vaske, and Bath 2015b).

The other four attitudinal questions measured participants' concerns about a variety of circumstances involving coyotes. Participants were asked how concerned they were about: coyotes near their home; having a face-to-face encounter with a coyote; coyotes attacking children; and coyotes attacking small pets. These questions helped measure participants' perceived impact and fear levels related to coyotes. The overall purpose of the second section of the preliminary questionnaire was to understand participants' baseline attitudes about coyotes.

The third and final section of the preliminary questionnaire asked seven questions about participants' experience with urban coyotes and citizen science. This section had two multiple choice questions, three yes or no questions, and three open-ended questions. Participants were asked questions like, "How many times have you seen a coyote in Portland in the past year?" and "Have you participated in citizen science projects besides the Portland Urban Coyote Project?" To understand how many participants had seen coyotes in Portland, and urban coyotes in general, participants were asked how many coyotes they had seen in Portland in the past year, and how many urban or suburban coyotes they had seen in their lifetime. Participants were allowed to enter any number when reporting coyote sightings because the number of coyote sightings by PMA residents was previously unknown. After the responses were recorded, they were 
organized into six categories based on number of sightings: $0,1-5,6-10,11-20,21-50$, and over 50 .

The purpose of the familiarity and experience section of the questionnaire was to develop a baseline of participants' experience with coyotes and citizen science. It was important to measure how often participants encounter coyotes, so that the relationship between attitudes, knowledge, and experience could be explored. This section also measured participants' use of the PUCP and other citizen science projects to see if the sample had a disproportionate number of citizen scientist participants.

The post-tutorial questionnaire had twenty-five questions split into three sections: attitudes (7 questions), knowledge (7 questions), and demographics (11 questions). In the post-tutorial questionnaire, the knowledge and attitudes sections were repeated from the preliminary survey, but the order of the sections was reversed. Participants were asked the same questions to measure whether or not the tutorial improved their knowledge or changed their attitudes. Identical wording for the questions was used because even slight changes in question wording can cause major differences in responses (Foddy 1993; Bradburn, Sudman, and Wansink 2004).

When repeated in the post-tutorial questionnaire, the attitudinal questions were evaluated for their change to more positive or (where appropriate) more research-based responses. Research-based attitudes, in this case, means that participants have attitudes that are in line with current findings about coyotes. This is not to imply that the participant has that attitude because of their familiarity with research, but instead, when analyzed, the attitude reflects current findings. For example, when participants were 
asked, "How concerned are you about having a face-to-face encounter with a coyote?", their preliminary and post-tutorial responses were compared to see if their response changed to reflect a more research-based answer (in this case, a reduced concern score because coyote attacks are relatively uncommon; Poessel et al. 2013).

The final section of the post-tutorial survey was a demographics section that asked multiple choice and fill-in questions about basic demographic details such as ethnicity, age, gender, and income. The primary purpose of this section was to compare the demographics of the sample to the general population (described above in "Sample Demographics").

\section{Analysis}

Analyses were conducted using the statistical analysis software SPSS. Univariate descriptive statistics were used to describe participants' experiences and familiarity, baseline attitudes, baseline knowledge, and demographics. To understand if and how attitudes changed after the tutorial, one-tailed paired sample $t$ tests were used for each question $^{3}$. To understand whether or not learning took place during the tutorial two knowledge scores calculated for each participant, one from the preliminary questionnaire and one from the post-tutorial questionnaire. Scores were calculated by awarding one point for correct answers and zero points for incorrect answers. Participants could

\footnotetext{
${ }^{3}$ The original analyses were planned and conducted as one-tailed tests. Now, with a better understanding of best practices, I would take the more conservative approach of conducting two-tailed tests in future studies. Nonetheless, all of the results listed below remain significant at $\mathrm{p}<.05$ for two-tailed tests.
} 
achieve a total knowledge score from zero to seven. Knowledge scores were compared using a one-tailed paired sample $t$ test. 


\section{CHAPTER 4: FINDINGS}

In this chapter, I present and discuss the results of the Tutorial Study. The Tutorial Study measured: (1) experiences with, attitudes toward, and knowledge of coyotes in the Portland Metropolitan Area (PMA); and (2) the efficacy of an online educational tutorial.

First, I describe what the study revealed about participant's familiarity and experience with coyotes and citizen science. Next, I describe baseline knowledge and attitudes. Finally, I present changes in knowledge and attitudes after the tutorial.

\section{Baseline Familiarity and Experience}

Most participants did not have experience with the PUCP or other citizen science projects before participating in this study. For all three questions related to the PUCP, only about one-third of participants reported that they were familiar with, or had participated in, the PUCP Table 4.1; Table 4.2).

Table 4.1 Responses to questionnaire items about the Portland Urban Coyote Project $\mathrm{N}=176$.

\begin{tabular}{|l|l|l|}
\hline Question & Yes & No \\
\hline $\begin{array}{l}\text { Have you visited the Portland Urban Coyote Project } \\
\text { Facebook, Twitter, or website? }\end{array}$ & $25 \%(\mathrm{n}=44)$ & $75 \%(\mathrm{n}=132)$ \\
\hline $\begin{array}{l}\text { Are you familiar with the Portland Urban Coyote Project } \\
\text { sightings map? }\end{array}$ & $36.9 \%(\mathrm{n}=65)$ & $63.1 \%(\mathrm{n}=111)$ \\
\hline
\end{tabular}

Table 4.2 Responses to questionnaire item: "Have you reported a sighting to the Portland Urban Coyote Project?" N = 173.

\begin{tabular}{|l|l|l|l|l|l|}
\hline Response & No & $\begin{array}{l}\text { Yes, I have } \\
\text { reported 1 } \\
\text { sighting. }\end{array}$ & $\begin{array}{l}\text { Yes, I have } \\
\text { reported 2-5 } \\
\text { sightings. }\end{array}$ & $\begin{array}{l}\text { Yes, I have } \\
\text { reported 6-10 } \\
\text { sightings. }\end{array}$ & $\begin{array}{l}\text { Yes, I have } \\
\text { reported over } \\
\text { 10 sightings. }\end{array}$ \\
\hline $\begin{array}{l}\text { Percent } \\
(\mathbf{n})\end{array}$ & $\begin{array}{l}74.6 \% \\
(\mathrm{n}=129)\end{array}$ & $\begin{array}{l}19.1 \% \\
(\mathrm{n}=33)\end{array}$ & $\begin{array}{l}5.2 \% \\
(\mathrm{n}=9)\end{array}$ & $\begin{array}{l}0 \% \\
(\mathrm{n}=0)\end{array}$ & $\begin{array}{l}1.2 \% \\
(\mathrm{n}=2)\end{array}$ \\
\hline
\end{tabular}


Participants reported even less participation (16\%) in other citizen science projects (besides the PUCP; Table 4.3). Those who did report participation in other citizen science projects listed projects such as: bird counts $(n=12)$; amphibian surveys $(n=4)$; other nature-related projects $(\mathrm{n}=11)$; and community projects $(\mathrm{n}=3)$. Participants $(\mathrm{n}=10)$ that did participate in other citizen science projects tended to list more than one project.

Table 4.3 Responses to questionnaire item: "Have you participated in citizen science besides the Portland Urban Coyote Project?" N = 175.

\begin{tabular}{|l|l|l|}
\hline Response & Yes & No \\
\hline Percent $(\mathbf{n})$ & $16 \%(\mathrm{n}=28)$ & $84 \%(\mathrm{n}=147)$ \\
\hline
\end{tabular}

About three-quarters of participants reported at least one coyote sighting in Portland in the past year (Table 4.4). Most participants (91.8\%) reported seeing at least one coyote in an urban or suburban area in their lifetime (Table 4.4).

Table 4.4 Responses to questionnaire items about coyote sightings.

\begin{tabular}{|l|l|l|l|l|l|l|}
\hline Question & $\mathbf{0}$ times & $\mathbf{1 - 5}$ times & $\begin{array}{l}\mathbf{6 - 1 0} \\
\text { times }\end{array}$ & $\begin{array}{l}\mathbf{1 1 - 2 0} \\
\text { times }\end{array}$ & $\begin{array}{l}\mathbf{2 1 - 5 0} \\
\text { times }\end{array}$ & $\begin{array}{l}\text { Over 50 } \\
\text { times }\end{array}$ \\
\hline $\begin{array}{l}\text { How many times have you } \\
\text { seen a coyote in the past } \\
\text { year in Portland?" } \\
\mathbf{N}=\mathbf{1 7 5}\end{array}$ & $\begin{array}{l}26.3 \% \\
(\mathrm{n}=46)\end{array}$ & $\begin{array}{l}59.4 \% \\
(\mathrm{n}=104)\end{array}$ & $\begin{array}{l}8 \% \\
(\mathrm{n}=14)\end{array}$ & $\begin{array}{l}3.4 \% \\
(\mathrm{n}=6)\end{array}$ & $\begin{array}{l}1.7 \% \\
(\mathrm{n}=3)\end{array}$ & $\begin{array}{l}1.1 \% \\
(\mathrm{n}=2)\end{array}$ \\
\hline $\begin{array}{l}\text { How many times have you } \\
\text { seen a coyote in an urban } \\
\text { or suburban area in your } \\
\text { lifetime? N = 171 }\end{array}$ & $\begin{array}{l}8.2 \% \\
(\mathrm{n}=14)\end{array}$ & $\begin{array}{l}42.7 \% \\
(\mathrm{n}=73)\end{array}$ & $\begin{array}{l}15.2 \% \\
(\mathrm{n}=26)\end{array}$ & $\begin{array}{l}11.1 \% \\
(\mathrm{n}=19)\end{array}$ & $\begin{array}{l}12.9 \% \\
(\mathrm{n}=22)\end{array}$ & $\begin{array}{l}9.9 \% \\
(\mathrm{n}=17)\end{array}$ \\
\hline
\end{tabular}

\section{Baseline Knowledge}

I expected baseline knowledge scores of participants to be moderate (with about half of participants answering correctly on most questions) based on previous findings 
(Kellert 1988; Draheim 2007). But overall, participants had high knowledge scores. In all seven knowledge questions, well over half of participants selected the correct answer. When asked how much an average coyote weighs, $63.4 \%$ of participants selected the correct answer (15-40 pounds), while $26.9 \%$ overestimated coyote weight at $40-60$ pounds (Figure 4.1).

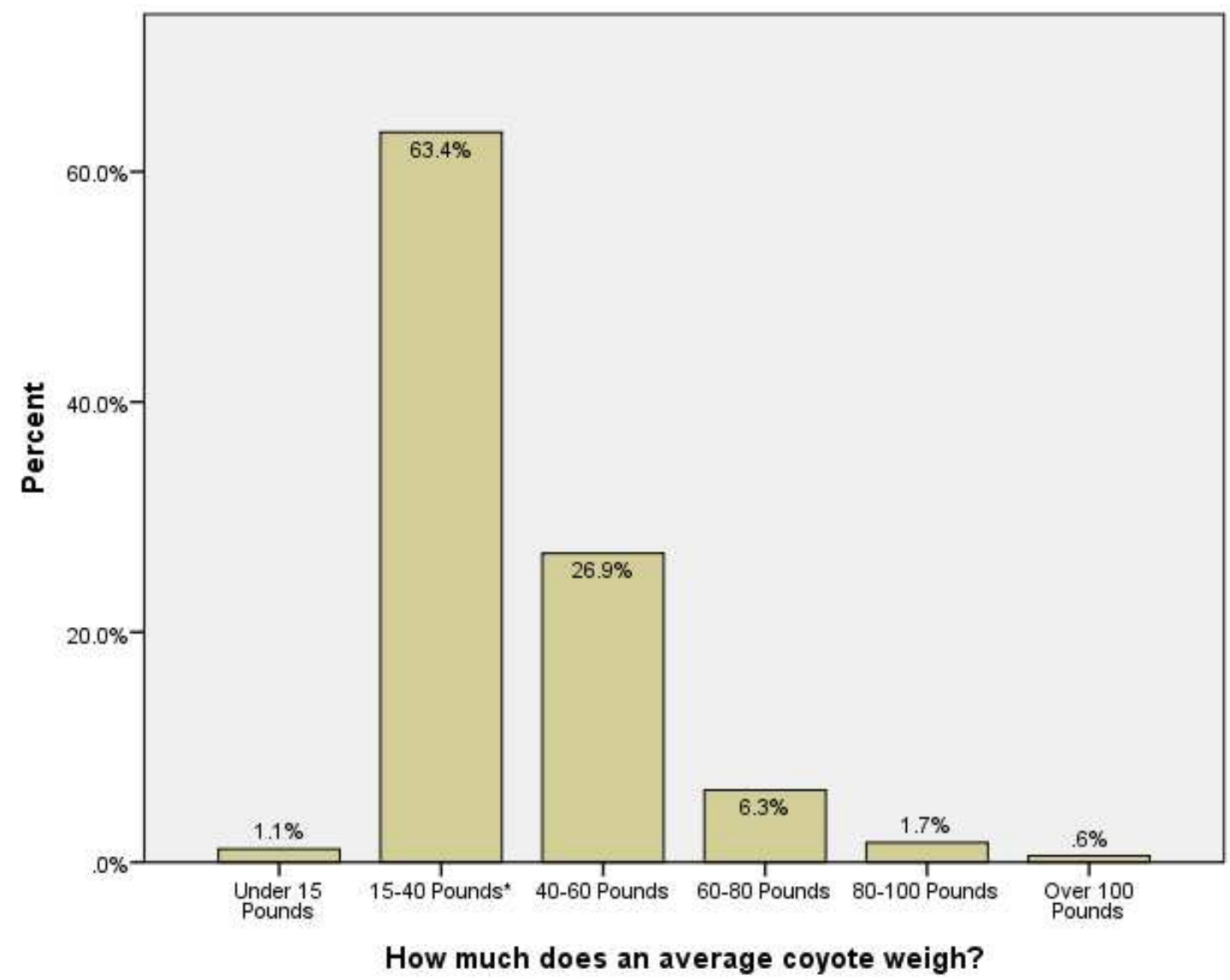

Figure 4.1 Responses to questionnaire item: "How much does an average coyote weigh?" $\mathrm{N}=175$ (*correct answer).

When asked what coyotes most commonly eat, $80 \%$ of participants selected the correct answer (Rodents). The next most common category selected was Garbage, at 13.1\% (Figure 4.2). 


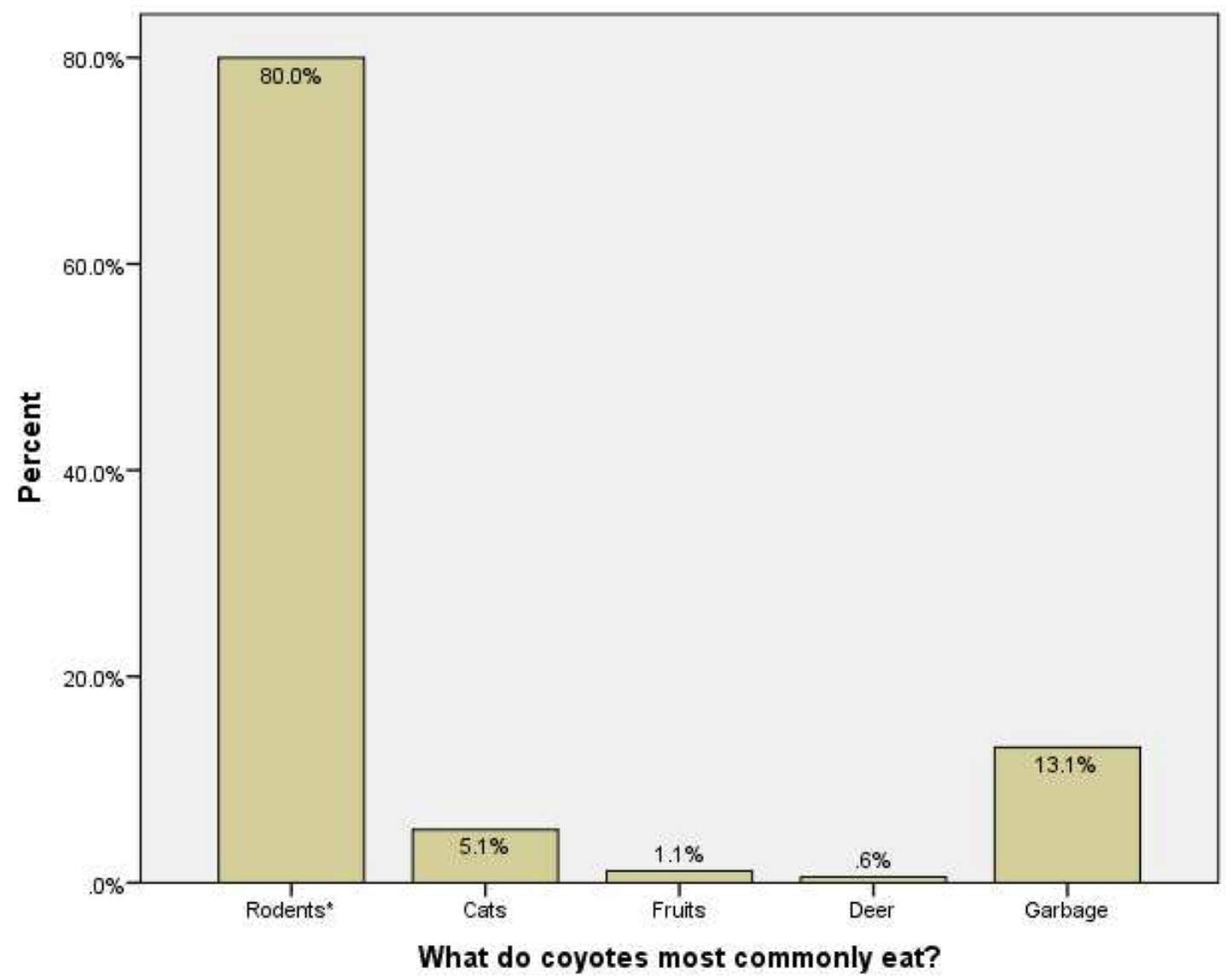

Figure 4.2 Responses to questionnaire item: "What do coyotes most commonly eat?" N $=175$ (*orrect answer).

In all five true or false questions, most participants selected the correct answer (Table 4.5). The most common correctly answered true or false question was "True or False: Coyote are responsible for human deaths every year.” with $94.9 \%$ of participants answering correctly (False). The least common correctly answered true or false question was "True or False: Coyotes often live in family groups, but hunt alone." with (still a strong majority) of $71.8 \%$ answering correctly (True). 
Table 4.5 Responses to true or false questions (correct answers italicized).

\begin{tabular}{|l|l|l|}
\hline True or False Statement & True & False \\
\hline $\begin{array}{l}\text { Coyotes are responsible for human deaths every year. } \\
\mathrm{N}=174\end{array}$ & $\begin{array}{l}5.1 \% \\
(\mathrm{n}=9)\end{array}$ & $\begin{array}{l}94.9 \% \\
(n=166)\end{array}$ \\
\hline $\begin{array}{l}\text { Studies show that cats are a main food source for } \\
\text { coyotes. } \\
\mathrm{N}=174\end{array}$ & $\begin{array}{l}19.5 \% \\
(\mathrm{n}=34)\end{array}$ & $\begin{array}{l}80.5 \% \\
(n=140)\end{array}$ \\
\hline $\begin{array}{l}\text { Coyote removal efforts in the United States have largely } \\
\text { been effective. } \\
\mathrm{N}=174\end{array}$ & $\begin{array}{l}19.5 \% \\
(\mathrm{n}=34)\end{array}$ & $\begin{array}{l}80.5 \% \\
(n=140)\end{array}$ \\
\hline $\begin{array}{l}\text { Removing individual coyotes helps to reduce the overall } \\
\text { coyote population of an area. } \\
\mathrm{N}=173\end{array}$ & $\begin{array}{l}21.4 \% \\
(\mathrm{n}=37)\end{array}$ & $\begin{array}{l}78.6 \% \\
(n=136)\end{array}$ \\
\hline $\begin{array}{l}\text { Coyotes often live in family groups, but hunt alone. } \\
\mathrm{N}=174\end{array}$ & $\begin{array}{l}71.8 \% \\
(n=125)\end{array}$ & $\begin{array}{l}28.2 \% \\
(\mathrm{n}=49)\end{array}$ \\
\hline
\end{tabular}

The mean total knowledge score was 5.463 points (out of 7 possible points). Both median and mode scores were 6 points (Table 4.6). Overall, knowledge scores for participants in this study were higher than previous findings. A possible explanation for these results is that participation in the study was volunteer-based. Participants who volunteered for the study might be more interested in coyotes, and so may have more knowledge about coyotes than the general population. Furthermore, the majority of participants had at least some college education. The generally high education level of the sample could help explain why participants already knew basic facts about coyotes.

Table 4.6 Total knowledge score (1 point awarded for each correctly answered knowledge question) $\mathrm{N}=175$.

\begin{tabular}{|l|l|l|l|l|l|l|l|}
\hline Score & $\mathbf{1}$ & $\mathbf{2}$ & $\mathbf{3}$ & $\mathbf{4}$ & $\mathbf{5}$ & $\mathbf{6}$ & $\mathbf{7}$ \\
\hline $\begin{array}{l}\text { Percent } \\
(\mathbf{n})\end{array}$ & $\begin{array}{l}0 \% \\
(\mathrm{n}=0)\end{array}$ & $\begin{array}{l}1.7 \% \\
(\mathrm{n}=3)\end{array}$ & $\begin{array}{l}6.3 \% \\
(\mathrm{n}=11)\end{array}$ & $\begin{array}{l}13.1 \% \\
(\mathrm{n}=23)\end{array}$ & $\begin{array}{l}24 \% \\
(\mathrm{n}=42)\end{array}$ & $\begin{array}{l}31.5 \% \\
(\mathrm{n}=55)\end{array}$ & $\begin{array}{l}23.4 \% \\
(\mathrm{n}=41)\end{array}$ \\
\hline
\end{tabular}


Another possible contributor to such high baseline knowledge scores could be explained by the culture of the PMA. There is a popular impression that Portland is a particularly environmentally-oriented city, coming in at or near the top of many "greenest city" lists (Sustainlane 2008; Svoboda 2008; Ross 2014). High rates of concern for the environment and wildlife could translate into increased knowledge about wildlife; however, the relationship between interest in nature and knowledge about wildlife requires further exploration. High knowledge scores in this study are likely influenced by increased interest in coyotes by self-selected participants, a highly educated sample, increased environmental literacy of Portland residents in general, or a combination of these factors.

\section{Baseline Attitudes}

I expected to find that baseline attitudes about coyotes would be neutral to positive. In general, participants had positive attitudes about coyotes $(\mathrm{N}=175)$. Participants were asked to rate how much they like coyotes on a scale from 1 (Dislike very much) to 5 (Like very much). Responses were generally positive, with a mean response of 3.777 (between Neutral and Like somewhat). The median response was 4 (Like somewhat), while the mode response was 5 (Like very much; Figure 4.3). 


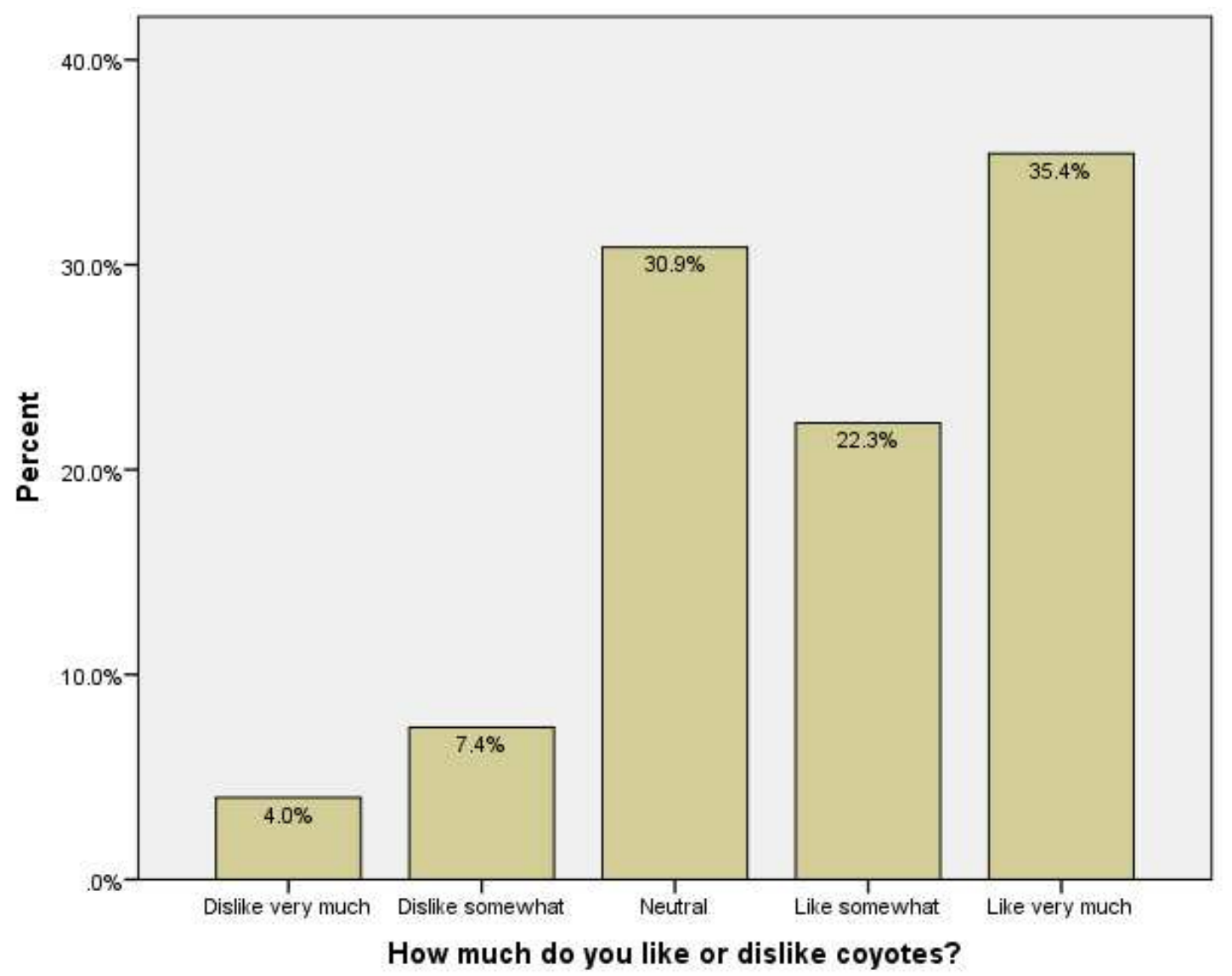

Figure 4.3 Responses to questionnaire item: "How much do you like or dislike coyotes?" $\mathrm{N}=175$.

Overall, there was moderate support for coyotes in the PMA. Participants were asked to rate how much they support coyotes living in the PMA on a scale from 1 (Very much) to 4 (Coyotes should be removed from the Portland Metropolitan Area). The mean response was 1.891 (between Very much and Somewhat). The median response was 2 (Somewhat), while the mode response was 1 (Very much; Figure 4.4). 


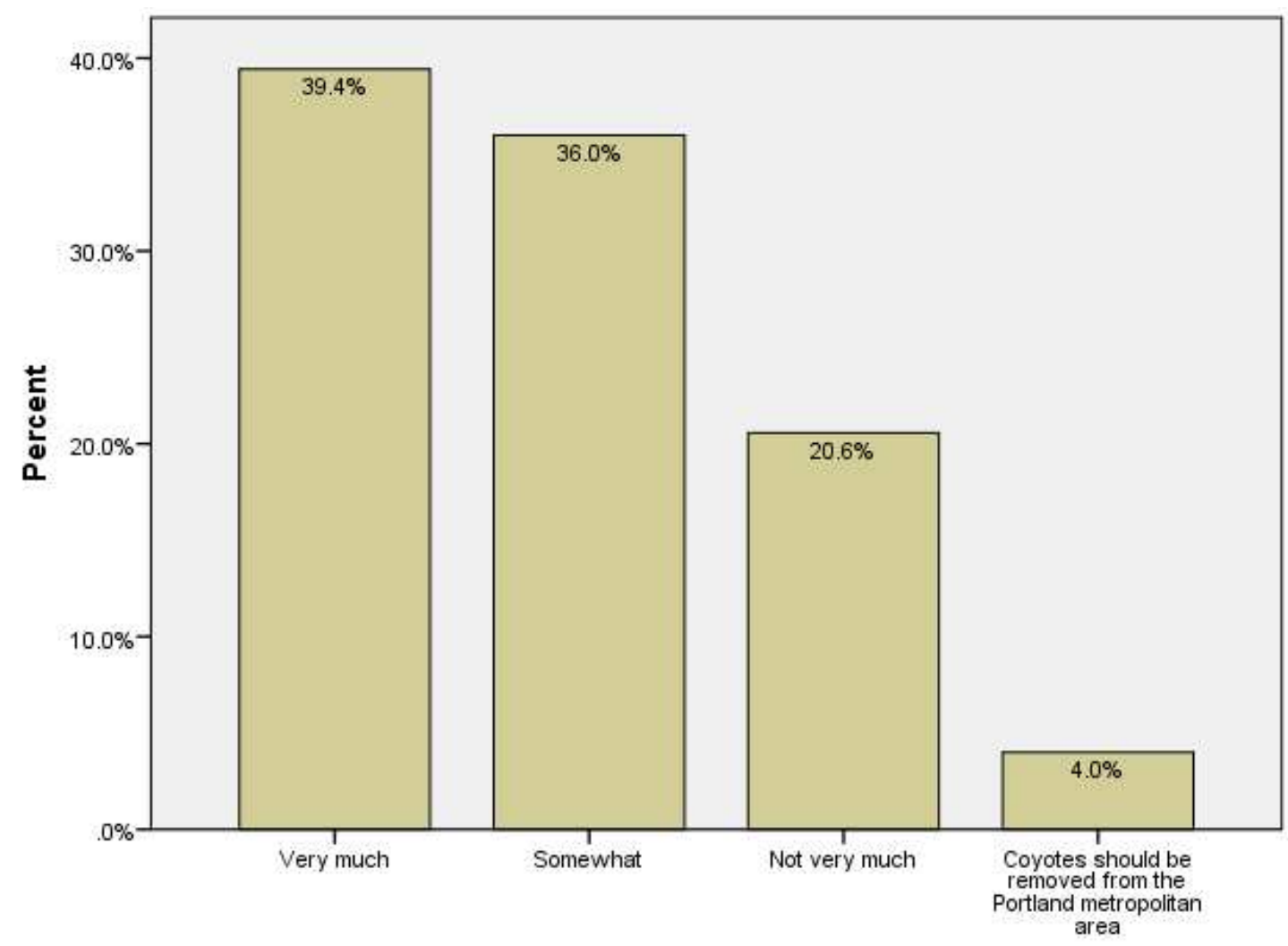

How much do you support coyotes living in the Portland metropolitan area?

Figure 4.4 Responses to questionnaire item: "How much do you support coyotes living in the Portland Metropolitan Area?" N = 175.

There was overwhelming disapproval of lethal removal for coyotes found in urban areas. Participants were asked to rate how they felt about lethal removal of urban coyotes on a scale from 1 (Strongly against) to 5 (Strongly in favor of). The mean response was 1.6 (between Strongly against and Somewhat against). Both the median and mode responses were 1 (Strongly against; Figure 4.5). 


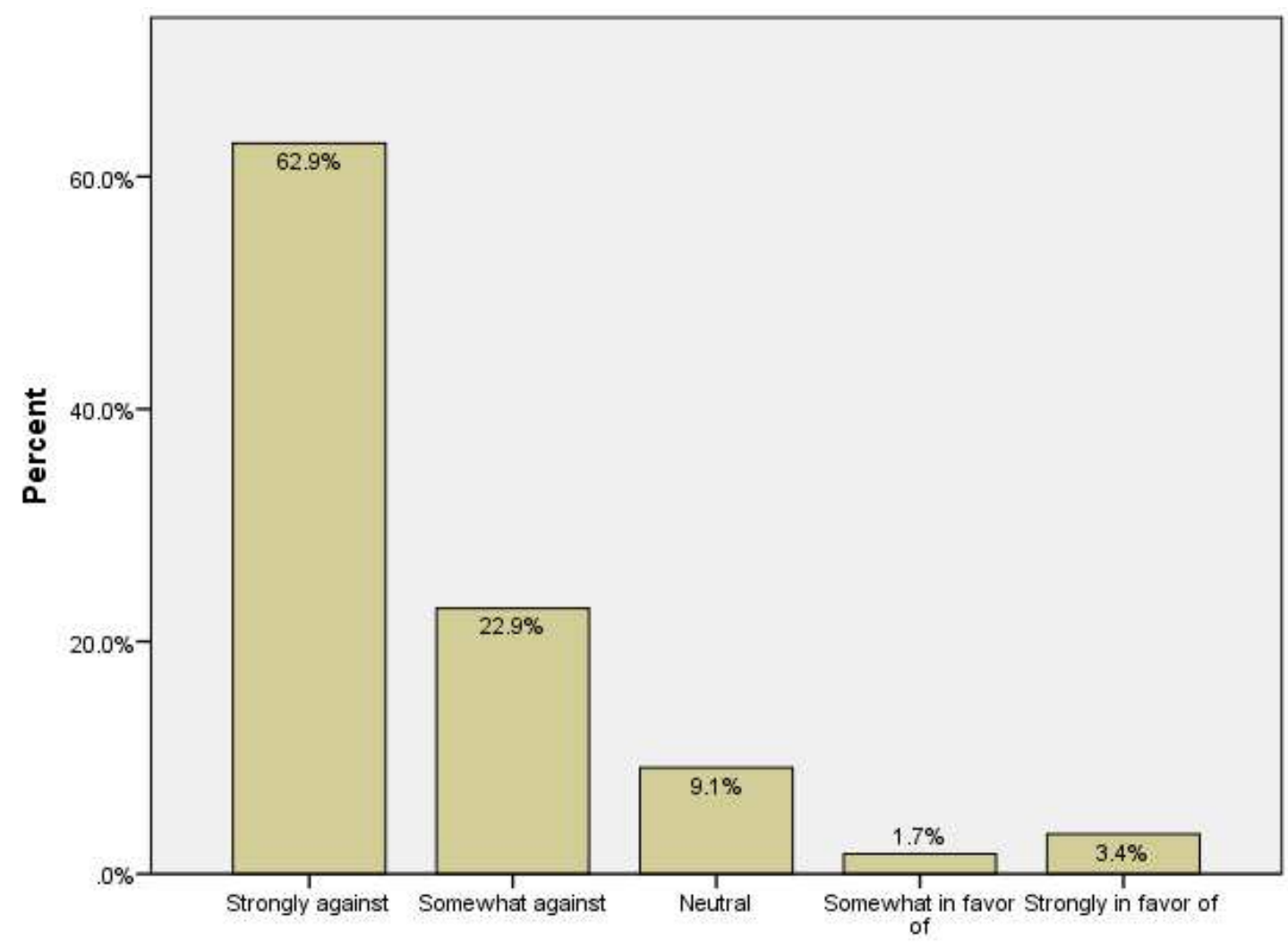

How do you feel about lethally removing (killing) coyotes found in urban areas?

Figure 4.5 Responses to questionnaire item: "How do you feel about lethally removing (killing) coyotes found in urban areas?" $\mathrm{N}=175$.

In other studies, researchers found that low support for lethal control is related to low perceived personal impact (Decker, Jacobsen, and Brown 2006). As we see below, participants reported relatively low levels of concern about coyotes near their homes, near children, and near themselves. This could help explain why participants were overwhelmingly against lethal control. Also, low support for lethal control has been associated with lower fear levels (Jackman and Rutberg 2015; Sponarski, Vaske, and Bath 2015b). Low levels of concern about coyotes in conjunction with low support for lethal control may indicate low overall fear levels of participants. 
There were four questions that measured how concerned participants would be in a variety of scenarios involving coyotes (Table 4.7). These questions were rated on a scale from 1 (Not at all concerned) to 4 (Very concerned). For three of the four questions in this set, participants' mean response was between 1 (Not at all concerned) and 2 (Slightly concerned). Median and mode responses for these questions were all 1 (Not at all concerned). For the question, "How concerned are you about coyotes attacking small pets?”, mean response was higher at 2.246 (between Slightly concerned and Moderately concerned). Both the median and mode scores for this question were 2 (Slightly concerned).

Table 4.7 Responses to questionnaire items about concern. $\mathrm{N}=175$.

\begin{tabular}{|l|l|l|l|l|l|}
\hline & $\begin{array}{l}\mathbf{( 1 )} \text { Not at all } \\
\text { concerned }\end{array}$ & $\begin{array}{l}\text { (2) Slightly } \\
\text { concerned }\end{array}$ & $\begin{array}{l}\mathbf{( 3 )} \\
\text { Moderately } \\
\text { concerned }\end{array}$ & $\begin{array}{l}\text { (4) Very } \\
\text { concerned }\end{array}$ & $\begin{array}{l}\text { mean, } \\
\text { median, } \\
\text { mode }\end{array}$ \\
\hline $\begin{array}{l}\text { How concerned are } \\
\text { you about coyotes } \\
\text { near your home? }\end{array}$ & $\begin{array}{l}52 \% \\
(\mathrm{n}=91)\end{array}$ & $\begin{array}{l}28 \% \\
(\mathrm{n}=49)\end{array}$ & $\begin{array}{l}12.6 \% \\
(\mathrm{n}=22)\end{array}$ & $\begin{array}{l}7.4 \% \\
(\mathrm{n}=13)\end{array}$ & $\begin{array}{l}1.754, \\
1,\end{array}$ \\
\hline $\begin{array}{l}\text { How concerned are } \\
\text { you about having a } \\
\text { face-to-face encounter } \\
\text { with a coyote? }\end{array}$ & $\begin{array}{l}73.7 \% \\
(\mathrm{n}=129)\end{array}$ & $\begin{array}{l}20 \% \\
(\mathrm{n}=35)\end{array}$ & $\begin{array}{l}5.1 \% \\
(\mathrm{n}=9)\end{array}$ & $\begin{array}{l}1.1 \% \\
(\mathrm{n}=2)\end{array}$ & $\begin{array}{l}1.337, \\
1,\end{array}$ \\
\hline $\begin{array}{l}\text { How concerned are } \\
\text { you about coyotes } \\
\text { attacking children? }\end{array}$ & $\begin{array}{l}66.9 \% \\
(\mathrm{n}=117)\end{array}$ & $\begin{array}{l}21.7 \% \\
(\mathrm{n}=38)\end{array}$ & $\begin{array}{l}6.3 \% \\
(\mathrm{n}=11)\end{array}$ & $\begin{array}{l}5.1 \% \\
(\mathrm{n}=9)\end{array}$ & $\begin{array}{l}1.49 \\
1,\end{array}$ \\
\hline $\begin{array}{l}\text { How concerned are } \\
\text { you about coyotes } \\
\text { attacking small pets? }\end{array}$ & $\begin{array}{l}26.3 \% \\
(\mathrm{n}=46)\end{array}$ & $\begin{array}{l}40 \% \\
(\mathrm{n}=70)\end{array}$ & $\begin{array}{l}16.6 \% \\
(\mathrm{n}=29)\end{array}$ & $\begin{array}{l}17.1 \% \\
(\mathrm{n}=30)\end{array}$ & $\begin{array}{l}2.246, \\
2\end{array}$ \\
\hline
\end{tabular}

Increased concern for pets suggests that PMA residents tend to have research-based concerns. Pet attacks that result in animal death do occur in urban areas; although these events are rare, they may be more likely to result in harm than the other concerns 
participants were polled about (Poessel et al. 2013). Increased concern in this case may indicate that participants understand that the likelihood of pet attacks is higher than other concerns.

An alternative (or concurrent) explanation is that $69 \%$ of participants reported owning a small dog or cat. In this case, increased concern about pets could be related to participant fear for their pet's safety (a perceived risk of negative personal impacts). In the post-tutorial survey, participants were asked if they owned cats or small dogs. An independent samples $t$ test revealed that pet-owning participants had higher concern scores $(m=2.240, s=.8423)$ than participants that did not report owning pets $(m=1.733$, $s=.7198), t(143)=3.499, \mathrm{p} \leq .01($ Table 4.8$)$.

Table 4.8 Independent $t$ test results comparing mean pet owner and non pet owners for the question, "How concerned are you about coyotes attacking small pets?" $\mathrm{N}=145, \mathrm{p} \leq .01$

\begin{tabular}{|l|l|l|}
\hline Question & Pet Owners & $\begin{array}{l}\text { Non Pet } \\
\text { Owners }\end{array}$ \\
\hline $\begin{array}{l}\text { How concerned are you about coyotes attacking small pets? } \\
\text { (1: Not at all concerned, 2: Slightly concerned, 3: Moderately } \\
\text { concerned, 4: Very concerned) }\end{array}$ & 2.240 & 1.733 \\
\hline
\end{tabular}

\section{Changes in Knowledge after Tutorial}

The pre/post knowledge portion of the survey sought to measure whether participants had increased knowledge scores after taking the tutorial.

Null Hypothesis: Participants will not have significantly higher knowledge scores after taking the tutorial

Hypothesis 1: Participants will have higher knowledge scores after taking the tutorial 
A one-tailed paired sample $t$ test revealed that participants had higher knowledge scores after taking the tutorial $(m=6.789, s=.5436)$ than before the tutorial $(m=5.50, s=$ 1.2590), $t(141)=-12.207, \mathrm{p} \leq .01 ; d=-1.0243$ (Table 4.9). According to Cohen's rule of thumb, there was a large effect on knowledge scores (Cohen 1988).

Table 4.9 Paired $t$ test results for total knowledge score before and after tutorial; possible score from $0-7$ points. $\mathrm{N}=142, \mathrm{p} \leq .01$

\begin{tabular}{|l|l|l|}
\hline & Response Before Tutorial & Response After Tutorial \\
\hline Knowledge Score & 5.5 & 6.789 \\
\hline
\end{tabular}

In this case, we can reject the null hypothesis and accept that participants had a higher knowledge score after taking the tutorial. These results suggest that learning does occur during the tutorial. It is important to note that knowledge scores were relatively high before the tutorial (discussed above in "Baseline Knowledge"). Beginning with a score of 5.5, post-tutorial knowledge scores could only increase by 1.5 (actual increase was $1.289, s=.5436)$. Nonetheless, participants did become more knowledgeable about coyotes after taking the online tutorial.

\section{Changes in Attitudes after Tutorial}

The pre/post attitudes portion of the study sought to measure whether participants had more positive attitudes after taking the tutorial.

Null Hypothesis: Participants will not have a significant change in attitudes after taking the tutorial.

Hypothesis 2: Participants will have more positive attitudes about coyotes after taking the tutorial.

All seven attitudinal pre- and post-tutorial responses were compared in one-tailed paired sample $t$ tests. As reviewed above (see "Baseline Attitudes"), participants had 
generally positive attitudes that were in-line with current research before participating in the tutorial; however, for all questions, attitudes became even more positive and (for research-relevant questions) research-based after the tutorial (Table 4.10). According to Cohen's rule of thumb, there was a small to medium effect on attitude scores (Cohen 1988).

Participants $(\mathrm{N}=141)$ reported that they liked coyotes more after the tutorial $(\mathrm{m}=$ $3.965, s=1.1046)$ than before the tutorial $(m=3.809, s=1.1396), t(140)=-4.423, \mathrm{p} \leq$ $.01 ; d=-0.3725$. Of all attitudinal questions, responses to this question showed the largest change in participant attitudes (small to medium effect). Participants ( $N=142)$ reported that they were slightly more supportive of coyotes living in the Portland Metropolitan Area after the tutorial $(m=1.768, s=.8223)$ than before the tutorial $(m=$ $1.880, s=.8791), t(141)=3.115, \mathrm{p} \leq .01 ; d=.2614$. Participants $(\mathrm{N}=142)$ reported that they were slightly less supportive of lethally removing coyotes found in urban areas after the tutorial $(m=1.444, s=.9266)$ than before the tutorial $(m=1.592, s=.9760), t(141)=$ $3.493, \mathrm{p} \leq .01 ; d=.2931$.

Of the four concern questions, the question that participants' attitudes changed most on was "How concerned are you about coyotes near your home?" Participants $(\mathrm{N}=141)$ reported that they were less concerned about coyotes near their home after the tutorial $(m=1.567, s=.8133)$ than before the tutorial $(m=1.730, s=.9326), t(140)=$ 3.083, $\mathrm{p} \leq .01 ; d=.2596$. Participants $(\mathrm{N}=142)$ reported that they were slightly less concerned about having a face-to-face encounter with a coyote after the tutorial $(m=$ 
$1.204, s=.5128)$ than before the tutorial $(m=1.331, s=.6157), t(141)=2.921, \mathrm{p} \leq .01 ; d$ $=.2451$.

Table 4.10 Summary table of paired $t$ test results for attitudes questions before and after tutorial. $\mathrm{p} \leq .01$

\begin{tabular}{|l|l|l|l|}
\hline Question & Range & $\begin{array}{l}\text { Mean Response } \\
\text { Before Tutorial }\end{array}$ & $\begin{array}{l}\text { Mean Response } \\
\text { After Tutorial }\end{array}$ \\
\hline $\begin{array}{l}\text { How much do you like or dislike } \\
\text { coyotes? }\end{array}$ & $\begin{array}{l}\text { (1) Dislike very much- } \\
\text { (5) Like very much }\end{array}$ & 3.809 & 3.965 \\
\hline $\begin{array}{l}\text { How much do you support } \\
\text { coyotes living in the Portland } \\
\text { Metropolitan Area? }\end{array}$ & $\begin{array}{l}\text { (1) Very much- } \\
\text { (4) Coyotes should be } \\
\text { removed from the } \\
\text { PMA }\end{array}$ & 1.880 & 1.768 \\
\hline $\begin{array}{l}\text { How do you feel about lethally } \\
\text { removing (killing) coyotes found } \\
\text { in urban areas? }\end{array}$ & $\begin{array}{l}\text { (1) Strongly against- } \\
\text { (5) Strongly in favor }\end{array}$ & 1.592 & 1.444 \\
\hline $\begin{array}{l}\text { How concerned are you about } \\
\text { coyotes near your home? }\end{array}$ & $\begin{array}{l}\text { (1) Not at all- } \\
\text { (4) Very concerned }\end{array}$ & 1.730 & 1.567 \\
\hline $\begin{array}{l}\text { How concerned are you about } \\
\text { having a face-to-face encounter } \\
\text { with a coyote? }\end{array}$ & $\begin{array}{l}\text { (1) Not at all- } \\
\text { (4) Very concerned }\end{array}$ & 1.331 & 1.204 \\
\hline $\begin{array}{l}\text { How concerned are you about } \\
\text { coyotes attacking children? }\end{array}$ & $\begin{array}{l}\text { (1) Not at all- } \\
\text { (4) Very concerned }\end{array}$ & 1.472 & 1.345 \\
\hline $\begin{array}{l}\text { How concerned are you about } \\
\text { coyotes attacking pets? }\end{array}$ & $\begin{array}{l}\text { (1) Not at all- } \\
\text { (4) Very concerned }\end{array}$ & 2.232 & 2.070 \\
\hline
\end{tabular}

Of the four concern questions, the question with the least change in attitudes posttutorial was "How concerned are you about coyotes attacking children?" with only a slight decrease in the already low concern about coyotes attacking children. Participants $(\mathrm{N}=142)$ reported that they were slightly less concerned about coyotes attacking children after the tutorial $(m=1.345, s=.6636)$ than before the tutorial $(m=1.472, s=.7962)$, $t(141)=2.544, \mathrm{p} \leq .01 ; d=.2135$. Participants $(\mathrm{N}=142)$ reported that they were less 
concerned about coyotes attacking small pets after the tutorial $(m=2.070, s=.8392)$ than before the tutorial $(m=2.232, s=1.0082), t(141)=2.794, \mathrm{p} \leq .01 ; d=.2345$.

We can reject the null hypotheses in all seven attitudinal paired sample $t$ tests and accept that participants had more positive attitudes about coyotes after taking the tutorial. As in the knowledge study above, it is important to note that attitude scores were relatively high before the tutorial (discussed above in "Baseline Attitudes"). High preliminary scores indicate that participants were already supportive of coyotes and had mostly research-based concerns and positive attitudes. The tutorial further increased these scores, but there was not as much room for scores to increase, as there might be in populations with more negative initial attitudes.

\section{Conclusion}

Overall, people who took part in the study were not familiar with the PUCP before participating. Almost all of the participants had seen an urban coyote, and about three-quarters of participants had seen a coyote in Portland in the last year. Knowledge about coyotes was high, but the questions were relatively easy. Participants generally knew what coyotes eat (usually rodents, not cats), that they are not very dangerous, are difficult to remove, and even knew more trivial information like the fact that coyotes hunt alone but tend to live in family groups. In future studies, it would be helpful to ask more difficult or complex questions about coyotes to get a better idea of how much PMA residents really know about coyotes. 
Participants generally liked coyotes, supported coyotes' presence in the PMA, and disapproved of lethal removal. Concern about coyotes near homes, in face-to-face encounters, attacking children, and attacking pets was generally low. Of these concerns, participants were most concerned about coyotes attacking pets, especially if those participants were pet owners themselves.

After completing the online tutorial, participants had significantly higher scores on knowledge-based questions; however, participants' knowledge scores were already relatively high, so their scores could only increase so much. Similarly, participants' attitudes were significantly more positive (and research-based in research-relevant questions) after taking the tutorial, but baseline attitudes were generally positive to begin with. Overall, the tutorial had a large effect on knowledge and a small effect on attitudes. Conducting a similar study on a less-informed sample would help us better understand how much learning can take place from a short, citizen science project's online tutorial. Nonetheless, these results suggest that educational tools in citizen science projects are effective for providing information and shaping attitudes about urban coyotes. Online tutorials like the PUCP can be useful tools to provide the crucial information people need to reduce human-coyote conflict. Citizen science education supports efficient and inexpensive management of urban coyote populations.

\section{Limitations and Future Directions}

During the process of designing and implementing this study, I learned a tremendous amount about coyotes, people, and the research process. In future studies, I 
will improve upon this research by attempting to more fully address issues of sampling bias and study design.

I would like to repeat this study using a random sampling technique. Participants in this study were self-selected, which can result in a skewed sample. In this case, participants were well informed and had generally positive attitudes about coyotes. While this is not unexpected for a highly educated sample and an environmentally-focused area like the PMA, we cannot be sure that a large portion of residents who do not like, or do not care about, coyotes were represented in this study. Furthermore, the sample did not represent the demographic distribution of the PMA (the sample was more female, more educated, wealthier, and whiter). Although useful results, a sample that more fully represents the target population would be preferable. It is notoriously difficult to sample disinterested participants, even with random sampling techniques, because of nonresponse bias (Berg 2005). However, repeating this study with a random sample might help us better understand the attitudes and knowledge of PMA residents about coyotes.

Most participants had no problem answering basic questions about coyotes, but it is unclear whether or not there are important knowledge gaps about coyotes that could have been captured with more complex or challenging questions. Relatedly, we might better understand the impacts of the tutorial by polling participants who are less knowledgeable about coyotes. Less-informed participants might be captured by random sampling or by specifically targeting certain populations. Similarly, in a follow-up study it would be valuable to repeat the attitudinal-change section of the study on participants 
with distinctly negative attitudes toward coyotes (captured through random sampling or by targeting special interest groups). In future studies, we might find that the degree of attitudinal change in participants with more negative attitudes is significantly different from the current sample.

In this study, participants were asked to report their attitudes and knowledge immediately after they completed the tutorial. Funding permitting, I would administer the post-tutorial questionnaire after a waiting period (roughly one week to one month) so that we could better understand if the changes in attitudes and knowledge persisted.

This study sought to measure the efficacy of the educational materials associated with citizen science projects; however, in future studies, I would like to make a tighter connection between actual citizen science activities and the associated learning materials. To further explore how citizen science can be used as a tool for education, I would include active participation in the project in the educational component of the study. For example, a study could include a tutorial about how to identify scat and follow-up activity where participants find and catalog scat in the city. Studies like this are more elaborate, but would improve our understanding of the utility of citizen science for education.

Even with the limitations discussed above, it is clear that citizen science education can play an important role in proactive management of urban coyotes. But this approach is not limited to urban coyotes. By widening the scope of study, the educational materials described above could be adapted and enhanced for a variety of other management challenges where lack of understanding drives human-wildlife conflict. 


\section{REFERENCES}

Adams, M. 2014. Evaluating the role of citizen science in the context of human-wildlife conflict management. Master of Science Thesis, Colorado State University, Department of Human Dimensions of Natural Resources.

Alexander, S. M. and M. S. Quinn. 2011. Interactions with humans and pets reported in the Canadian print media (1995-2010). Human Dimensions of Wildlife 16(5): 345-59.

Andelt, W. F. and B. R. Mahan. 1980. Behavior of an urban coyote. The American Midland Naturalist 103(2): 399-400.

Arthur, L. M. 1981. Coyote control: The public response. Journal of Range Management 34(1): 14-15.

Au, J., B. Bagchi, B. Chen, R. Martinez, S. A. Dudley, and G. J. Sorger. 2000. Methodology for public monitoring of total coliforms, Escheri coli and toxicity in waterways by Canadian high school students. Journal of Environmental Management, 58: 213-230.

Bateman, P. W. and P. A. Fleming. 2011. Big city life: Carnivores in urban environments. Journal of Zoology 287(1): 1-23.

Berg, N. 2005. Non-Response Bias. In Encyclopedia of social measurement, ed. K. Kempf-Leonard, Vol. 2, pp. 865-873. London: Academic Press.

Bekoff M. and E. M. Gese. 2003. Coyote (Canis latrans). In Wild mammals of North America: Biology, management, and conservation, $2^{\text {nd }}$ edition, eds. G. A. Feldhamer, B. C. Thompson, and J. A. Chapman, pp. 467-481. Baltimore: Johns Hopkins University Press.

Bonney, R. C. B. Cooper, J. Dickinson, S. Kelling, T. Phillips, K. V. Rosenberg, and J. Shirk. 2009. Citizen science: A developing tool for expanding science knowledge and scientific literacy. BioScience 59(11): 977-84.

Blumler, M.A., A. Cole, J. Flenley, and U. Schickoff. 2011. History of biogeographical thought. In The sage handbook of biogeography, eds. A. C. Millington, M. Blumler and U. Schickoff, pp. 23-42. Los Angeles: Sage Publications, Inc. 
Buller, H. 2014. Animal geographies I. Progress in Human Geography 38(2): 308-18.

Buller, H. 2015. Animal geographies II: Methods. Progress in Human Geography 39(3): 374-384

Butt, Bilal, A. Shortridge, and A. WinklerPrins. 2009. Pastoral herd management, drought coping strategies, and cattle mobility in southern Kenya. Annals of the Association of American Geographers 99(2): 309-34.

Bradburn, N., S. Sudman, and B. Wansink. 2004. Asking questions: The definitive guide to questionnaire design-For market research, political polls, and social and health questionnaires. San Francisco: John Wiley \& Sons, Inc.

Branchini, S., M. Meschini, C. Covi, C. Piccinetti, F. Zaccanti, and S. Goffredo. 2015. Participating in a citizen science monitoring program: Implications for environmental education. PLOS ONE.

Brossard, D., B. Lewenstein, and R. Bonney. 2005. Scientific knowledge and attitude change: The impact of a citizen science project. International Journal of Science Education 27(9): 1099-1121.

CBC News. 2009. Coyotes attack woman in N. S. October 27. http://www.cbc.ca/news/canada/nova-scotia/story/2009/10/27/ns-coyoteattack.html (last accessed 10 August 2015).

Cohen, J. 1988. Statistical Power Analysis for the Behavioral Sciences. Statistical power analysis for the behavioral sciences. Hillsdale: Lawrence Erlbaum Associates, Publishers.

Connolly, G. E. 1978. Predator control and coyote populations: A review of simulation models. In Coyotes: Biology, behavior, and management, ed M. Bekoff, 327-345. New York: Academic Press.

Connors, J. P., S. Lei, and M. Kelly. 2012. Citizen science in the age of neogeography: Utilizing volunteered geographic information for environmental monitoring Annals of the Association of American Geographers 102(6): 1267-1289. 
Conrad, C. C. and K. G. Hilchey. 2011. A review of citizen science and community-based environmental monitoring: issues and opportunities. Environmental Monitoring and Assessment 176(1-4): 273-291.

Cowell, M. C. and A. J. Parker. 2004. Biogeography in the annals. Annals of the Association of American Geographers 94(2): 256-68.

Cox, C., W. Morse, C. Anderson, and L. Marzen. 2014. Applying public participation geographic information systems to wildlife management. Human Dimensions of Wildlife 19(2): 200-214.

Doughty, R. W. 1975. Feather fashions and bird preservation: a study in nature protection. Berkeley: University of California Press.

Doughty, R. W. 1989a. Wildlife and man in Texas: Environmental change and conservation. College Station: A\&M University Press.

Doughty, R. W. 1989b. Return of the whooping crane. Austin: University of Texas Press.

Decker, D. J., C. A. Jacobson, and T.L. Brown. 2006. Situation-specific 'impact dependency' as a determinant of management acceptability: Insights from wolf and grizzly bear management in Alaska. Wildlife Society Bulletin 34(2): 426-32.

Draheim, M. 2007. Who's afraid of the big, bad coyote? A survey of messaging and existing attitudes in the National Capital Region. Master of Science Thesis, George Mason University, Department of Environmental Science and Policy.

Draheim, M. M., L. L. Rockwood, G. Guagnano, and E. C. M. Parsons. 2011. The impact of information on students' beliefs and attitudes toward coyotes. Human Dimensions of Wildlife 16(1): 67-72.

Draheim, M., K. Patterson, L. Rockwood, G. Guagnano, and E. Parsons. 2013. Attitudes of college undergraduates towards coyotes (Canis latrans) in an urban landscape: Management and public outreach implications. Animals 3(1): 1-18.

Elwood, S., M. F. Goodchild, and D. Z. Sui. 2012. Researching volunteered geographic information: Spatial data, geographic research, and new social practice. Annals of the Association of American Geographers 102(3): 571-90. 
Emel, J. 1998. Are you man enough, big and bad enough? Wolf eradication in the US. In Animal geographies: Place, politics, and identity in the nature-culture borderlands, eds. J. Wolch and J. Emel, pp. 91-116. London: Verso.

Emel, J., C. Wilbert, and J. Wolch. 2002. Animal Geographies. Society and Animals 10(4): 407-412.

Evans, C., E. Abrams, R. Reitsma, K. Roux, L. Salmonsen, and P. P. Marra. 2005. The neighborhood Nestwatch program: Participant outcomes of a citizen-science ecological research project. Conservation Biology 19(3): 589-594.

Foddy, W. 1993. Constructing questions for interviews and questionnaires. Cambridge: Cambridge University Press.

Gehrt, S. D. n.d. Urban Coyote Ecology and Management. The Cook County, Illinois, Coyote Project. Bulletin 929.

Gehrt, S. D. 2007. Ecology of coyotes in urban landscapes. Wildlife Damage Management Conferences-Proceedings. Paper 63. University of Nebraska, Lincoln.

Gehrt, S. D., and S. Prange. 2007. Interference competition between coyotes and raccoons: A test of the mesopredator release hypothesis. Behavioral Ecology 18(1): 204-214.

Gehrt, S. D., C. Anchor, and L.A. White. 2009. Home range and landscape use of coyotes in a metropolitan landscape: Conflict or coexistence? Journal of Mammalogy 90(5): 1045-1057.

Gehrt, S. D., S. P. D. Riley, and B. L. Cypher. 2010. Urban carnivores: ecology, conflict, and conservation. Baltimore: Johns Hopkins University Press.

Gehrt, S. D, J. L. Brown, and C. Anchor. 2011. Is the urban coyote a misanthropic synanthrope? The case from Chicago. Cities and the Environment 4(1): 1-23.

Gehrt, S. D., E. C. Wilson, J. L. Brown, and C. Anchor. 2013. Population ecology of free-roaming cats and interference competition by coyotes in urban parks. PLoS ONE. 
Goldman, M. 2009. Constructing connectivity: Conservation corridors and conservation politics in east African rangelands. Annals of the Association of American Geographers 99(2): 335-59.

Goodchild, M. F, and Linna Li. 2012. Assuring the quality of volunteered geographic information. Spatial Statistics 1: 110-20.

Gullo, J., U. Lassiter, J. Wolch 1998. The cougar's tale. In Animal geographies: Place, politics, and identity in the nature-culture borderlands, eds. J. Wolch and J. Emel, pp. 139-161. London: Verso.

Grubbs, S.E., and P.R. Krausman. 2009. Use of urban landscape by coyotes. The Southwestern Naturalist 54(1): 1-12.

Haklay, M. 2010. How good is volunteered geographical information? A comparative study of OpenStreetMap and ordnance survey datasets. Environment and Planning B: Planning and Design 37(4): 682-703.

Haywood, B. K. 2014. Birds and beaches: The affective geographies and sense of place of participants in the coasst citizen science program. Ph.D. dissertation, University of South Carolina, Department of Geography.

Hennessy, C., J. Dubach, and S. D. Gehrt. 2012. Long-term pair bonding and genetic evidence for monogamy among urban coyotes (Canis latrans). Journal of Mammalogy 93(3): 732-742.

Howell, R. G. 1982. The urban coyote problem in Los Angeles county. Proceedings of the Tenth Vertebrate Pest Conference 10: 21-23. Paper 22. University of Nebraska, Lincoln.

Jackman, J. L, and A. T. Rutberg. 2015. Shifts in attitudes toward coyotes on the urbanized east coast : The Cape Cod experience, 2005 -2012. Human Dimensions of Wildlife 20: 333-348.

Jacobs, M. H. 2012. Human emotions toward wildlife. Human Dimensions of Wildlife 17(1): 1-3. 
Jacobs, M. H., P. Fehres, and M. Campbell. 2012. Measuring emotions toward wildlife: A review of generic methods and instruments. Human Dimensions of Wildlife 17(4): 233-247.

Jordan, R. C., S. A. Gray, D. V. Howe, W. R. Brooks, and J. G. Ehrenfeld. 2011. Knowledge Gain and Behavioral Change in Citizen-Science Programs Conservation Biology 25(6): 1148-54.

Kellert, S. R. 1985. Public Perceptions of predators, particularly the wolf and coyote. Biological Conservation 31(2): 167-89.

Kellert, S. R. 1988. Human-animal interactions: A review of American attitudes to wild and domestic animals in the twentieth century. In Animals and people sharing the world, ed. A. N. Rowan, pp. 137-175. Hanover: University Press of New England.

Kenaga, B. A., R. A. Krebs, and W. B. Clapham Jr. 2013. Coyote land use inside and outside urban parks. The American Midland Naturalist 170(2): 298-310.

Kitchen, A. M., E. M. Gese, and E. R. Schauster. 2000. Changes in coyote activity patterns due to reduced exposure to human persecution. Canadian Journal of Zoology 78(5): 853-57.

Lawrence, S. E, and P. R Krausman. 2011. Reactions of the public to urban coyotes (Canis latrans). The Southwestern Naturalist 56(3): 404-9.

Leeming, D. A. 2005. The Oxford companion to world mythology. Oxford: Oxford University Press.

Leydet, F. 1977. The coyote: Defiant songdog of the west. United States: University of Oklahoma Press.

Lukasik, V. M. 2009. The diet and human interactions of urban coyotes in Calgary, Alberta. Master of Science Thesis, University of Calgary, Department of Geography.

Lukasik, V. M., \& S. M. Alexander. 2011. Human-coyote interactions in Calgary, Alberta. Human Dimensions of Wildlife 16(2): 114-127. 
Martínez-Espiñeira, R. 2006. Public attitudes toward lethal coyote control. Human Dimensions of Wildlife 11(2): 89-100.

Miller, C. A., L. K. Campbell, and J. A. Yeagle. 2001. Attitudes of homeowners in the greater Chicago metropolitan region toward nuisance wildlife. Human Dimensions Program Report SR-00-02. Illinois Natural History Survey, Champaign, IL.

Morey, P. S., E. M. Gese, and S. Gehrt. 2007. Spatial and temporal variation in the diet of coyotes in the Chicago Metropolitan Area. The American Midland Naturalist 158(1): $147-161$.

Nagy C. M., M. E. Weckel, A. Toomey, C. E. Burns, and J. Peltz. 2012. Validation of a citizen science-based model of coyote occupancy with camera traps in suburban and urban New York, USA. Wildlife Biology in Practice 8(1): 23-35.

Nali, C., and G. Lorenzini. 2007. Air quality survey carried out by schoolchildren: An innovative tool for urban planning. Environmental Monitoring and Assessment 131: 201-210.

Newman, G., D. Zimmerman, A. Crall, M. Laituri, J. Graham, and L. Stapel. 2010. User-friendly web mapping: Lessons from a citizen science website. International Journal of Geographical Information Science 24(12): 1851-69.

Oakmapper. OakMapper: Sudden oak death mapping. http://oakmapper.org/ (last accessed September 7, 2015).

Olive, A. 2014. Urban awareness and attitudes toward conservation: A first look at Canada's cities. Applied Geography 54: 160-68.

United States Census Bureau. 2013. 2010 Census urban area facts: Urban areas. US Department of Commerce. Available at https://www.census.gov/geo/reference/ua/uafacts.html (last accessed 10 August 2015).

Parkin, Michael. 2008 Priming. In Encyclopedia of survey research methods, ed. P. J. Lavrakas, pp. 612-13. Thousand Oaks: Sage Publications, Inc. 
Philo C. 1995. Animals, geography, and the city: Notes on inclusions and exclusions. Environment and planning $d$ : Society and space 13(6): 655-81

Poessel, S.A., S.W. Breck, T.L. Teel, S. Shwiff, K.R. Crooks, and L. Angeloni. 2013. Patterns of human-coyote conflicts in the Denver metropolitan area. The Journal of Wildlife Management 77(2): 297-305.

Quinn, T. 1995. Using public sighting information to investigate coyote use of urban habitat. Journal of Wildlife Management 59: 238-245.

Rasmussen, Z. 2015. [Portland Urban Coyote Project]. Unpublished raw data.

Regional Land Information System (RLIS). 2014. http://rlisdiscovery.oregonmetro.gov/ (last accessed November 14, 2015)

Riesch, H. and C. Potter. 2014. Citizen science as seen by scientists: Methodological, epistemological and ethical dimensions. Public Understanding of Science 23(1): $107-20$.

Ross, P. 2014. US and climate change: Here are the top 10 greenest cities in America. International Business Times. http://www.ibtimes.com/us-climate-change-here-are-top-10-greenest-citiesamerica-1695727. (last accessed November 15, 2015).

Ryden, Hope. 1979. God's dog: The North American coyote. New York: The Lyons Press.

Sakakibara, C. 2010. Kiavallakkikput agviq (into the whaling cycle): Cetaceousness and climate change among the Iñupiat of arctic Alaska. Annals of the Association of American Geographers 100(4): 1003-12.

Sallinger, B. 2011. God's dog rides the MAX: Urban coyotes. In Wild in the city: Exploring the intertwine, ed. M. C. Houck and M. J. Cody, 2nd ed., pp. 293-96. United States: Oregon State University Press.

Saris, W. E, M. Revilla, J. A. Krosnick, and E. M. Shaeffer. 2010. Comparing questions with agree/disagree response options to questions with item-specific response options. Survey Research Methods 4(1): 61-79. 
Sickler, J., T. M. Cherry, L. Allee, R. R. Smyth, and J. Losey. 2014. Scientific value and educational goals: Balancing priorities and increasing adult engagement in a citizen science project. Applied Environmental Education \& Communication 13(2), 109-119.

Siemer, W. F., H. W. Hudenko, and D. J. Decker. 2007. Coyote management in residential areas: Human dimensions research needs. Proceedings of the 12th Wildlife Damage Management Conference 12 (August): 421-30.

Smith, L. L., and R. W. Doughty. 1984. The amazing armadillo: geography of a folk critter. Austin: University of Texas Press.

Sponarski, C. C., J. J. Vaske, and A. J. Bath. 2015a. Attitudinal differences among residents, park staff, and visitors toward coyotes in Cape Breton Highlands National Park of Canada. Society \& Natural Resources 28:720-732.

Sponarski, C. C., J. J. Vaske, and A. J. Bath. 2015b. The role of cognitions and emotions in human-coyote interactions. Human Dimensions of Wildlife 20: 238254.

Sustainlane. 2008. How green is your city: Sustainlane US city rankings. Gabriola: New Society Publishers.

Svoboda, E. 2008. America's 50 greenest cities. Popular Science. http://www.popsci.com/environment/article/2008-02/americas-50-greenestcities?image $=5$ (last accessed November 15, 2015).

Tang, Z., and T. Liu. 2015. Evaluating internet-based public participation GIS (PPGIS) and volunteered geographic information (VGI) in environmental planning and management. Journal of Environmental Planning and Management 1-18.

Taylor, D. 2004. Conservation education and its relevance to wild canids. In Canids: Foxes, wolves, jackals and dogs: Status survey and conservation action plan, eds. C. Sillero-Zubiri, M. Hoffman, and D. W. Macdonald, pp. 298-305. Cambridge: IUCN.

Thompson S. and R. Bonney. 2007. Evaluating the impacts of participation in an online citizen science project: A mixed-methods approach. In Museums and the Web: Archives and Museum Informatics, eds. J. Trant J. and D. Bearman, pp. 187-199. 
Trumbull, D. J, R. Bonney, D. Bascom, and A. Cabral. 2000. Thinking scientifically during participation in a citizen-science project. Science Education 84(2): $265-75$.

Twain, Mark. 1872. Roughing It. n.p.

US Census. 2010.

http://www.census.gov/2010census/ (last accessed November 14, 2015)

Vaske, J. J. and M. D. Needham. 2007. Segmenting public beliefs about conflict with coyotes in an urban recreation setting. Journal of Park and Recreation Administration 25(4): 79-98.

Weckel, M. E., D. Mack, C. Nagy, R. Christie and A. Wincorn. 2010. Using citizen science to map human-coyote interaction in suburban New York, USA. The Journal of Wildlife Management 74(5): 1163-1171.

Whatmore, S. and L. Thorne. 1998. Wild(er)ness: Reconfiguring the geographies of wildlife. Transactions of the Institute of British Geographers 23(4): 435-454.

White, L. A., and S. D. Gehrt. 2009. Coyote attacks on humans in the United States and Canada. Human Dimensions of Wildlife 14(6): 419-432.

Wilson, D. E. and D. M. Reeder, eds. 2005. Mammal Species of the World. A Taxonomic and Geographic Reference (3rd ed), Baltimore: Johns Hopkins University Press.

Wine, S., S. A. Gagné, and R. K. Meentemeyer. 2015. Understanding human-coyote encounters in urban ecosystems using citizen science data: What do socioeconomics tell us? Environmental Management 55(1): 159-70.

Wittmann, K., J. J. Vaske, M. J. Manfredo, and H. C. Zinn. 1998. Standards for lethal response to problem urban wildlife. Human Dimensions of Wildlife 3(4): 29-48.

Wolch, J. 1998. Zoopolis. In Animal geographies: Place, politics, and identity in the nature-culture borderlands, eds. J. Wolch and J. Emel, 119-138. London: Verso.

Wolch, J. 2002. Anima Urbis. Progress in Human Geography 26(6): 721-42. 
Young, J. K., Z. Ma, A. Laudati, and J. Berger. 2015. Human-carnivore interactions: Lessons learned from communities in the American west. Human Dimensions of Wildlife 20: 349-366. 


\title{
APPENDIX A: PRELIMINARY SURVEY
}

\section{Part 1: Urban Coyote Tutorial Survey}

\author{
${ }^{*}$ Required
}

\section{Consent}

\author{
The Portland State University Consent to Participate in Research \\ Portland Urban Coyote Project Education Research \\ INTRODUCTION \\ July 4, 2015 \\ You are being asked to participate in a research study that is being done by Dr. Barbara Brower, who is the Principal Investigator and \\ graduate student researcher Zuriel Rasmussen, from the Department of Geography, at Portland State University in Portland, Oregon. This \\ research is studying human-coyote interactions and nature education in Portland. \\ You are being asked to participate in this study because you are a resident of the Portland metropolitan area. \\ This form will explain the research study, and will also explain the possible risks as well as the possible benefits to you. We encourage you \\ to talk with your family and friends before you decide to take part in this research study. If you have any questions, please ask one of the \\ study investigators. \\ What will happen if I decide to participate? \\ If you agree to participate, the following things will happen: \\ You will be asked to complete a questionnaire, explore our tutorial, and complete a follow-up questionnaire in one session. \\ How long will I be in this study? \\ Participation in this study will take about 40 minutes \\ What are the risks or side effects of being in this study? \\ There are no significant risks associated with this study. However, you may be inconvenienced by the time taken out of your day to \\ complete the study. \\ For more information about risks and discomforts, ask the investigator. \\ What are the benefits to being in this study? \\ There are no direct benefits of being in this study. However, you will help us learn more about humans and coyotes in Portland. \\ How will my information be kept confidential? \\ This survey is anonymous. All of your responses from the survey will be secured in a password-protected database \\ Information contained in your study records is used by study staff. \\ Your name will not be used in any published reports about this study. \\ Will I be paid for taking part in this study? \\ No, but you will have the option of entering a drawing for a $\$ 50$ gift certificate to Fred Meyer. \\ Can I stop being in the study once I begin? \\ Your participation in this study is completely voluntary. You have the right to choose not to participate or to withdraw your participation at \\ any point in this study without penalty or loss of benefits to which you are otherwise entitled. \\ Whom can I call with questions or complaints about this study? \\ If you have any questions, concerns or complaints at any time about the research study, Dr. Brower, or her associates will be glad to \\ answer them at (503) $725-8044$ \\ If you need to contact someone after business hours or on weekends, please call (503) 725-8044 and ask for Dr. Brower. \\ Whom can I call with questions about my rights as a research participant? \\ If you have questions regarding your rights as a research participant, you may call the PSU Office for Research Integrity at (503) $725-2227$ or \\ (877) 480-4400. The ORl is the office that supports the PSU instutional Revew Board (RB). The IRB is a group of people from PSU and the \\ information, you may also access the IRB website at https://sites. google.com/a/pdx.edu/research/integrity. \\ CONSENT \\ You are making a decision whether to participate in this study. Your signature below indicates that you have read the information provided \\ (or the information was read to youl. By signing this consent form, you are not waiving any of your legal rights as a research participant. \\ participate in this study" below, you agree to participate in this study.
}


1. Do you consent to participate in this study? * Mark only one oval.

Yes, I consent to participate in this study skip to question 3.

After the last question in this section,

$\bigcirc$ No, I do not wish to participate in this study

After the last question in this section, stop filling out this form.

2. Please enter your Anonymous

Identification Number (AIN) from the previous page:

\section{Section 1 of 3}

This section asks you to answer general questions about coyotes. If you are unsure of an answer, please select your best guess.

\section{How much does an average coyote weigh?}

Mark only one oval.

$\bigcirc$ Under 15 pounds

15-40 pounds

40-60 pounds

60-80 pounds

80-100 pounds

Over 100 pounds

4. What do coyotes most commonly eat?

Mark only one oval.

$D_{\text {Cats }}$
Fruit $_{\text {Rodents }}$
Garbage

5. True or False: Coyote removal efforts in the United States have largely been effective. Mark only one oval.

$$
\bigcirc \text { True }
$$

False 
6. True or False: Removing individual coyotes helps to reduce the overall coyote population of an area.

Mark only one oval.

True

False

7. True or False: Coyotes often live in family groups, but hunt alone.

Mark only one oval.

True

$\bigcirc$ False

8. True or False: Studies show that cats are a main food source for coyotes. Mark only one oval.

$\bigcirc$ True

False

9. True or False: Coyotes are responsible for human deaths every year.

Mark only one oval.

True

False

\section{Section 2 of 3}

In the following section, you will be asked about your feelings toward coyotes.

10. How much do you like or dislike coyotes?

Mark only one oval.

$\bigcirc$ Dislike very much

Dislike somewhat

Neutral

Like somewhat

Like very much

11. How much do you support coyotes living in the Portland metropolitan area? Mark only one oval.

$\bigcirc$ Very much

Somewhat

Not very much

Coyotes should be removed from the Portland metropolitan area 
12. How do you feel about lethally removing (killing) coyotes found in urban areas? Mark only one oval.

Strongly against

Somewhat against

Neutral

Somewhat in favor of

Strongly in favor of

13. How concerned are you about coyotes near your home?

Mark only one oval.

Not at all concerned

Slightly concerned

Moderately concerned

Very concerned

14. How concerned are you about coyotes attacking small pets? Mark only one oval.

Not at all concerned

Slightly concerned

Moderately concerned

Very concerned

15. How concerned are you about coyotes attacking children? Mark only one oval.
Not at all concerned
Slightly concerned
Moderately concerned
Very concerned

16. How concerned are you about having a face-to-face encounter with a coyote? Mark only one oval.
Not at all concerned
Slightly concerned
Moderately concerned
Very concerned

\section{Section 3 of 3}

This section asks about your personal experiences with coyotes and the Portland Urban Coyote Project. 
17. How many times have you seen a coyote in the past year in Portland?

18. About how many times have you seen a coyote in an urban or suburban area in your lifetime?

19. Have you reported a sighting to the Portland Urban Coyote Project? Mark only one oval.

$\bigcirc$ No

Yes, I have reported 1 sighting.

Yes, I have reported 2-5 sightings.

Yes, I have reported 6-10 sightings.

Yes, I have reported over 10 sightings.

20. Have you visited the Portland Urban Coyote Project Facebook, Twitter, or website? please do not include your visit today Mark only one oval.

$\bigcirc$ Yes

No

21. Are you familiar with the Portland Urban Coyote Project sightings map?

an online interactive map that represents coyote sightings Mark only one oval.

$\bigcirc$ Yes

No

22. Have you participated in citizen science projects besides the Portland Urban Coyote Project?

Mark only one oval.

$\bigcirc$ Yes

No 
23. If yes, please list other citizen science projects you have participated in.

\section{Powered by}

\# Google Forms 


\section{APPENDIX B: TUTORIAL}

\section{Participate in research to help us learn about humans, coyotes, and education!}

Many people have questions about urban coyotes in Portland. We have created the Urban Coyote Tutorial to help answer those questions. The Urban Coyote Tutorial is a click-through interactive tutorial with information about coyote life history, coyotes in Portland, coyote tracking, and coyote safety.

In this study, we are asking Portland metropolitan area residents to answer some questions and to complete the tutorial to help us learn about humans, coyotes, and education.

If you choose to participate, you will be asked to do three things:

1. Complete a short survey (10 minutes) before beginning the tutorial.

2. Complete our new Urban Coyote Tutorial (20 minutes).

3. Complete a short follow-up survey (10 minutes) after completing the survey.

Participants in the project will be entered to win a $\$ 50$ gift certificate for Fred Meyer!

Click the button below to participate in our research!

\section{CLICK HERE TO PARTICIPATE}


Thank you for your interest in participating in our study! Before we begin, please write down the following number:

\section{4}

This number is your Anonymous Identification Number (AIN).

Your AIN will help us anonymously connect your responses. We will ask you to report the number twice.

CLICK HERE TO BEGIN THE STUDY 


\section{LEARN MORE ABOUT URBAN COYOTES}

In this tutorial, you will learn about:

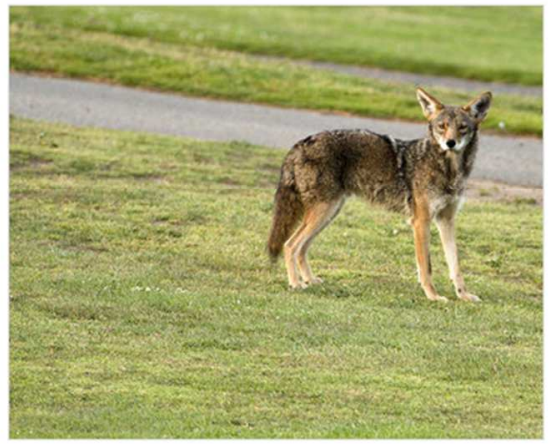

1. General Life History About Coyotes

2. Coyotes in Portland

3. How to Identify Coyotes and Coyote Signs

4. Coexisting with Coyotes 
Section 1 of 4: Coyote Life History

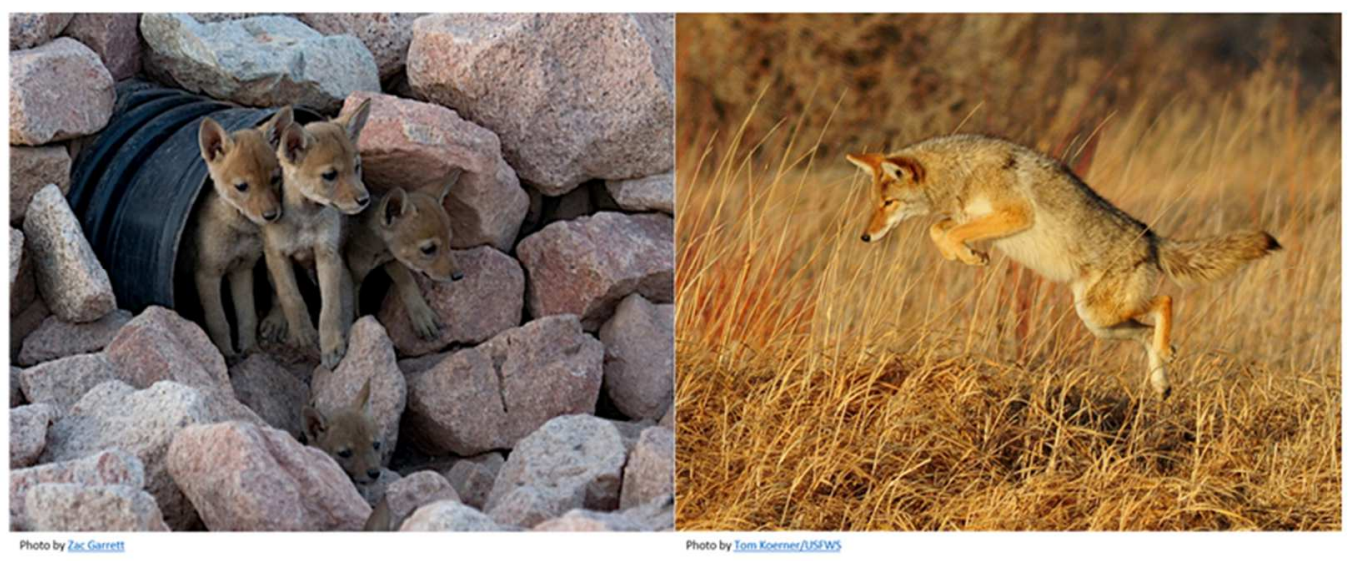

In this section, you will learn:

1. Where coyotes live

2. Coyote size

3. What coyotes eat

4. When coyotes have pups 


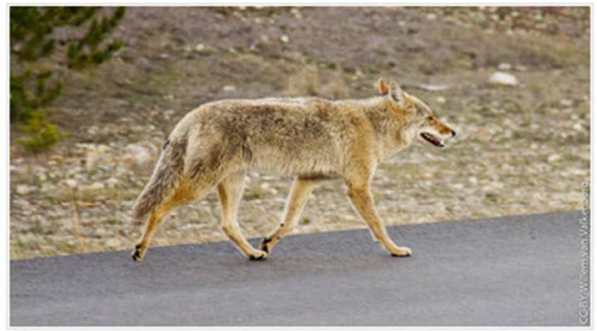

Coyotes are a member of the dog family (Canidae). Their Latin name, Canis latrans, means "barking dog." Coyotes are increasingly reported in cities, but where did they come from? 
Coyotes are incredibly adaptive. Historically, coyotes could be found in prairies and deserts, native only to Mexico and central North America. Until the 1940s, coyotes in Oregon were considered somewhat rare west of the Cascades. Now, coyotes have more than doubled their range, and can be found from Mexico to Canada and across the United States.

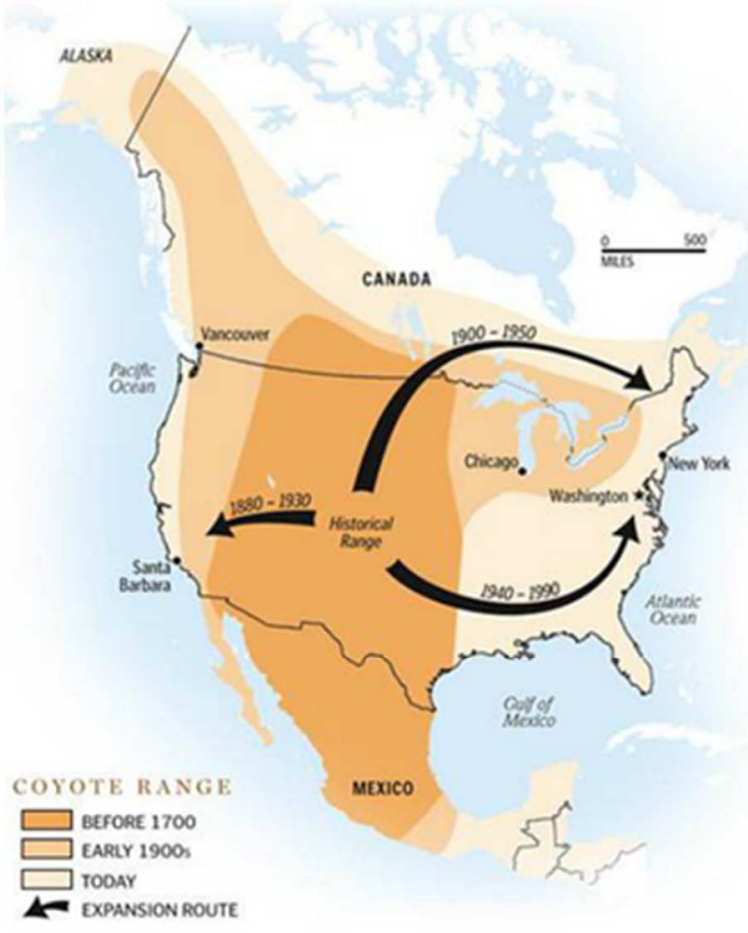

Map courtesy of the Cook County Coycte Project 
How much do you think a coyote in Oregon weighs?

click on an image to make your selection

German Shepherd | 60-80 Pounds

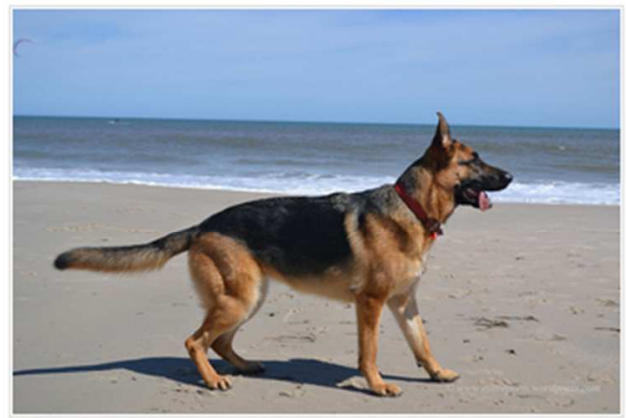

Whippet | 15-40 Pounds

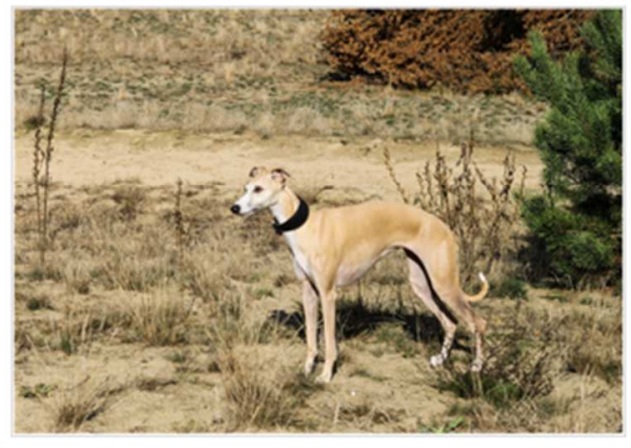

Husky | 40-60 Pounds

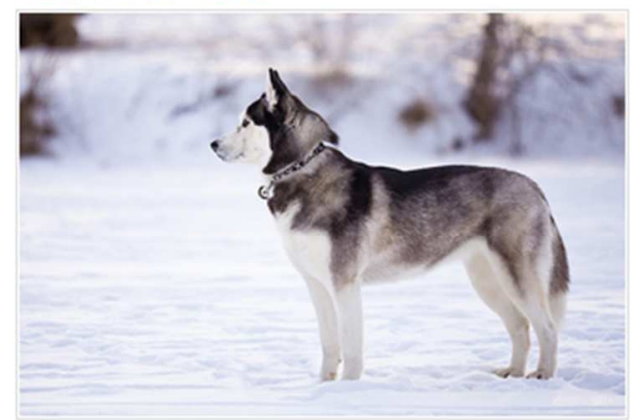

Papillon | 8-10 Pounds

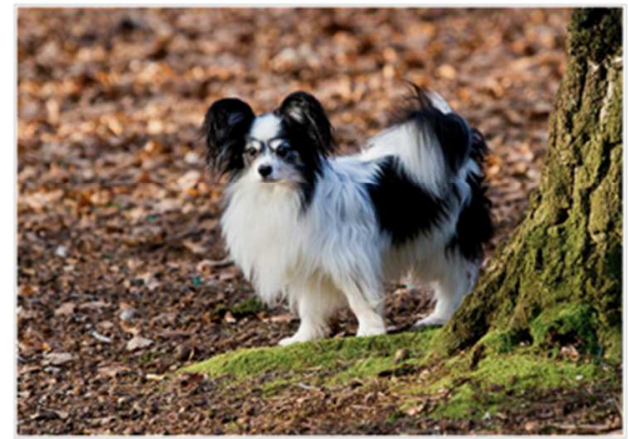


Quiz yourself! How much do you think a coyote in Oregon weighs?

$$
\text { click on an image to make your selection }
$$

Try again! Coyotes are much smaller than a German Shepherd.

German Shepherd | 60-80 Pounds

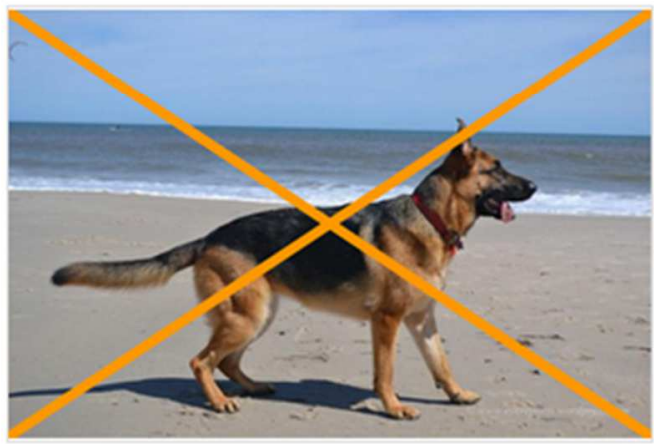

Whippet $15-40$ Pounds

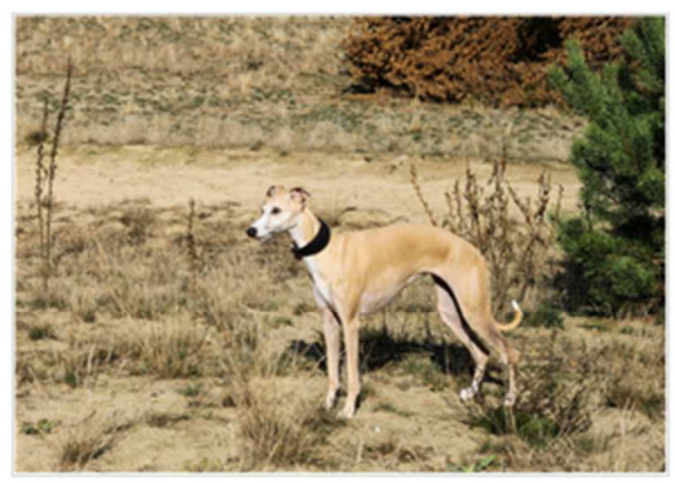

Husky | 40-60 Pounds

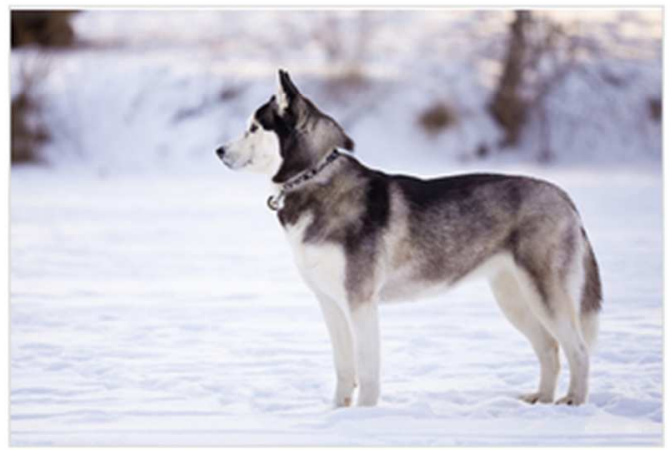

Papillon | 8-10 Pounds

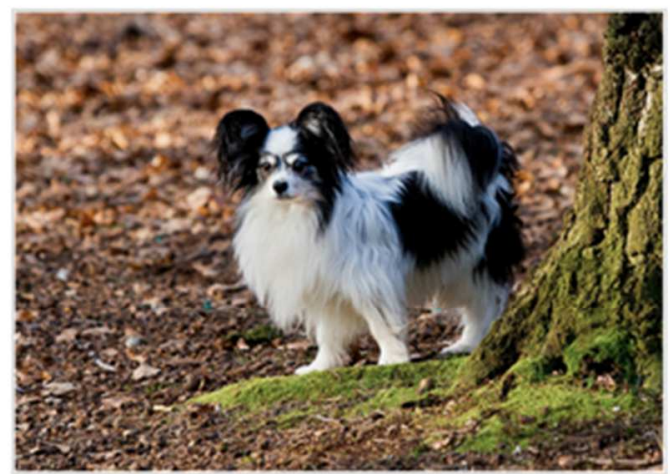


How much do you think a coyote in Oregon weighs?

$$
\text { click on an image to make your selection }
$$

Try again! Coyotes are not quite as big as a Husky.

German Shepherd | 60-80 Pounds

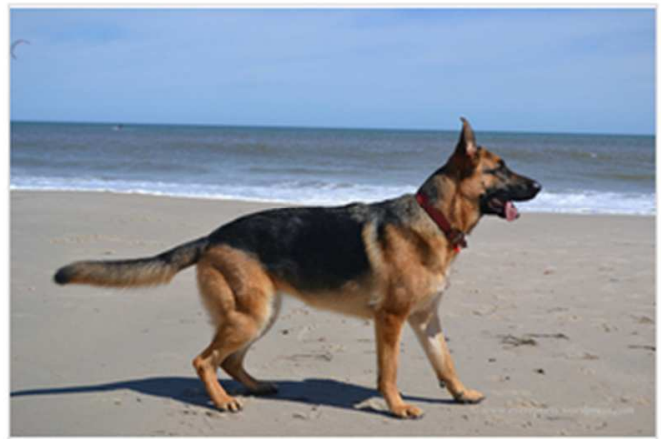

Whippet | 15-40 Pounds

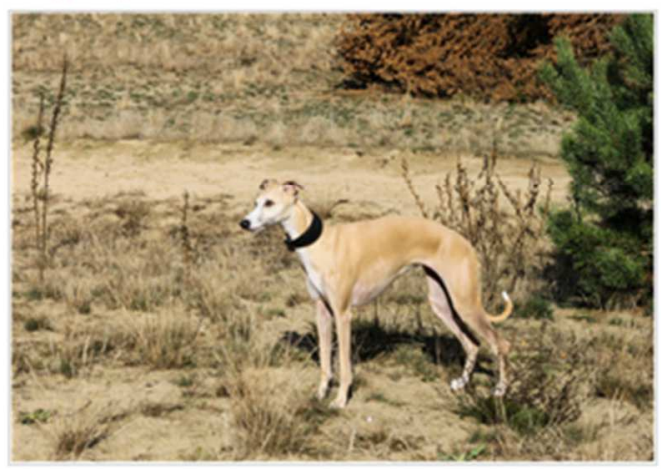

Husky | 40-60 Pounds

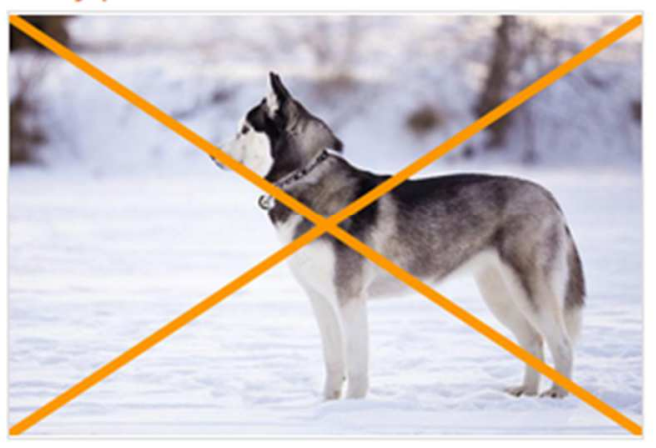

Papillon | 8-10 Pounds

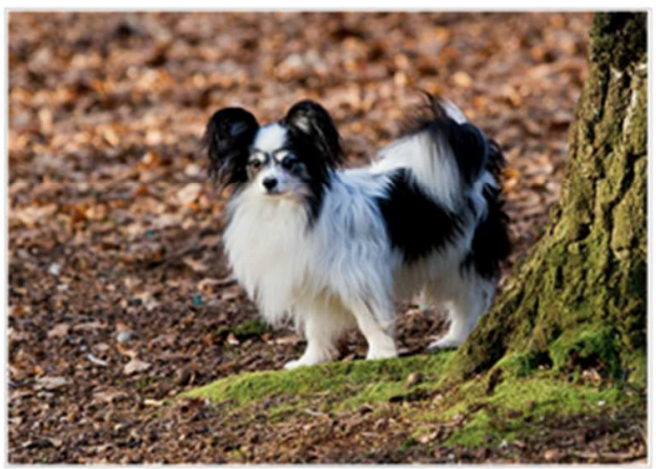


How much do you think a coyote in Oregon weighs?

click on an image to make your selection

Try again! Coyotes are a bit larger than small dogs like Papillons.

German Shepherd | 60-80 Pounds

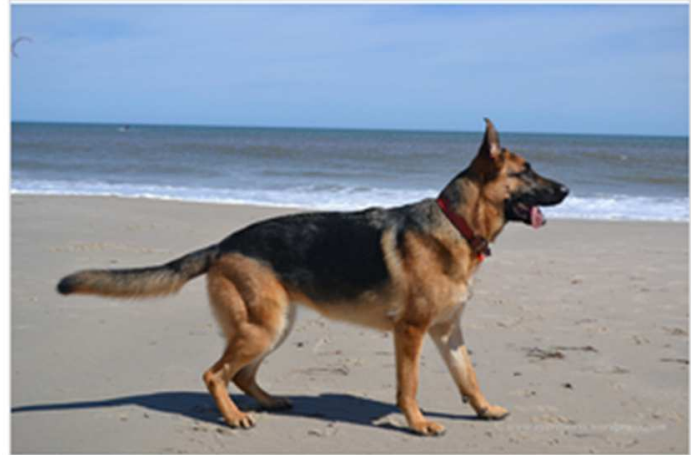

Whippet | 15-40 Pounds

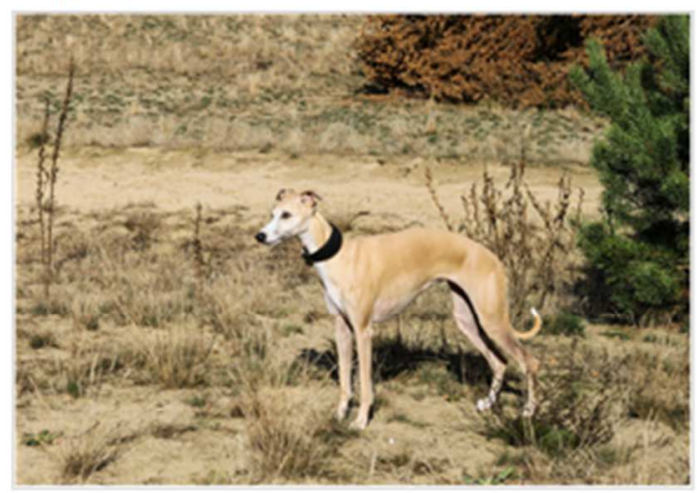

Husky | 40-60 Pounds

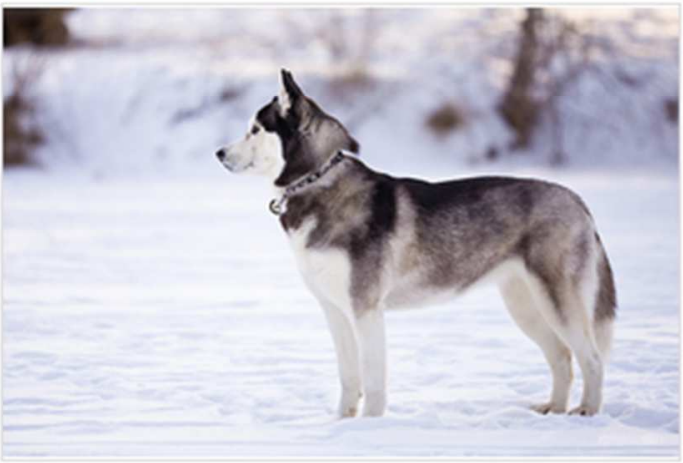

Papillon | 8-10 Pounds

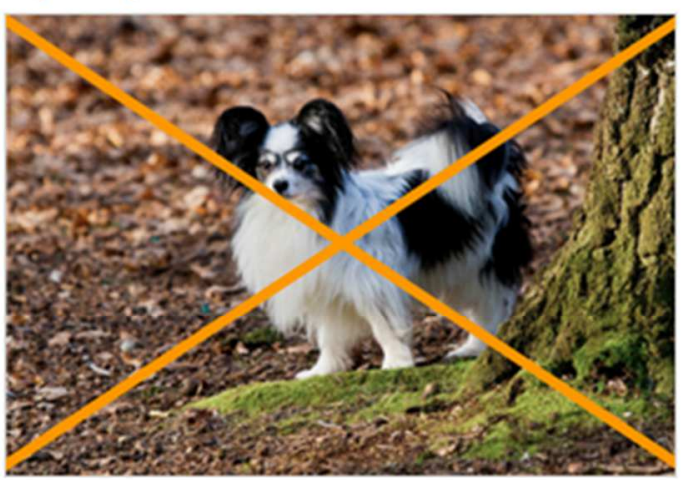


How much do you think a coyote in Oregon weighs?

That's right! Thick dense fur can make coyotes appear larger than they really are. Coyotes found in Oregon (western coyotes) typically weigh between 22 and 30 pounds.

German Shepherd | 60-80 Pounds

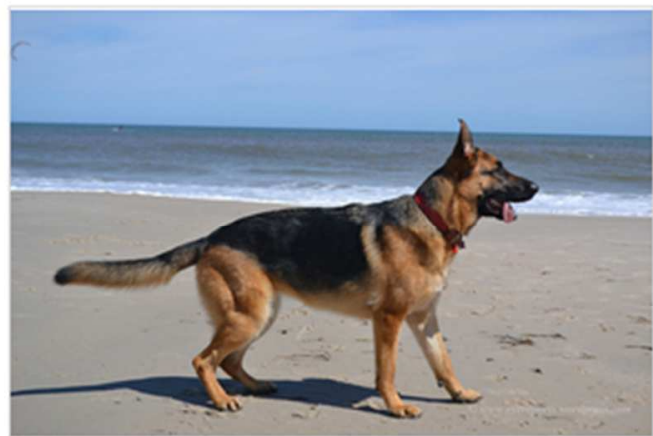

Whippet | 15-40 Pounds

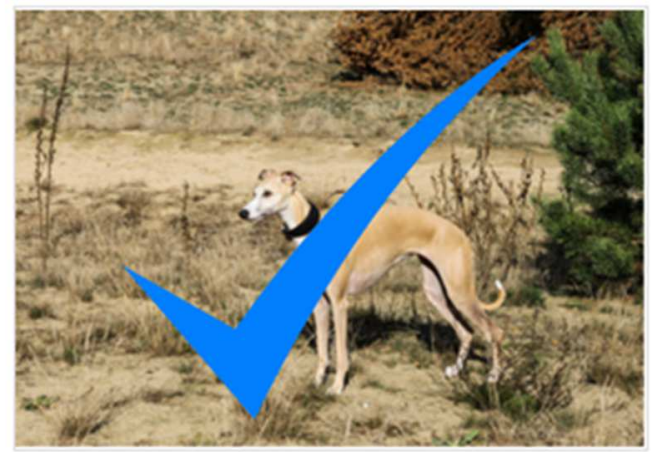

Husky | 40-60 Pounds

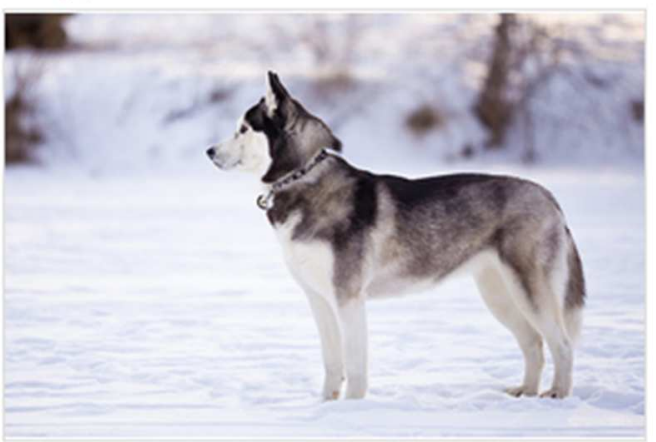

Papillon | 8-10 Pounds

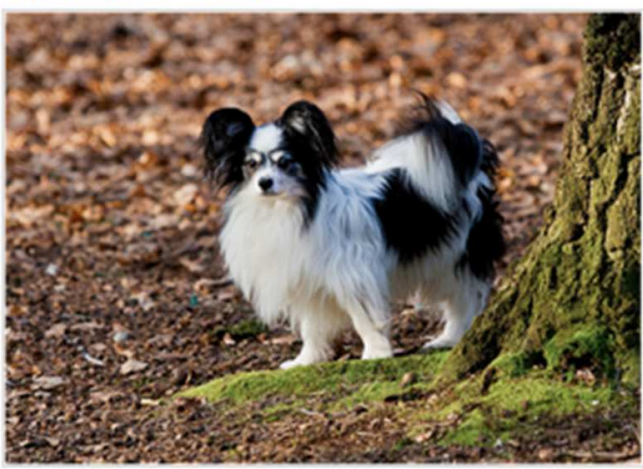


What do you think coyotes most commonly eat?

click on an image to make your selection
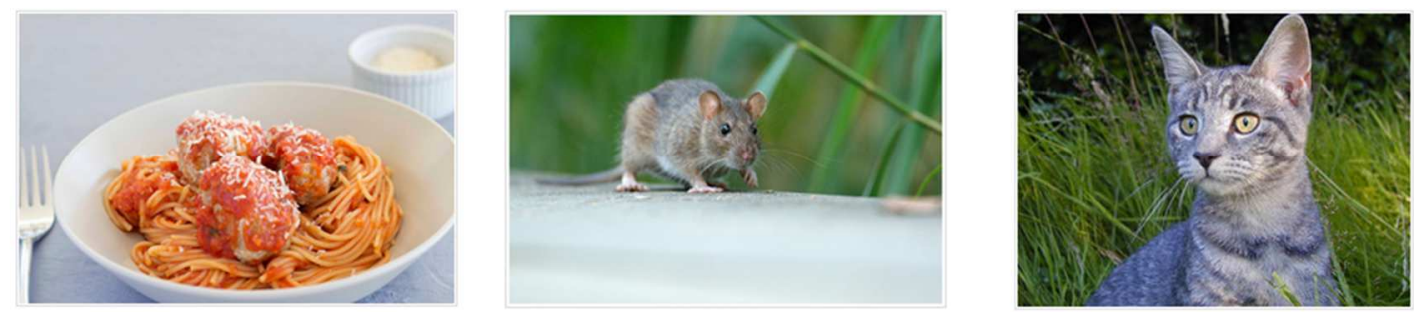

Back

Spaghetti by Wei-Duan Woo: Cat by Filikr, Rat by Jean-jacques Boujot 


\section{What do you think coyotes most commonly eat? click on an image to make your selection}

Try again! Coyotes have been known to prey upon cats, but studies show that cats make up only about $1-2 \%$ of an urban coyote's diet.
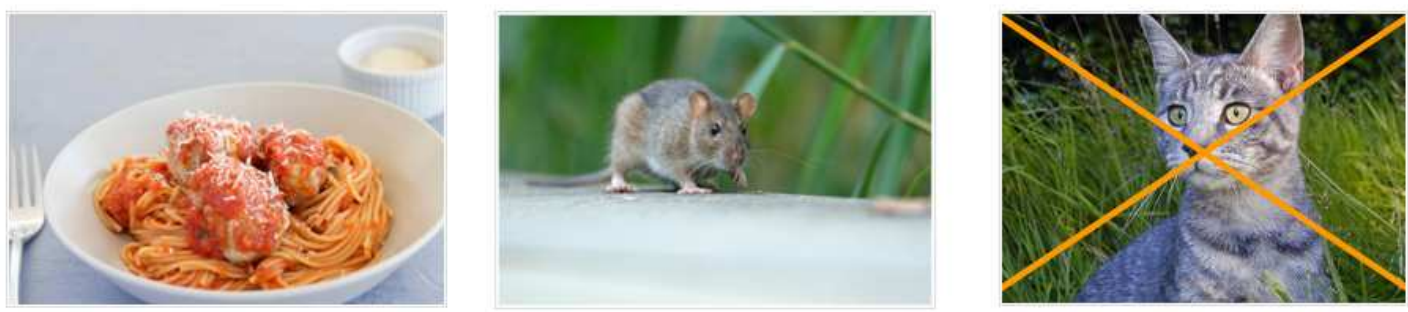

For more information, check out this article by Cook County Coyote Project researcher, Stanley Gehrt. 


\section{What do you think coyotes most commonly eat?}

click on an image to make your selection

Try again! Coyotes have been known to snack on leftovers, but studies show that anthropogenic food (food from human sources) only makes up about 2-35\% of an urban coyote's diet.
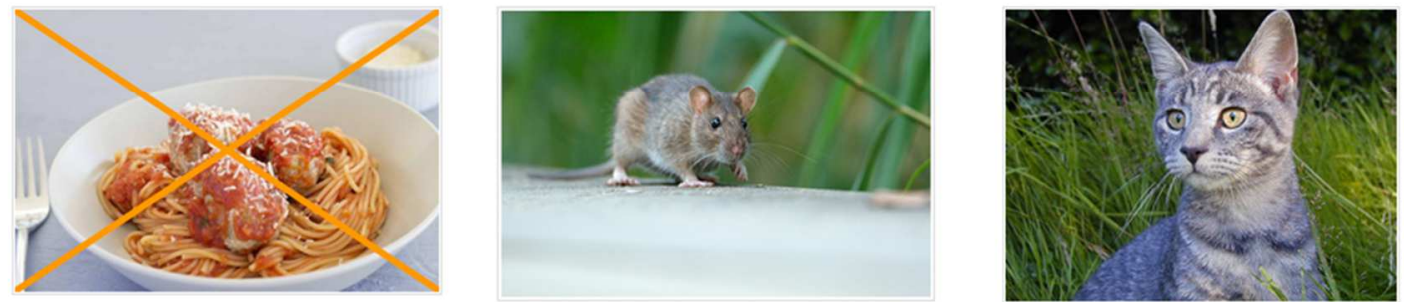

For more information, check out this article by Cook County Coyote Project researcher, Stanley Gehrt. 


\section{What do you think coyotes most commonly eat?}

Correct! Coyotes mainly eat rodents, but they are very opportunistic and will consume a wide variety of other foods. This can include birds and insects, fruit and vegetables, human garbage and compost, outdoor pet food, and small free-roaming pets.
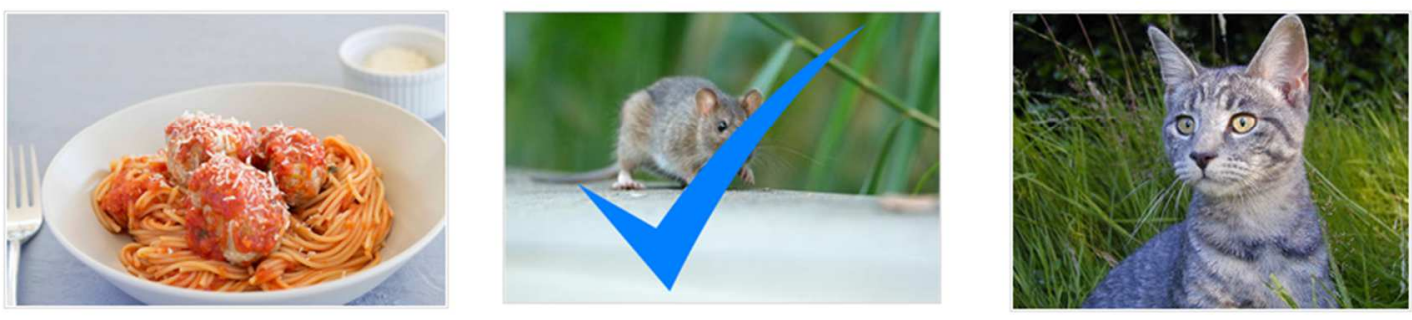

Back 


\section{Family Structure}

Coyotes form monogamous pair bonds. Research suggests that these pairs often remain together for life.

Coyotes tend to live in family groups, but often hunt alone. Generally the dominant pair in a family group (the parents) are the only breeding pair, and they produce one litter per year.

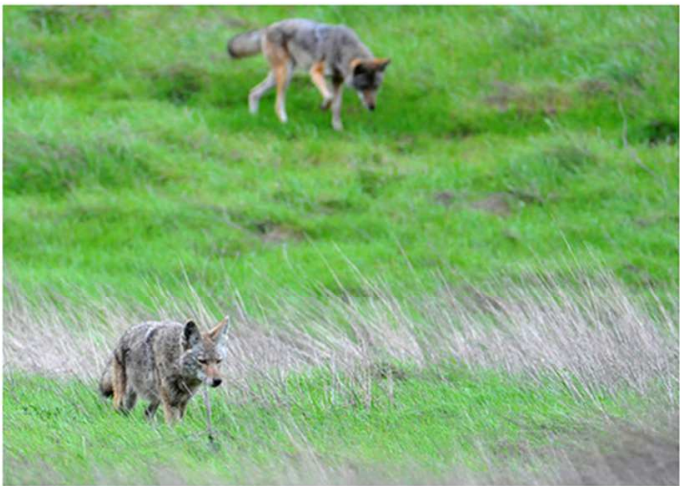

Coyotes Hunting in Tandem by Matt Knoth

For more information about coyote pair bonding, check out this article by Cecilia A. Hennessey et al. 


\section{Breeding Season}

Coyotes generally mate between January and March. A female coyote's gestation period (length of pregnancy) lasts for 62-65 days.

Coyote litters average about 4-7 pups.

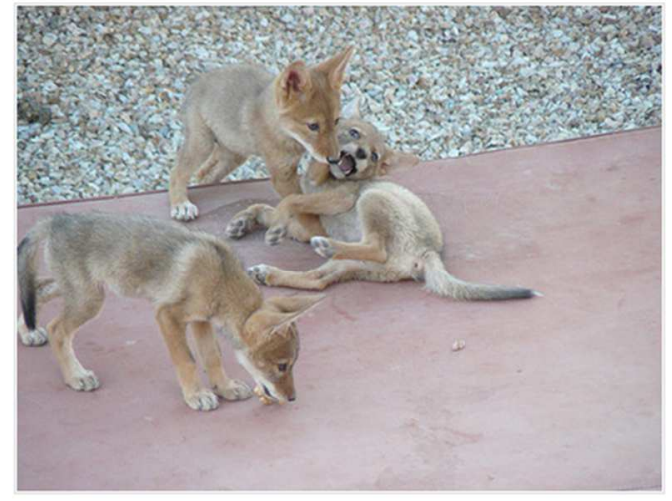




\section{When do coyotes have pups?}

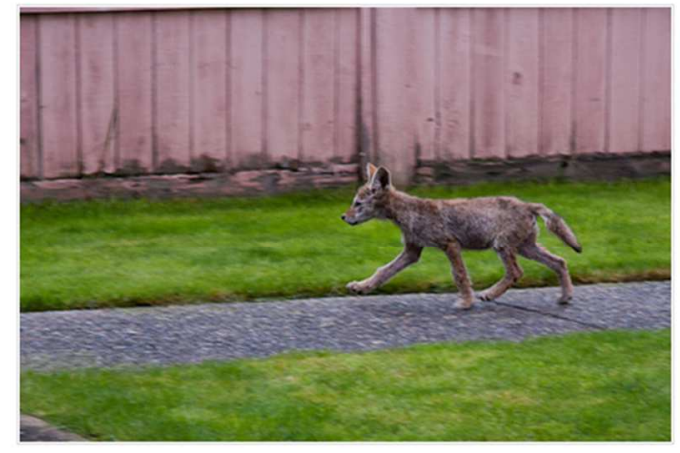

Young coyotes are born between March and May and stay with their parents until late summer. During this time, coyotes teach their young important skills, like how to hunt.

Coyotes are at home in a variety of habitat types and will den in burrows, under downed trees, in thick brambles, and in culverts (tunnels for streams or runoff).

Coyote Pup by Steve Tannock Wild Urban Coyotes Playing by pauly 4560 


\section{Let's review! In this section, you learned:}

1. Coyotes originated from deserts and prairies in Mexico and central North America, but are now found from Mexico to Canada.

2. Western coyotes weigh about as much as a Whippet (around 15-40 pounds), but their dense fur can make them appear larger.

3. Coyotes primarily eat rodents, but will also eat birds, insects, fruits, and vegetables. They do kill cats, but studies show that cats make up a very small percentage of a coyote's diet.

4. Coyotes typically have young from March to May. Coyote pups stay with their parents throughout the summer months. 
Section 2 of 4: Coyotes in Portland

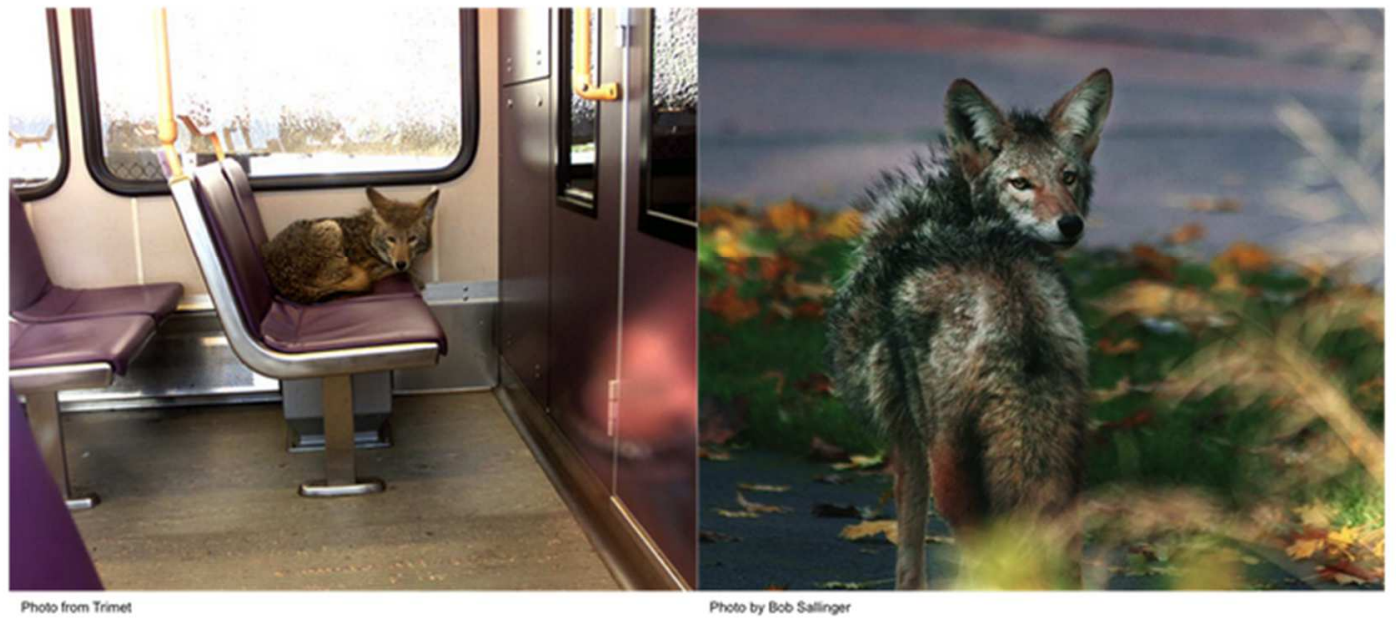

In this section, you will

1. Learn about coyotes in Portland

2. Explore where coyotes have been seen

3. Explore photos and video of coyotes in Portland 


\section{Coyotes have been spotted across Portland!}

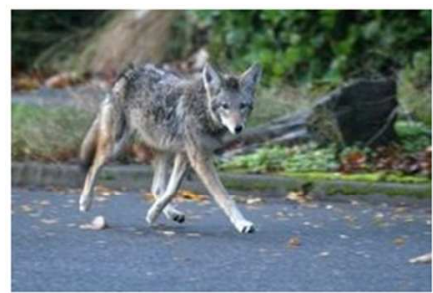

Sightings in and around Portland began in the 1980s and have increased over the past 15 years. Now, coyotes are regularly spotted across the Portland metropolitan area.

By providing accessible garbage cans, compost bins, outdoor pet bowls, and free-roaming pets, humans have unintentionally invited coyotes into their backyards.

Photo by Bob Sallinger 
Take a moment to explore coyote sightings that have been reported to the Portland Urban Coyote Project

Pan and zoom with your mouse. Click on a sighting to find out when the coyote was spotted.

Most recent sightings are shown in yellow.

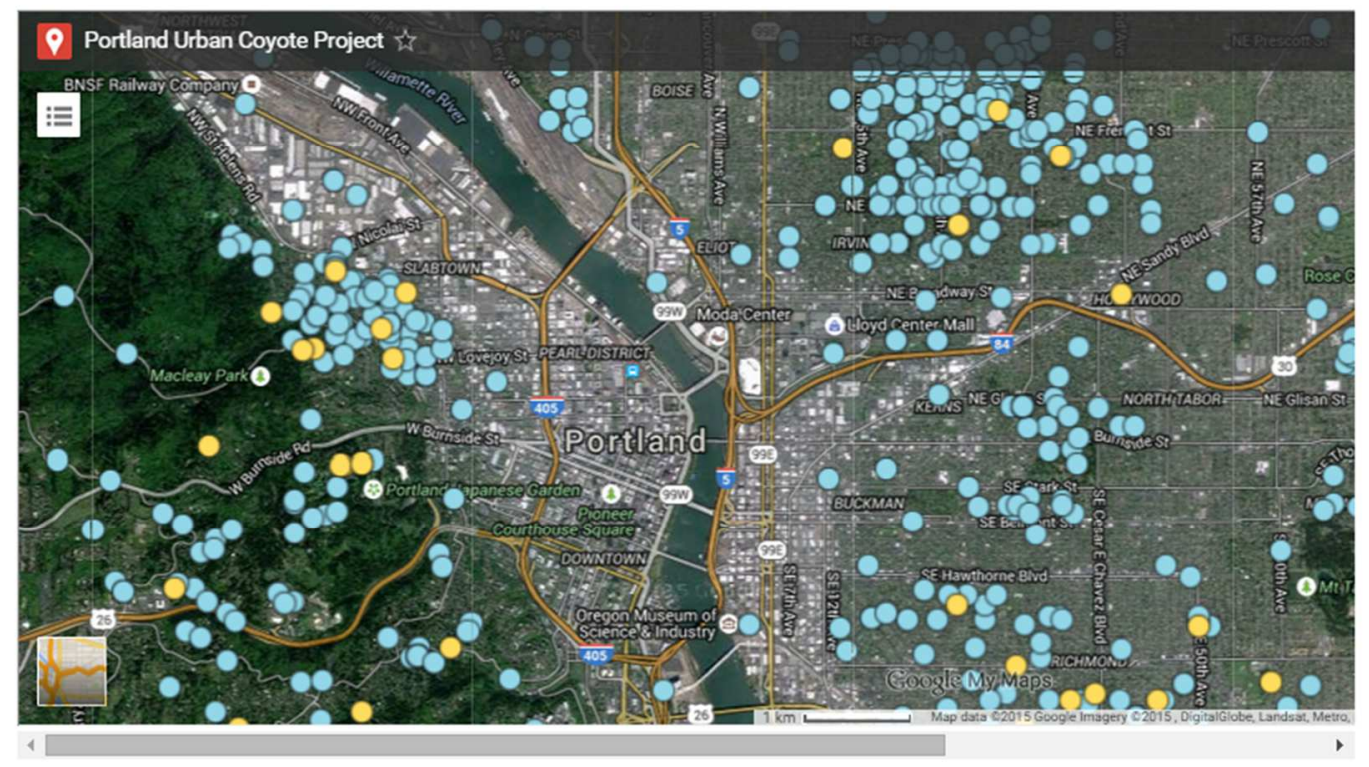

Find your neighborhood. How many coyote sightings have occurred near your home? Any recent sightings? 
Check out these photos of coyotes in Portland that have been shared with the Portland Urban Coyote Project

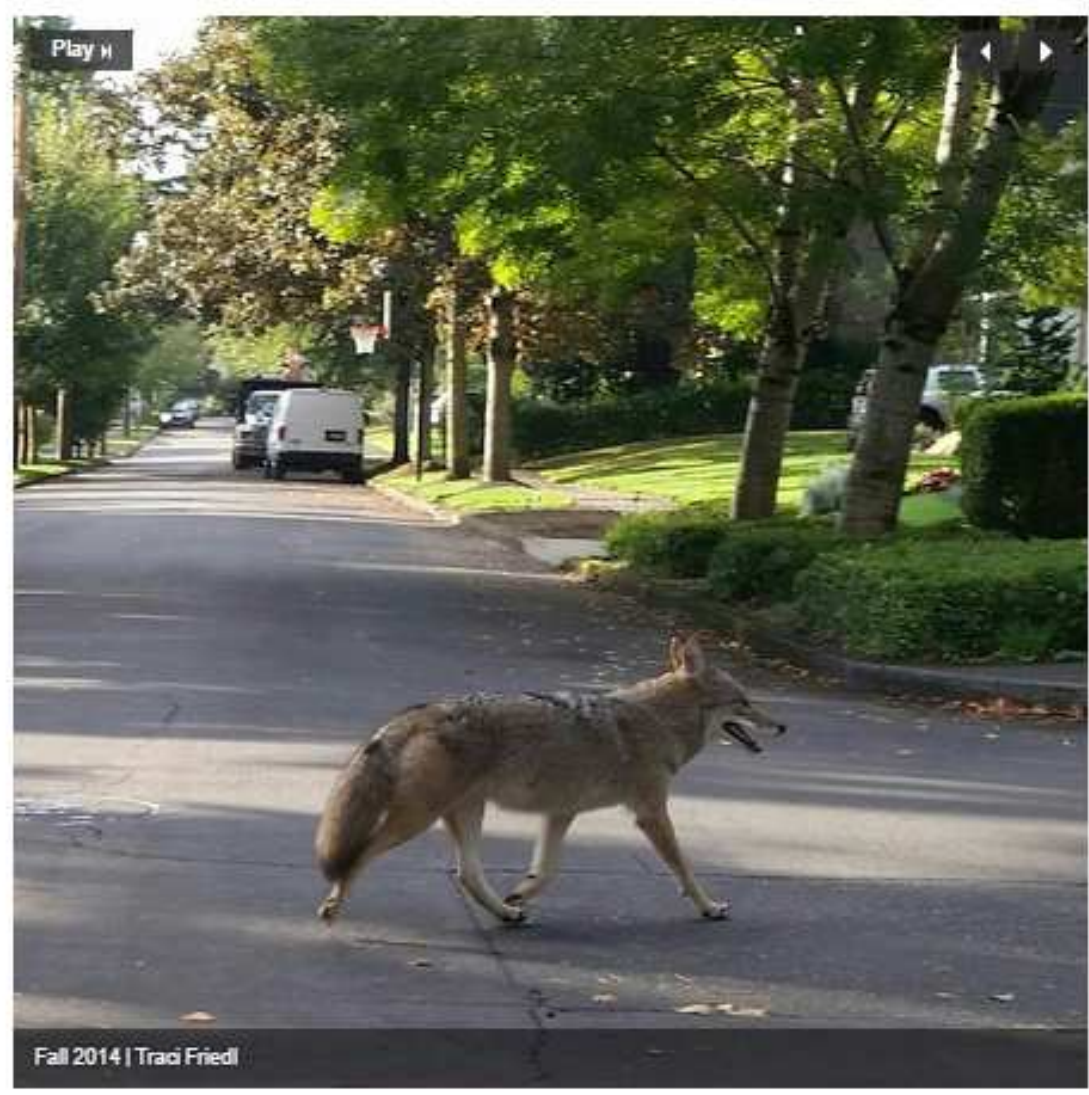


This video shows footage of a coyote trotting through a Portland neighborhood

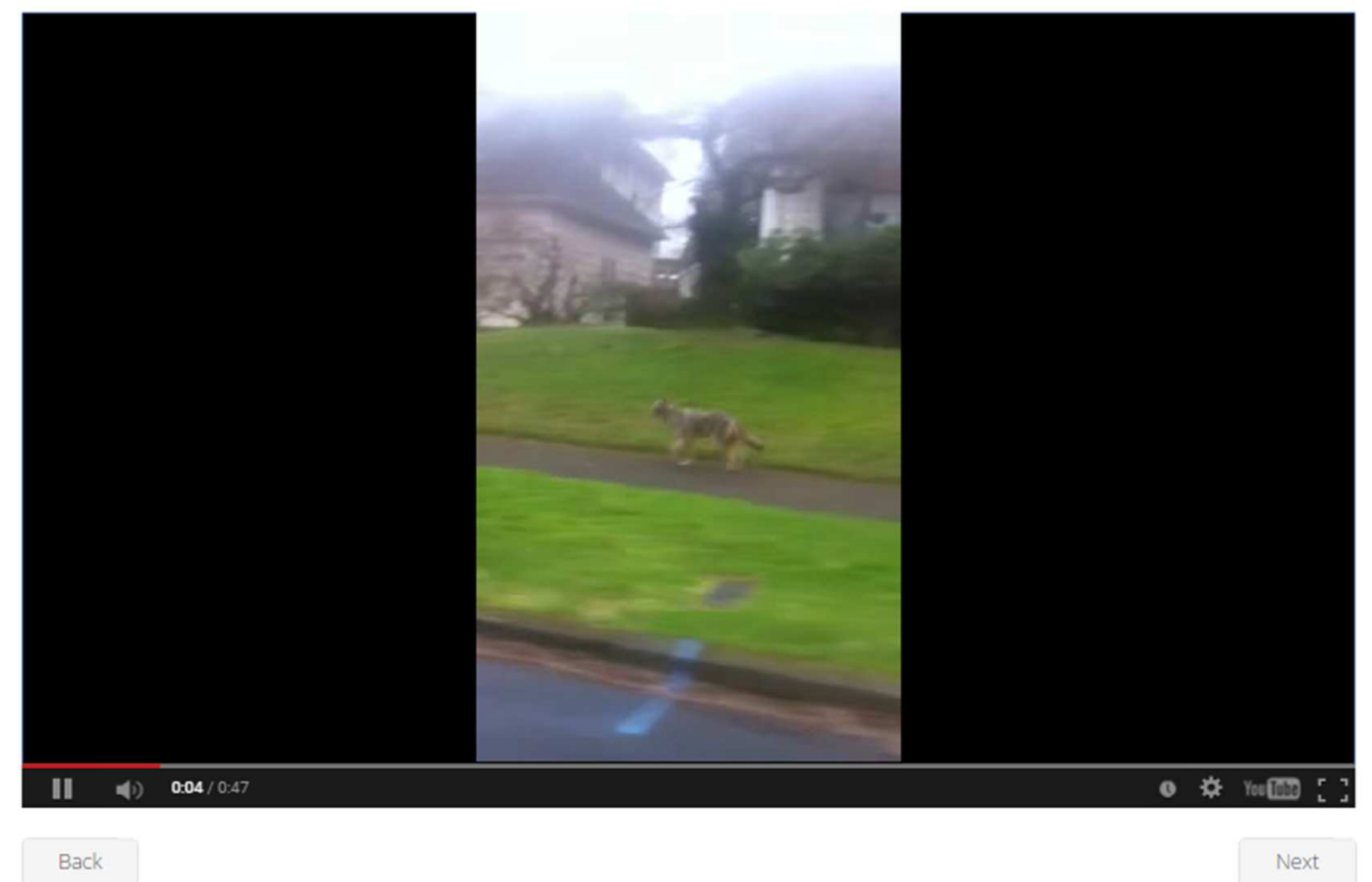

If you have videos of coyotes in Portland you would like to share, please send them to us : portlandcoyote@gmail.com 


\section{Let's review! In this section, you learned:}

1. Coyotes are commonly seen in the Portland metropolitan area.

2. The Portland Urban Coyote Project has an interactive sightings map that Portlanders can contribute their own coyote sightings to.

3. Portlanders have shared photos and videos of coyotes in the area that can be explored online. 
Section 3 of 4: Coyote Tracking

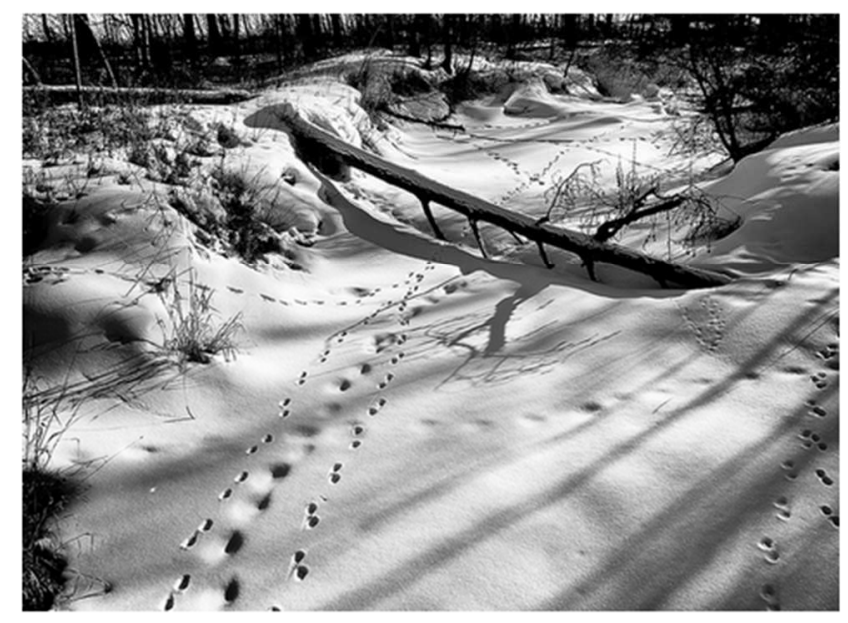

In this section, you will learn:

1. How to how to identify a coyote

2. How to identify a coyote print

3. How to identify coyote scat 


\section{Which one is a coyote?}

Sometimes it's tricky to tell if you've seen a coyote or a loose dog in your

neighborhood, especially when the critter is running fast and far away. Luckily, there are some ways to distinguish coyotes from similar animals.

Click the silhouette that is most likely to be a coyote below.
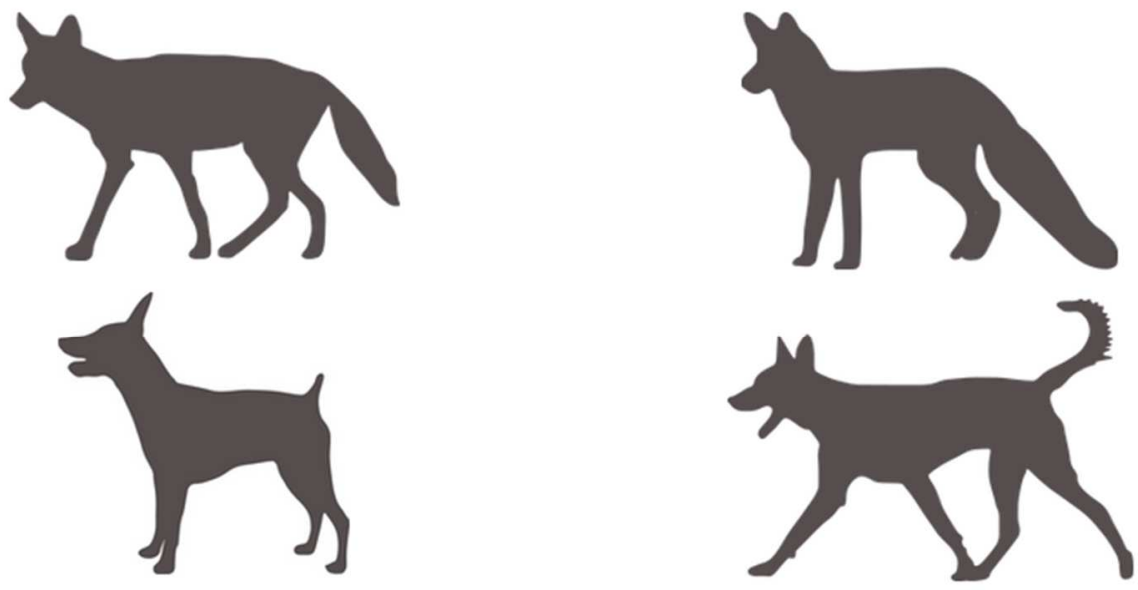


\section{Which one is a coyote?}

Not quite! This is a red fox. Foxes have much longer and bushier tails than coyotes relative to their body size. Notice how the fox tail hangs so low it trails behind the fox on the ground.

Click the silhouette that is most likely to be a coyote below.
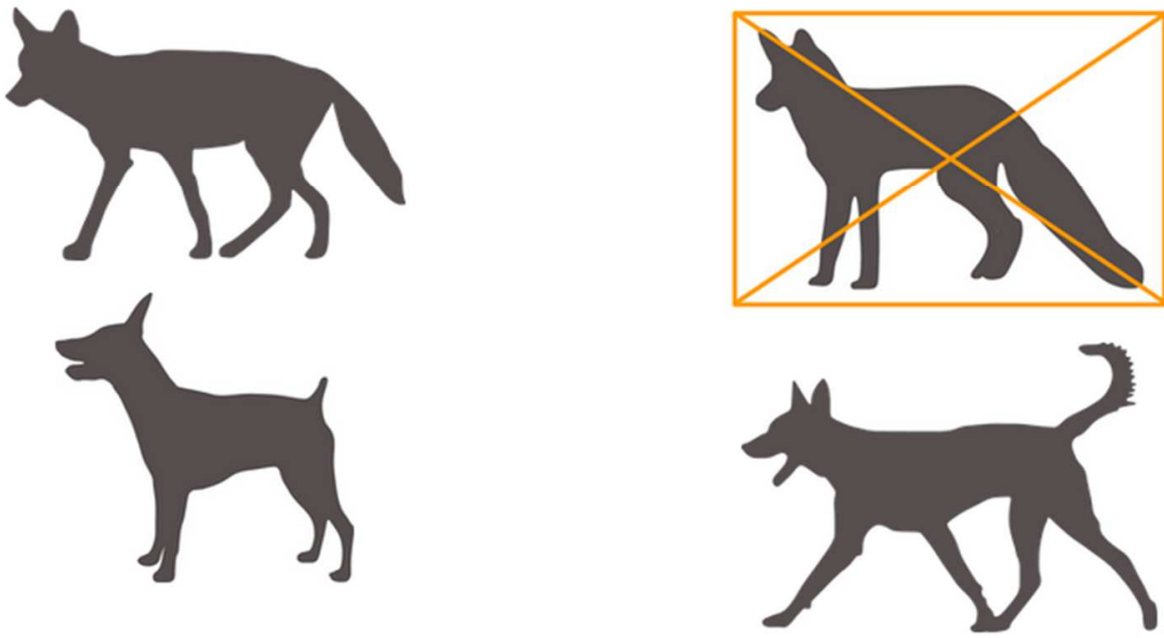


\section{Which one is a coyote?}

Guess again! Coyotes have more elongated bodies with a more compact chest. Also, unless something happened to it, coyotes have relatively long, full tails.

Click the silhouette that is most likely to be a coyote below.
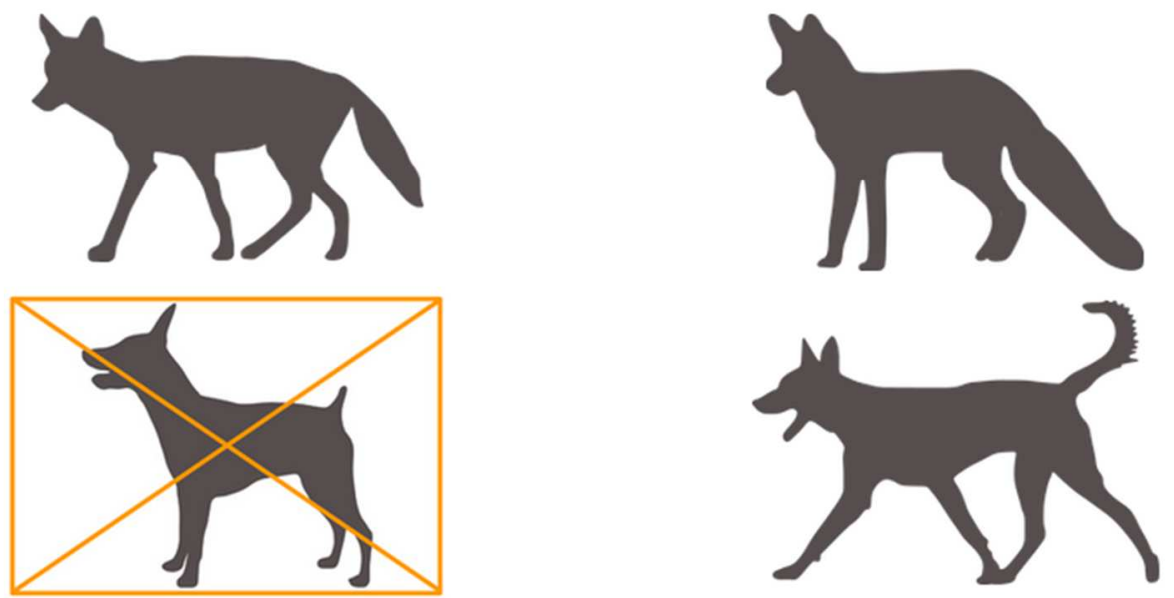
Which one is a coyote?

Not quite! This dog's body shape is similar to a coyote's, but coyotes never run with their tail up and curled.

Click the silhouette that is most likely to be a coyote below.
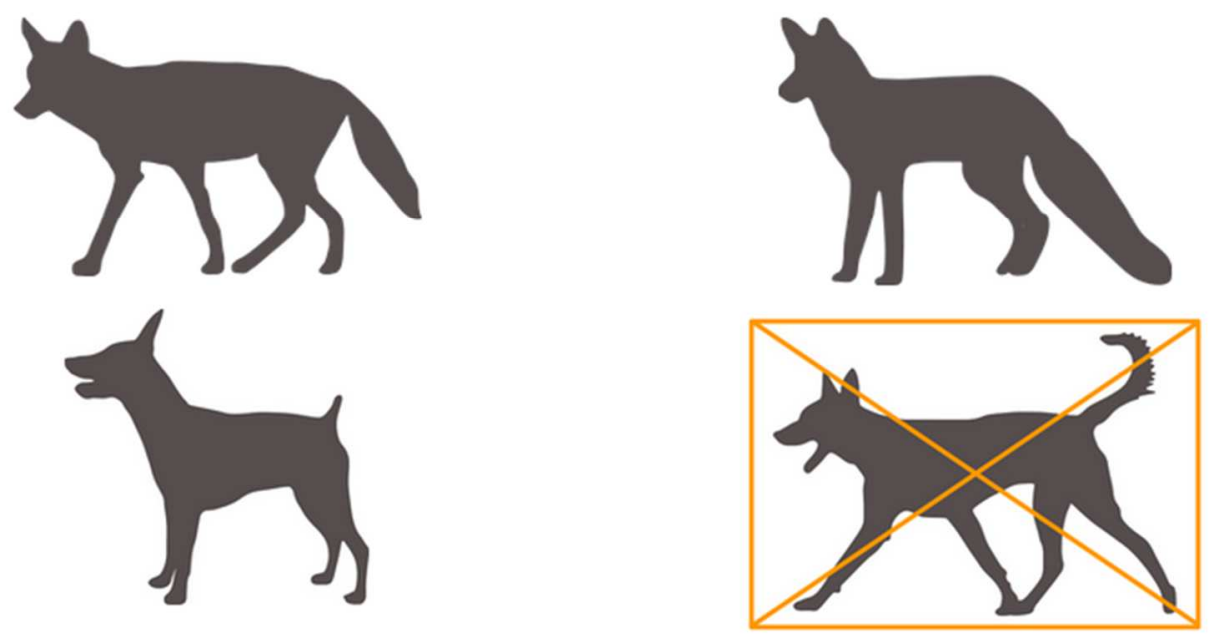


\section{Which one is a coyote?}

That's right! Coyotes always run with their tails straight out or pointing down (never up or wagging).

Click the silhouette that is most likely to be a coyote below.
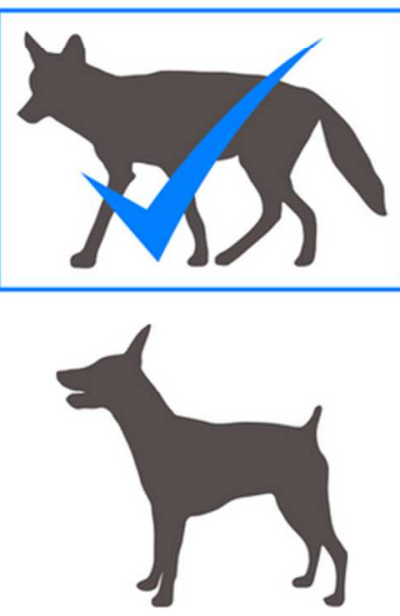
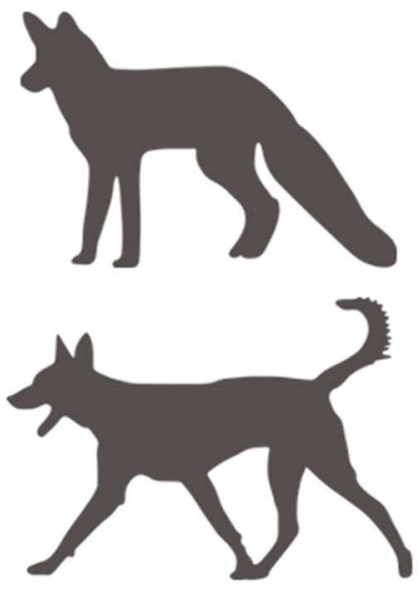


\section{Coyote tracks}

Coyote tracks can be found in snow, mud, dust, and dirt. Learn to identify coyote tracks so that you can find them in your neighborhood. The images below show prints from a dog, a coyote, a red fox, and a gray fox.

Click each set of prints to learn which animal made them
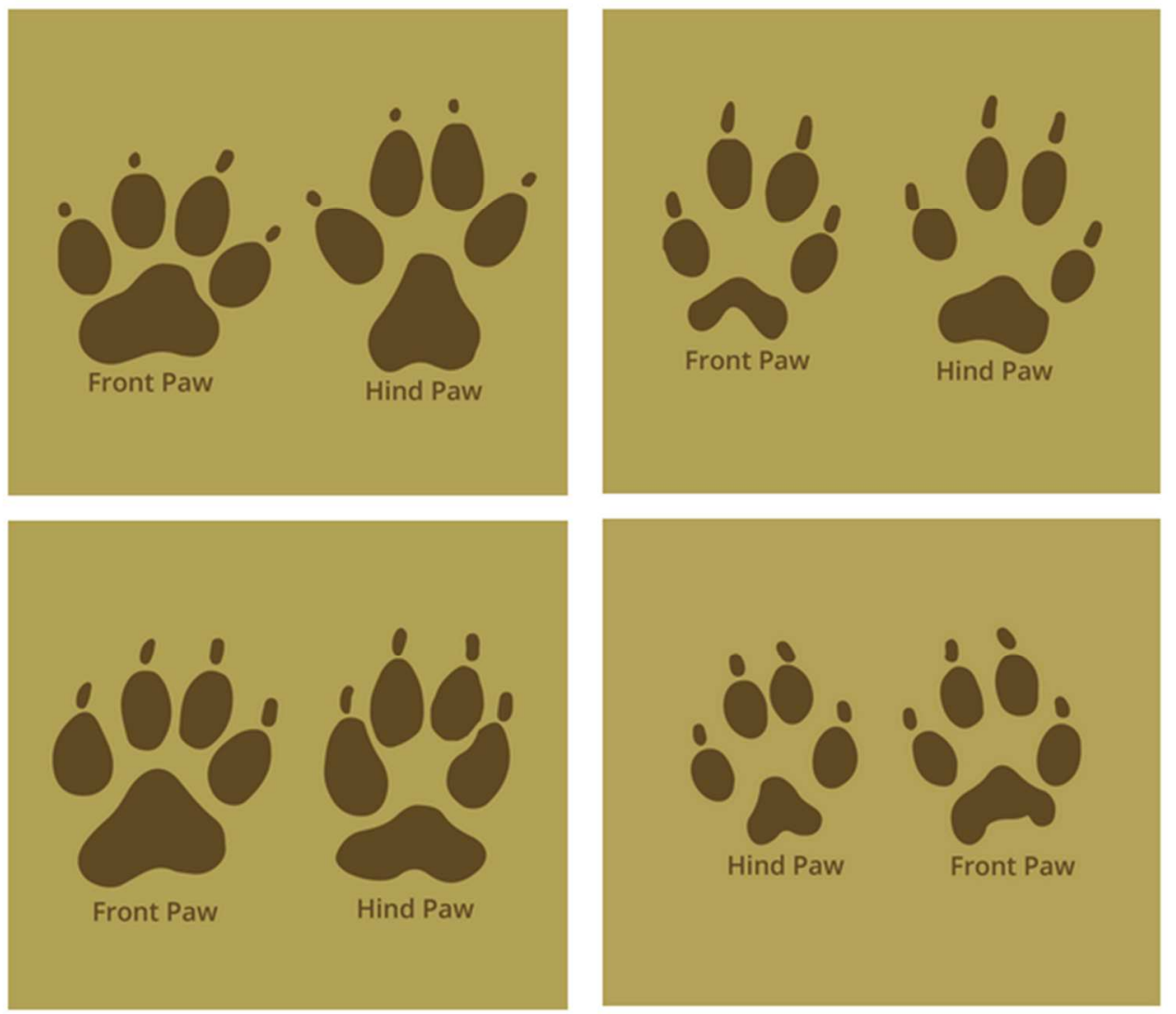


\section{Coyote tracks}

Notice how the toes in a dog print point outward. A coyote print is much more compact and oval-shaped.

Coyote tracks can be found in snow, mud, dust, and dirt. Learn to identify coyote tracks so that you can find them in your neighborhood. The images below show prints from a dog, a coyote, a red fox, and a gray fox,

Click each set of prints to learn what animal made them
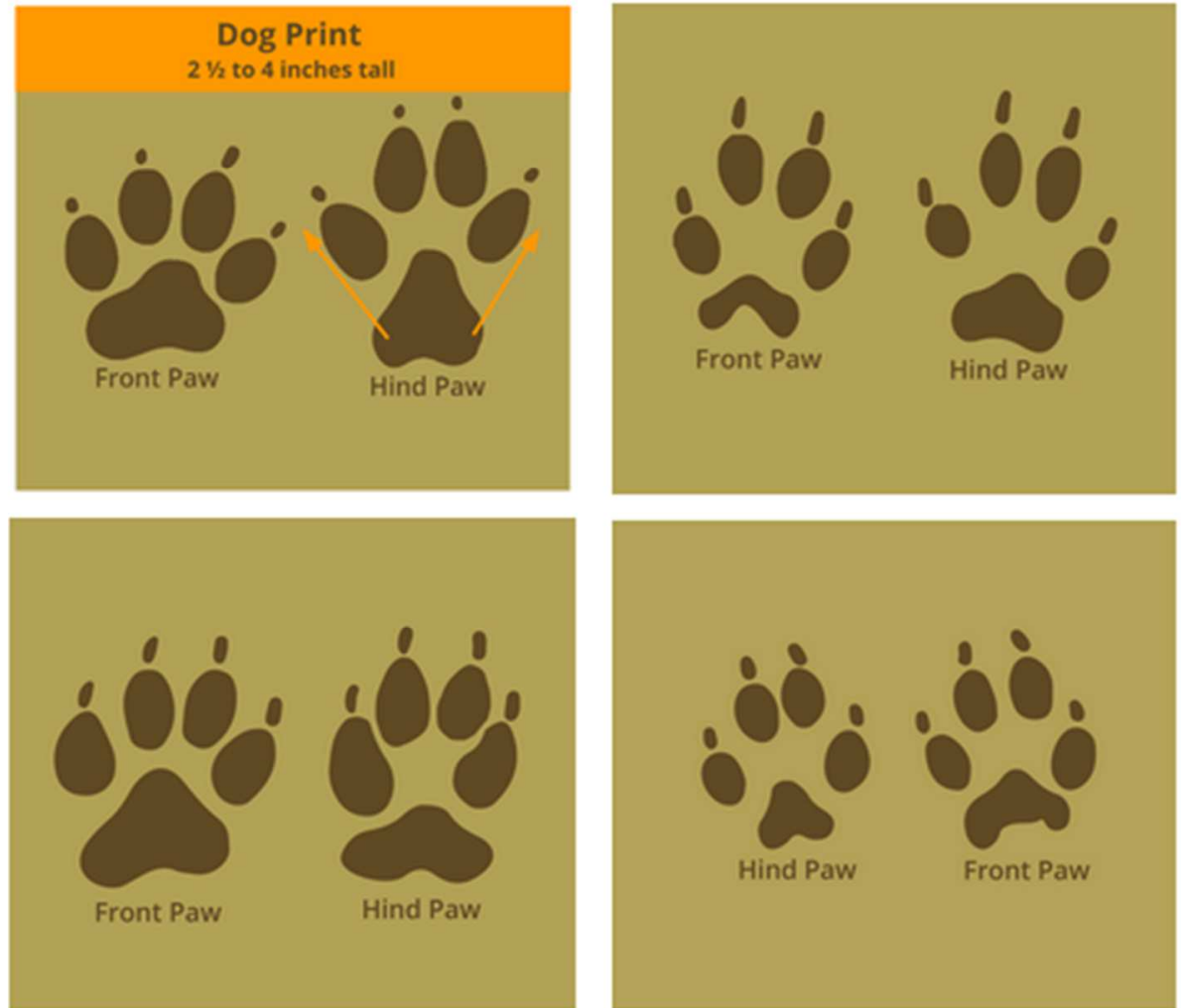

alck the encre print to morect 


\section{Coyote tracks}

Coyote tracks can be found in snow, mud, dust, and dirt. Learn to identify coyote tracks so that you can find them in your neighborhood. The images below show prints from a dog, a coyote, a red fox, and a gray fox.

Click each set of prints to learn what animal made them
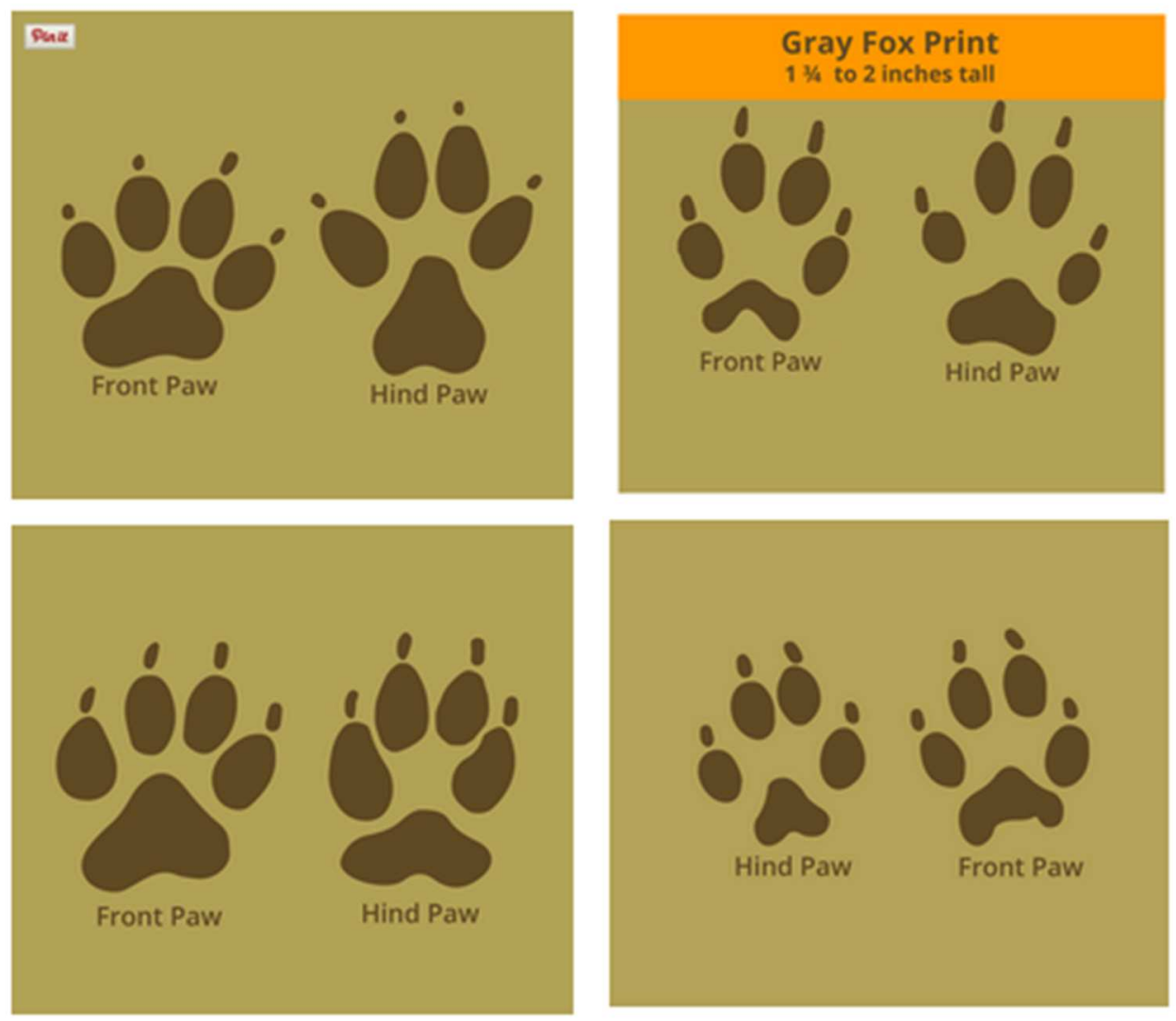

clek the cogere print to procend 


\section{Coyote tracks}

Coyote tracks can be found in snow, mud, dust, and dirt. Learn to identify coyote tracks so that you can find them in your neighborhood. The images below show prints from a dog, a coyote, a red fox, and a gray fox.

Click each set of prints to learn what animal made them
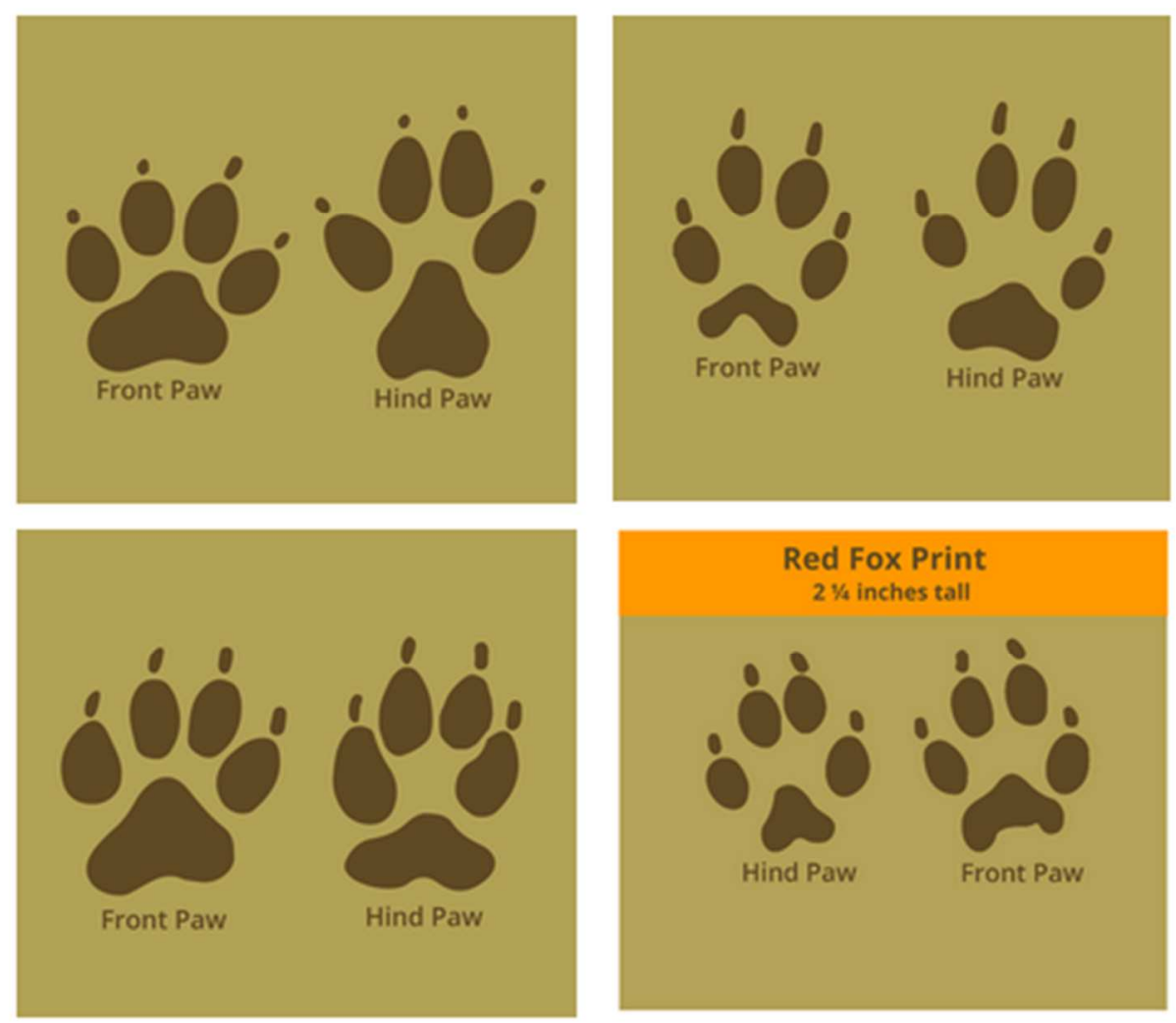

clok the coycte print to procend 


\section{Coyote tracks}

A coyote print measures about $21 / 4 \cdot 21 / 2$ inches tall. You can differentiate a coyote print from a dog print because the pads of the paw point inward, forming an oval.

Coyote tracks can be found in snow, mud, dust, and dirt. Learn to identify coyote tracks so that you can find them in your neighborhood. The images below show prints from a dog, a coyote, a red fox, and a gray fox.

Click each set of prints to learn what animal made them
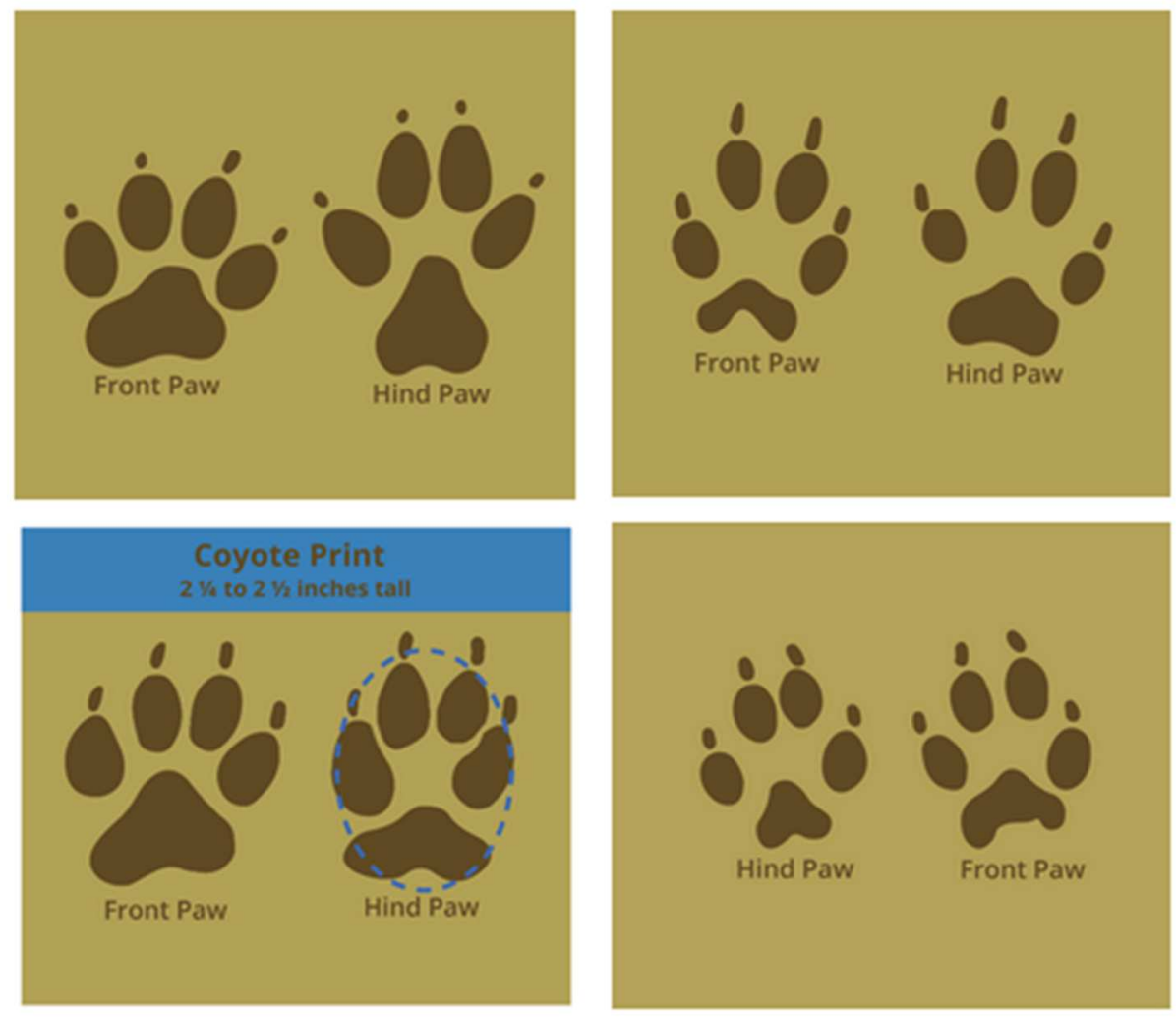
Let's take a closer look!

Below you will find examples of coyote prints on different types of ground. Notice how the prints look different depending on the texture of the ground. Pay attention to the recognizable oval shape found in each set of prints.

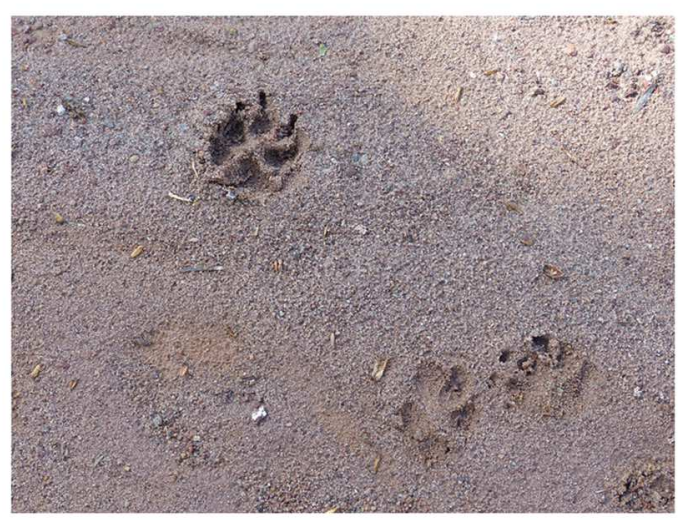

Lels take a closer loose

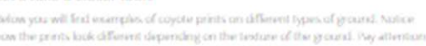
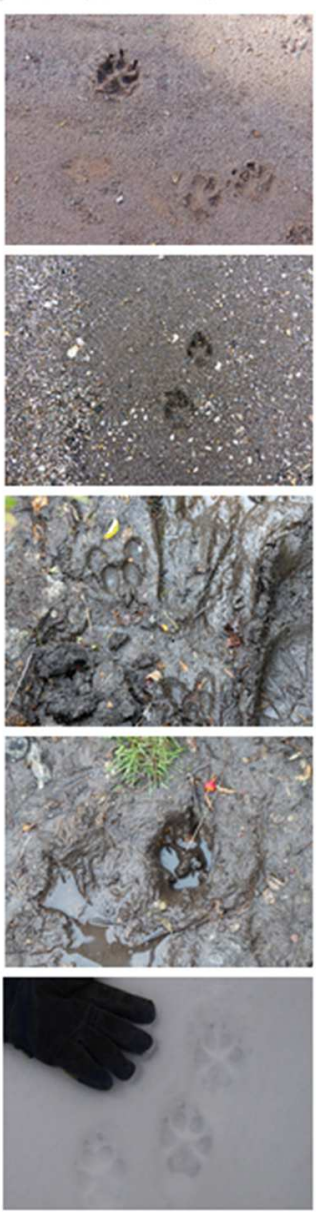

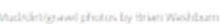




\section{Scat!}

Even if you don't see a coyote or a coyote print, there is another way to tell if coyotes are in your neighborhood: scat! Coyote scat (feces) vary in appearance, but there are a few things to look for when identifying coyote scat.

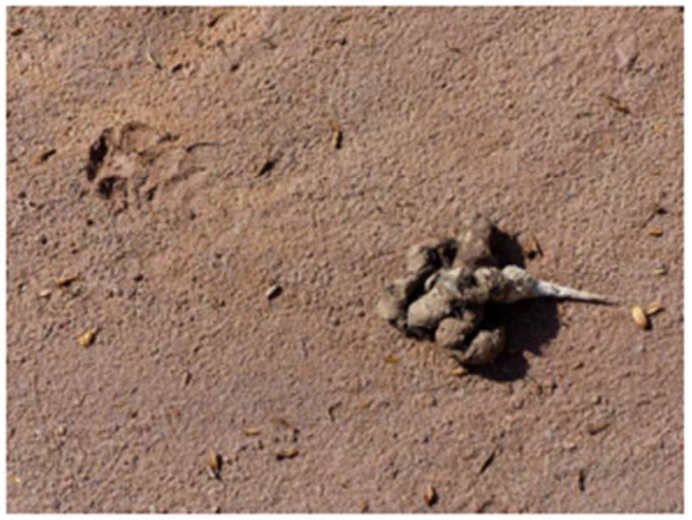

1. Location: Coyotes often leave scat in the middle of a trail as a signal to other coyotes.

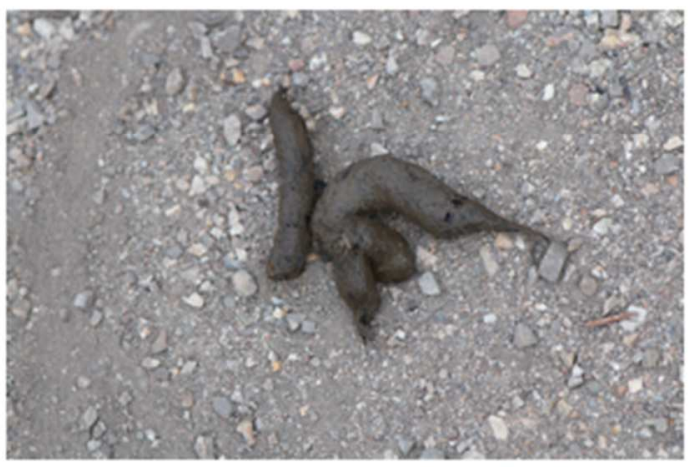

2. Shape: Coyotes tend to have narrow, twisted, and tapered scat.

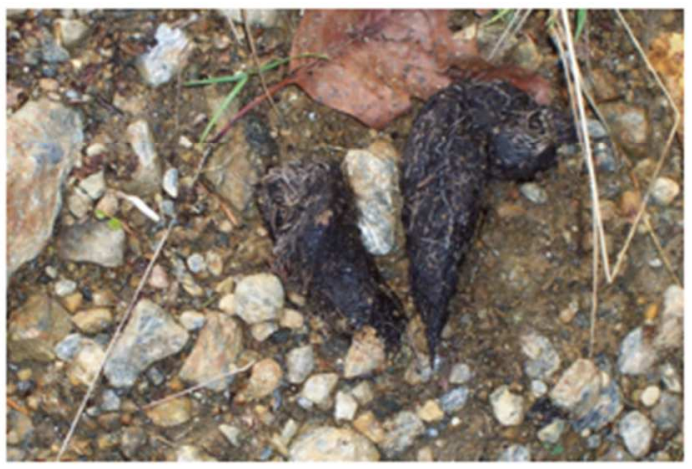

3. Contents: Coyotes eat rodents and fruits (among other things) and their scat often has evidence of their diet. Coyote scat can have visible berries or seeds in it, and often has animal fur.

Phosos by jerry Writart, brian worbbum and fortheloncotec 


\section{Let's review! In this section, you learned:}

1. You can identify a coyote by looking at its tail. A coyote does not run with its tail up or wagging. A coyote's tail hangs straight or low.

2. Coyote tracks are oval-shaped, with toes pointing inward. This is unlike dog prints, where toes are splayed outward.

3. Coyote scat can be found in the middle of trails and is identified by its twisted, tapered appearance and by the presence of fur and seeds.

Back

Next Section 


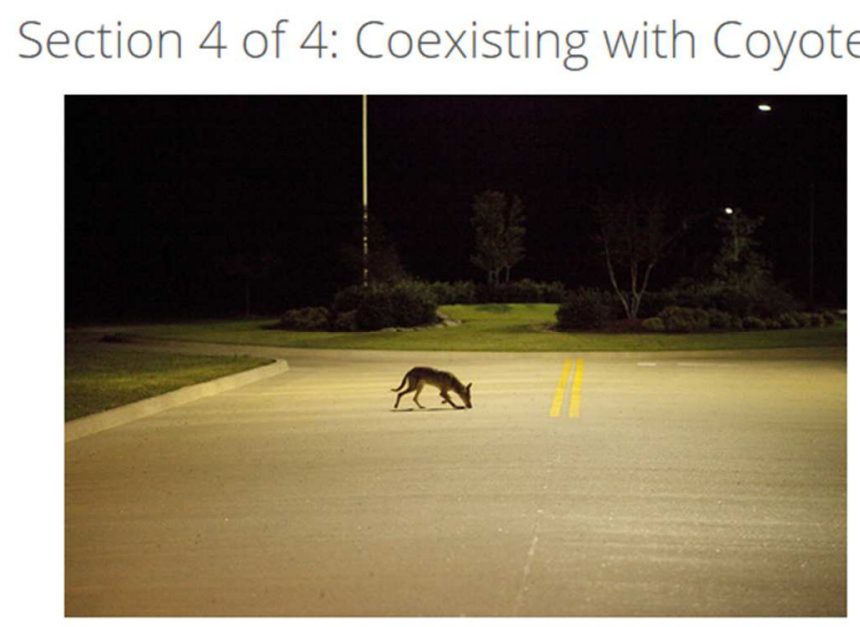

In this section, you will learn:

1. What to do when you see a coyote

2. Whether coyotes pose a threat to your family

3. How to keep pets safe

4. Techniques for coexisting with coyotes 


\section{Coyotes in Your Neighborhood}

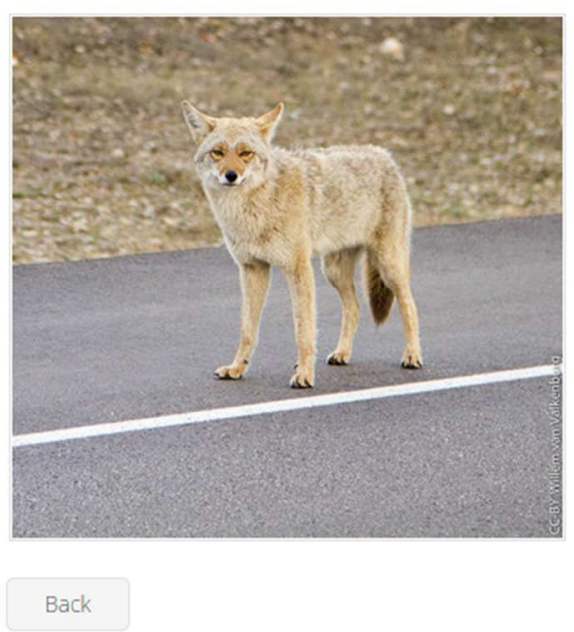

When a coyote is spotted in your

neighborhood, do you know what to do?

Coyotes generally stay hidden and are wary of people, but sometimes they

become habituated (used to being around people). The most important thing to do when you see a coyote in your neighborhood is to reinforce its natural fear of humans. 


\section{Are coyotes dangerous?}

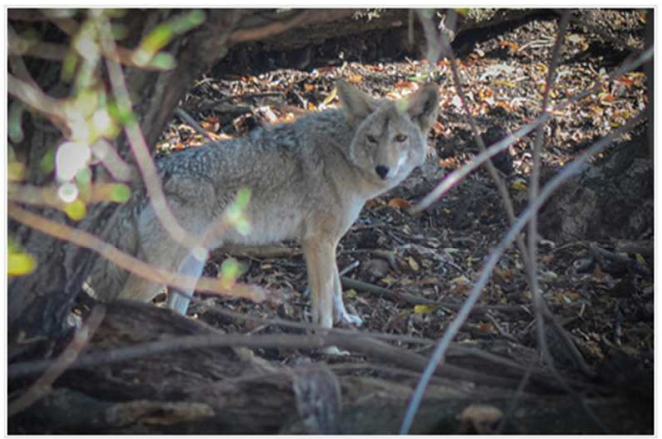

Coyote attacks are rare. Overall, coyote attacks on humans are minor, including nips, bites, and scratches. In most cases, attack victims are able to scare coyotes away by yelling or throwing objects. Often, coyote attacks occur in areas where coyotes have been fed by humans. Serious attacks on humans from coyotes are rare.

There have been only two human deaths attributed to coyotes. In 1970, a coyote attacked and killed a threeyear-old child, whose parents had been regularly feeding the coyote. In 2008 , a young woman was attacked by a group of coyotes while hiking in Canada. This incident has surprised many experts and is considered very unusual behavior for coyotes.

For more detailed information about coyote attacks, visit Coyote Conflicts: A Research Perspective by the Cook County Coyote Project 


\section{Coyotes and Pets}

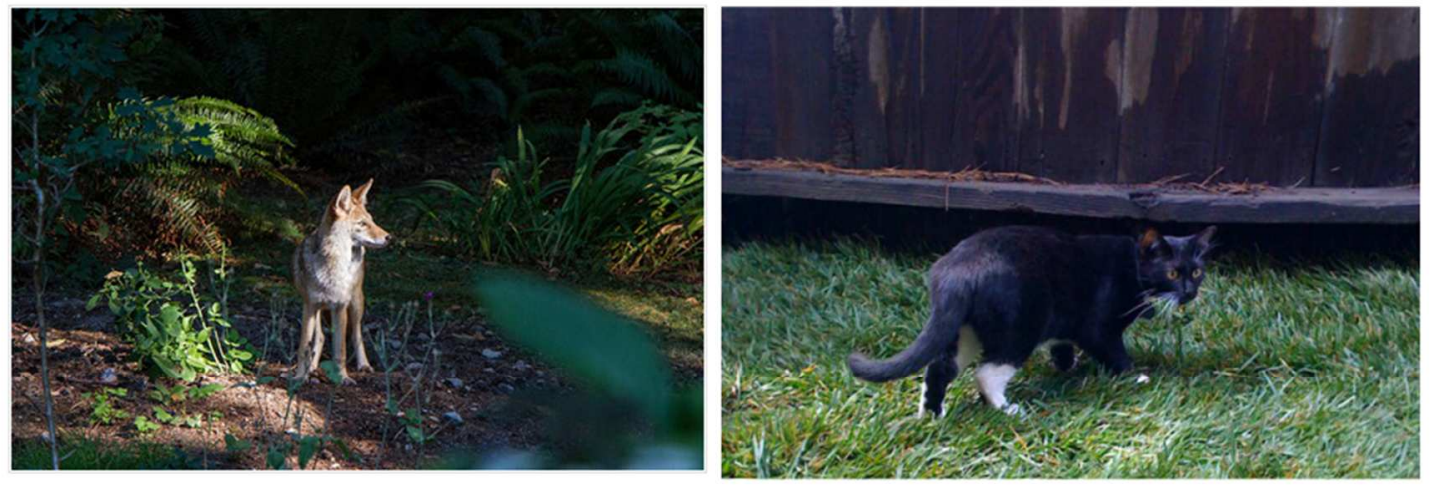

Although attacks on humans are rare, coyotes are opportunistic and will prey upon free-roaming cats and small dogs. The best prevention is to keep pets supervised, indoors, on a leash, or within a fenced yard. 


\section{Can we remove coyotes from cities?}

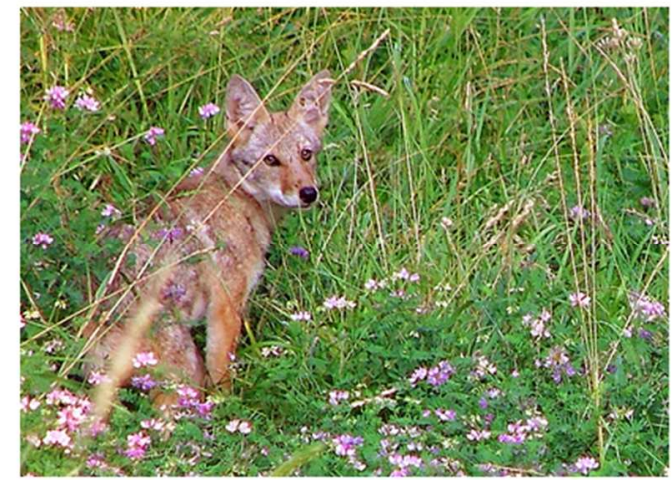

Despite widespread efforts to reduce coyote populations, coyotes have managed to survive and thrive among human populations.

While coyote control can be effective in eliminating specific individuals, it does not help reduce local populations. Killing coyotes disrupts population structure, causing more coyotes to breed and have larger litters. Coyotes will also quickly fill into vacated habitat from adjacent areas. For these reasons, eradication efforts frequently lead to increases in local coyote populations. 
It looks like coyotes are here to stay in cities, so how do we coexist? Follow these guidelines to reduce human-coyote conflict.

\section{Reducing Human-Coyote Conflicts}

- Never deliberately feed a coyote or other wild mammals.

- Securely cover garbage cans and compost bins.

- Remove fallen fruit from yards.

- Eliminate opportunities for rats to breed in and around your yard.

- Never deliberately approach a coyote and teach children to respect all wildlife from a distance.

- Keep house pets indoors and allow only controlled access to the outdoors (fenced yards and leashes). Always keep pets in from dusk to dawn when coyotes are most active.

- Discourage coyotes in your backyard by removing unnecessary brush, installing a motion-sensitive lighting system, or installing a coyote proof fence. To be effective, fences must be at least six feet tall, have no openings greater than four inches, and should be flush with the ground.

- Let coyotes know they are not welcome if they get too close to you or your house by using hazing techniques. Hazing techniques, such as shouting, making noise, or waving your arms, help train coyotes to regain their wariness of humans. 


\section{Create a Hazing Rattle}

On the previous page, we talked about hazing coyotes (scaring coyotes away). One of the best ways to haze coyotes is to scare them away with loud noises. A simple coffee can with change or rocks in it will sometimes do the trick!

\section{To make a hazing rattle:}

1. Find a coffee can, oatmeal can, or other metal container with a lid.

2. Fill the can with rocks, coins, or anything else that will make a loud clanging noise when it hits the sides of the can.

3. Shake the can vigorously when a coyote is too close to you or your home. Note: you can use duct tape to secure the top of the can.

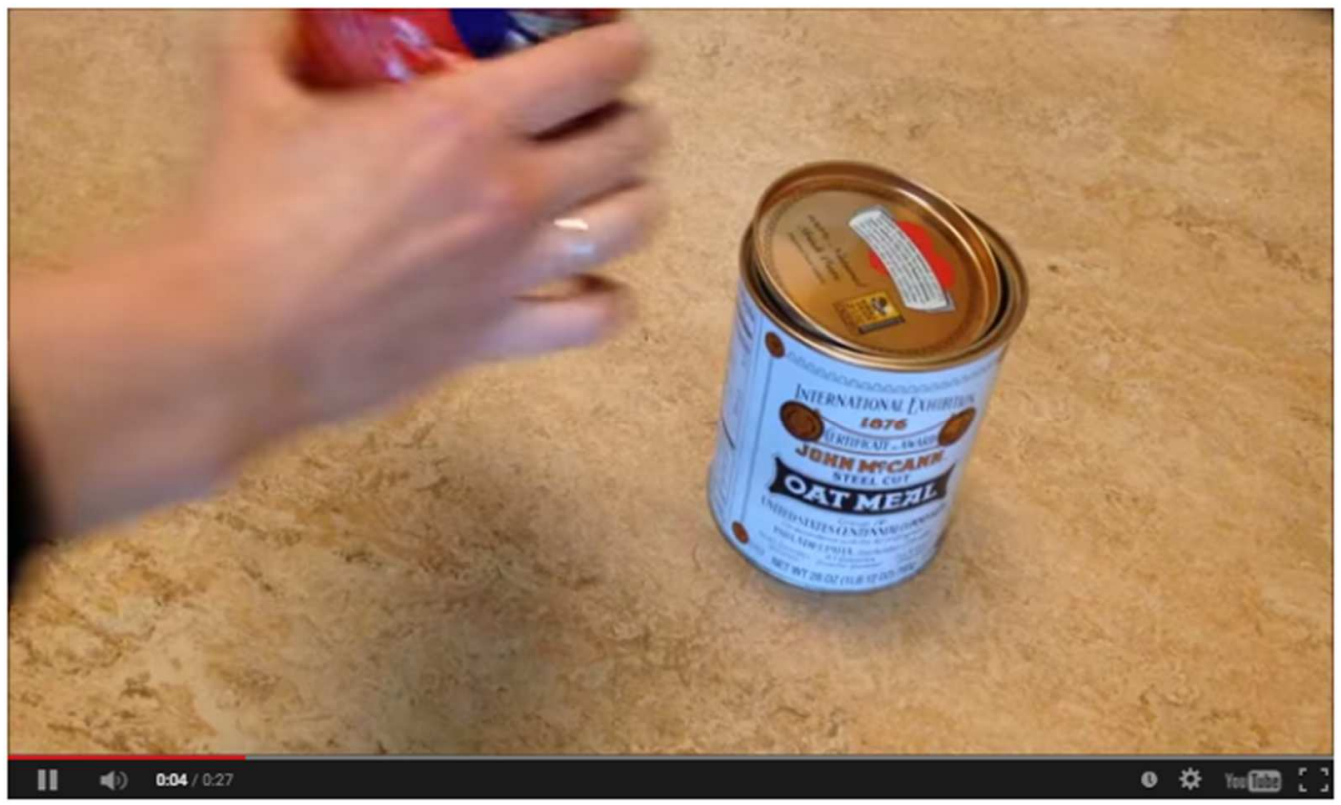




\section{Let's review! In this section, you learned:}

1. Coyotes generally stay away from humans or watch curiously at a distance.

2. Serious coyote attacks on humans are rare and mainly occur when a coyote has been habituated.

3. The best way to protect pets from coyotes is by supervising them anytime they are outdoors.

4. Removing coyotes from cities is not a realistic option. When a coyote is removed, other coyotes quickly move into their habitat and reproduce.

5. To reduce the chances of human-coyote conflict do not feed coyotes, keep trash cans covered, and train them to stay away from your yard by using hazing techniques. 
This concludes the tutorial, please click the button below to complete the final step in our study.

\section{CLICK HERE FOR FINAL QUESTIONNAIRE}

In this tutorial, you learned:

1. General Life History About Coyotes

2. Coyotes in Portland

3. How to Identify Coyotes and Coyote Sign

4. How to Stay Safe Around Coyotes

If you'd like to review any of these sections, click the links above.

Special thanks to: Jonathan van Belle, Kira Smith, Barbara Brower, Bob Sallinger, Emilly Wise, and Jenny Grant

Coyote illustration by Kezia Rasmussen

Tutorial By Zuriel Rasmussen zuriel@pdx.edu 


\section{APPENDIX C: POST-TUTORIAL SURVEY}

\section{Part 3: Urban Coyote Tutorial Survey}

This questionnaire is the final step in the Portland Urban Coyote Project research project. After you complete this survey, you will be directed to a questionnaire to provide your email address or phone number to be entered to win a $\$ 50$ gift certificate to Fred Meyer.

1. Please enter your Anonymous

Identification Number (AIN) from the

beginning of the study:

\section{Section 1 of 3}

In the following section, you will be asked about your feelings toward coyotes.

2. How concerned are you about coyotes attacking small pets?

Mark only one oval.
Not at all concerned
Slightly concerned
Moderately concerned
$\bigcirc$ Very concerned

3. How concerned are you about coyotes attacking children?

Mark only one oval.

$\bigcirc$ Not at all concerned

Slightly concerned

Moderately concerned

Very concerned

4. How concerned are you about having a face-to-face encounter with a coyote? Mark only one oval.

$\square$ Not at all concerned
Slightly concerned
Moderately concerned
Very concerned


5. How do you feel about lethally removing (killing) coyotes found in urban areas? Mark only one oval.

Strongly against

Somewhat against

Neutral

Somewhat in favor of

Strongly in favor of

6. How concerned are you about coyotes near your home?

Mark only one oval.

$\bigcirc$ Not at all concerned

Slightly concerned

Moderately concerned

Very concerned

7. How much do you support coyotes living in the Portland metropolitan area? Mark only one oval.

Very much

Somewhat

Not very much

Coyotes should be removed from the Portland metropolitan area

8. How much do you like or dislike coyotes?

Mark only one oval.

Dislike very much

Dislike somewhat

Neutral

Like somewhat

Like very much

\section{Section 2 of 3}

In the following section, you will be asked about your feelings toward coyotes.

9. True or False: Coyote removal efforts in the United States have largely been effective. Mark only one oval.

$\bigcirc$ True

$\Longrightarrow$ False 
10. True or False: Studies show that cats are a main food source for coyotes. Mark only one oval.

$\bigcirc$ True

False

11. True or False: Coyotes often live in family groups, but hunt alone.

Mark only one oval.

True

False

12. True or False: Removing individual coyotes helps to reduce the overall coyote population of an area.

Mark only one oval.

$\bigcirc$ True

False

13. True or False: Coyotes are responsible for human deaths every year.

Mark only one oval.

True

False

14. What do coyotes most commonly eat?

Mark only one oval.

Deer

Cats

Fruit

Rodents

Garbage

15. How much does an average coyote weigh?

Mark only one oval

$\bigcirc$ Under 15 pounds

15-40 pounds

40-60 pounds

60-80 pounds

80-100 pounds

Over 100 pounds

\section{Section 3 of 3}


16. What is the highest degree or level of school you have completed? Mark only one oval.

Did not complete high school

High school graduate, diploma, or equivalent (for example: GED)

Some college credit, no degree

Associate's degree

Bachelor's degree

Master's or Doctoral degree

17. Are you currently a college student?

Mark only one oval.

Yes, I attend a 2-year college or technical school.

Yes, I am an undergraduate at a 4-year college.

Yes, I am a graduate student.

No, I am not currently a college student.

18. What is your annual household income?

Mark only one oval.

Less than $\$ 30,000$

$\$ 30,000-\$ 49,999$

$\$ 50,000-\$ 99,999$

$\$ 100,000$ - $\$ 249,000$

$\$ 250,000$ or more

19. Would you describe yourself as:

choose all that apply

Check all that apply.
American Indian/Native American
Asian
Black/African American
Hispanic/Latino
White/Caucasian
Pacific Islander
Other:

20. What is your gender? 
21. What is your age?

Mark only one oval.

$18-24$

25-34

$35-44$

$45-54$

55-64

65-74

Over 74

22. What is your zip code?

23. How long have you lived in the Portland metropolitan area? Mark only one oval.

$\longrightarrow$ Less than 1 year

1-5 years

6-10 years

11-20 years

Over 20 years

24. Do you own cats or small dogs? Mark only one oval.

$\bigcirc$ Yes

No

25. How did you hear about this study? Mark only one oval.

Portland Urban Coyote Project Website

Facebook

Twitter

Flyer

Other: 
26. If you have any comments you would like to share about the questionnaires, tutorial, or the study in general, please write them below.

optional

Powered by

$\equiv$ Google Forms 


\title{
APPENDIX D: HUMAN SUBJECTS REVIEW APPROVAL
}

\section{Portland State}

\author{
Post Office Box 751 \\ Portland, Oregon 97207-0751 503-725-8170 fax \\ Human Subjects Research Review Committee \\ hsrrc@lists.pdx.edu
}

Date: July 21, 2015

To: $\quad$ Barbara Brower / Zuriel Rasmussen

From: Karen Cellarius, HSRRC Chair

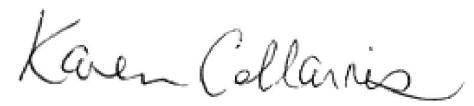

Re: $\quad$ HSRRC approval for your project titled, "Citizen Science as a Tool for Nature Education: The Portland Urban Coyote Project"

HSRRC Proposal \# 153507

Review Type: Exempt, Category 2

In accordance with your request, the Human Subjects Research Review Committee has reviewed your proposal referenced above for compliance with PSU and DHHS policies and regulations covering the protection of human subjects. The Committee is satisfied that your provisions for protecting the rights and welfare of all subjects participating in the research are adequate, and your project is approved. Please note the following requirements:

Approval: You are approved to conduct this research study after receipt of this approval letter; and the research must be conducted according to the plans and protocol submitted (approved copy enclosed).

Consent: Signed consent is waived from all participants in this study. A written consent statement is required.

Changes to Protocol: Any changes in the proposed study, whether to procedures, survey instruments, consent forms or cover letters, must be outlined and submitted to the Committee immediately. The proposed changes cannot be implemented before they have been reviewed and approved by the Committee.

Adverse Reactions and/or Unanticipated Problems: If any adverse reactions or unanticipated problems occur as a result of this study, you are required to notify the Committee immediately. If the issue is serious, approval may be withdrawn pending an investigation by the Committee.

Completion of Study: Please notify the Committee as soon as your research has been completed. Study records, including protocols and signed consent forms for each participant, must be kept by the investigator in a secure location for three years following completion of the study (or per any requirements specified by the project's funding agency).

If you have questions or concerns, please contact the Office of Research Integrity in the PSU RSP at 503-725-2227, 1600 SW $4^{\text {th }}$ Ave., Market Center Building, Suite 620. 